\title{
Molecular and Comparative Genetics of Mental Retardation
}

\author{
Jennifer K. Inlow ${ }^{*, 1}$ and Linda L. Restifo $o^{*,+,+, 2}$ \\ *Arizona Research Laboratories Division of Neurobiology, ${ }^{\dagger}$ Department of Neurology, ${ }^{\ddagger}$ Genetics Graduate \\ Interdisciplinary Program, University of Arizona, Tucson, Arizona 85721-0077 \\ Manuscript received August 14, 2003 \\ Accepted for publication November 14, 2003
}

\begin{abstract}
Affecting 1-3\% of the population, mental retardation (MR) poses significant challenges for clinicians and scientists. Understanding the biology of MR is complicated by the extraordinary heterogeneity of genetic MR disorders. Detailed analyses of $>1000$ Online Mendelian Inheritance in Man (OMIM) database entries and literature searches through September 2003 revealed 282 molecularly identified MR genes. We estimate that hundreds more MR genes remain to be identified. A novel test, in which we distributed unmapped MR disorders proportionately across the autosomes, failed to eliminate the well-known $\mathrm{X}$-chromosome overrepresentation of MR genes and candidate genes. This evidence argues against ascertainment bias as the main cause of the skewed distribution. On the basis of a synthesis of clinical and laboratory data, we developed a biological functions classification scheme for MR genes. Metabolic pathways, signaling pathways, and transcription are the most common functions, but numerous other aspects of neuronal and glial biology are controlled by MR genes as well. Using protein sequence and domainorganization comparisons, we found a striking conservation of MR genes and genetic pathways across the $\sim 700$ million years that separate Homo sapiens and Drosophila melanogaster. Eighty-seven percent have one or more fruit fly homologs and $76 \%$ have at least one candidate functional ortholog. We propose that D. melanogaster can be used in a systematic manner to study MR and possibly to develop bioassays for therapeutic drug discovery. We selected 42 Drosophila orthologs as most likely to reveal molecular and cellular mechanisms of nervous system development or plasticity relevant to MR.
\end{abstract}

M ENTAL RETARDATION (MR) is a common form of cognitive impairment affecting between 1 and $3 \%$ of the population of industrialized countries (RoELEVELD et al. 1997; AICARDi 1998). Although there is debate over the definition and classification of MR (LEONARD and Wen 2002), it is often defined by an IQ of $<70$, with deficits in adaptive skills included as diagnostic criteria (Luckasson et al. 1992; Daily et al. 2000). Behavioral and cognitive therapies can help mentally retarded patients reach their maximum potential (BATHAEE 2001; BUTLER et al. 2001), but they are not curative and often focus on treating habit disorders, aggression, or self-injurious behavior that can accompany MR (Long and Miltenberger 1998; Dosen and Day 2001). MR due to congenital hypothyroidism is now largely preventable through screening and hormone replacement (Gruters et al. 2002). Aside from this, the only molecular-based therapeutic approaches are dietary restrictions and supplements for inborn errors of metabolism such as phenylketonuria (DASHMAN and SANSARICQ 1993; LeVy 1999; KabRa and Gulati 2003). Few, if any,

${ }^{1}$ Present address: Department of Chemistry, Indiana State University, Terre Haute, IN 47809.

${ }^{2}$ Corresponding author: Arizona Research Laboratories Division of Neurobiology, 611 Gould-Simpson Bldg., 1040 E. 4th St., University of Arizona, Tucson, AZ 85721-0077. E-mail: 11r@neurobio.arizona.edu clinical conditions affect such large numbers of children and young adults and yet have no effective pharmacological therapy. One reason for the lack of drug treatments is the limited understanding of the molecular and cellular bases for MR.

Many environmental and genetic factors can cause MR, including premature birth, prenatal infections, chromosomal abnormalities, and single-gene mutations (Kinsbourne and Graf 2000). An etiology can be established in $60-75 \%$ of cases of severe MR, but only in $38-55 \%$ of mild cases. Estimates of genetic causes of severe MR range from 25 to 50\% (MCLAREN and BRYSON 1987). There are two categories of hereditary MR. Isolated MR with no other consistent defining features is known as nonspecific or nonsyndromal MR. To date, all but one of these (Molinari et al. 2002) are X-linked, but other autosomal genes may have eluded identification because of the considerably greater difficulty of mapping disorders to autosomal loci. MR also occurs, with variable penetrance and expressivity, as a phenotypic feature of numerous hereditary syndromes. The challenge of understanding the biological bases of hereditary MR is heightened by its enormous genetic heterogeneity and the limited knowledge of cellular phenotypes in the brains of mentally retarded individuals. Recent rapid progress in human genetics, however, has provided us with an opportunity for a comprehensive 
analysis of the biochemical and cellular processes underlying the MR phenotype. A search for "mental retardation" in the Online Mendelian Inheritance in Man (OMIM) database (Hamosh et al. 2002) yields $>1000$ entries, suggesting that hundreds of human genes can mutate to a MR phenotype. We conducted a detailed analysis to determine how many MR genes have been molecularly identified and what molecular and biological functions they encode.

Controversies over the definition of MR are based on both sociopolitical and biological considerations (LEONARD and WEN 2002). Narrow definitions of MR restrict it to cases of nonprogressive cognitive impairment present from birth and categorize as "dementia" cases of progressive cognitive deterioration beginning some time after a period of normal development. Nonetheless, hereditary neurodegenerative disorders are often said to cause MR (see STEvenson et al. 2000), even when the onset is in late childhood or adolescence (e.g., progressive epilepsy with mental retardation, one of the neuronal ceroid lipofuscinoses; CLN8). Moreover, the distinction between MR and dementia blurs in disorders such as Rett syndrome (MECP2), where phenotypes span a wide spectrum of severity and clinical course (HAMmer et al. 2002). For the purpose of our analysis of hereditary MR, we chose a broader, albeit less precise, definition that includes progressive disorders with onset of cognitive impairment in childhood and, occasionally, as late as adolescence.

In parallel with human genetics research, progress in Drosophila melanogaster genetics and genome sequencing (AdAms et al. 2000) allows a comparative approach to the biological study of MR. Not only do homologous mammalian and fruit fly genes share biological functions (PAdgetT et al. 1993; Bonini et al. 1997; Johnston et al. 1997; Leuzinger et al. 1998; NAGAo et al. 1998; DEARBorn et al. 2002), but also Drosophila provides useful models of human disease, including spinocerebellar ataxia (WARrick et al. 1998), Parkinson's disease (FEANy and Bender 2000), Huntington's disease (JACKson et al. 1998), and type 1 diabetes (Rulifson et al. 2002). Moreover, neurodegeneration in the Drosophila model of Huntington's disease can be suppressed by treatment with a specific peptide (KAzANTSEv et al. 2002). Hence, we propose that this neurogenetic model system can reveal cellular phenotypes responsible for hereditary MR and will provide bioassays for potential drug therapies. By searching the Drosophila genome, we found candidate functional orthologs for the majority of molecularly identified human MR genes. Several dozen of these genes are most likely to have mutant phenotypes due to primary developmental defects of neurons or glia and thereby provide clues to the causes and treatment of MR due to single-gene mutations. Treatment strategies based on the understanding of hereditary MR may be useful for acquired MR as well.

\section{MATERIALS AND METHODS}

Databases and bioinformatics tools: The OMIM database [McKusick-Nathans Institute for Genetic Medicine, Johns Hopkins University and National Center for Biotechnology Information (NCBI), National Library of Medicine; HAMOsH et al. 2002] was accessed online (http://www.ncbi.nlm.nih. gov/entrez/query.fcgi?db=OMIM) to search for genes and mental retardation disorders. BLASTP (ALTsCHUL et al. 1997) at the NCBI (http://www.ncbi.nlm.nih.gov/BLAST/) and the Homophila Human-Disease-to-Drosophila-Gene database (REITER et al. 2001; http://homophila.sdsc.edu/) were used to search for $D$. melanogaster homologs of the human MR genes. Pairwise sequence alignments were performed with LALIGN (http://www.ch.embnet.org/software/LALIGN_form.html; Huang and Miller 1991). DotPlot and TransMem of the Accelrys GCG Wisconsin Package were accessed through the Arizona Research Laboratories Biotechnology Computing Facility and were used to compare homologous protein sequences by dot matrix analysis (MAIZEL and LENK 1981) and prediction of transmembrane regions, respectively. The InterPro resource for protein families, domains, and sites (APwEILER et al. 2001; http://www.ebi.ac.uk/interpro/scan. html) was used to determine and compare the locations of functional domains in homologous proteins. The Gene Ontology (GO) database (Gene Ontology Consortium 2001) was accessed online (http://www.geneontology.org/) to determine the molecular-function classification of MR gene products. FlyBase (FlyBase Consortium 2002) was accessed online (http://flybase.bio.indiana.edu/) to obtain information on Drosophila genes. Newly isolated $P$-element insertions were found through the P-Screen Database (http://flypush.imgen. bcm.tmc.edu/pscreen/).

Identifying human mental retardation genes through OMIM: We searched all OMIM fields on February 21, 2002, using the phrase "mental retardation" and reviewed each of the resulting 1010 entries. To include very mild MR, we also searched for "cognitive impairment" and "learning disability," obtaining 38 additional entries for evaluation. In retrospect, "developmental delay" and "psychomotor retardation" would have been useful search phrases as well. Other MR genes were identified by periodic literature searches through September 30, 2003, using NCBI's PubMed.

Careful evaluation of individual OMIM search results and cross-referencing with literature-search results revealed both false positives and false negatives. OMIM contains many partially redundant entries, which makes it impossible to equate numbers of entries obtained from a search for a specific phenotype with the number of genes that can mutate to that phenotype. OMIM entries for a genetic disorder or gene are organized into some or all of the following fields: title, MIM number, gene map, clinical synopsis, text (literature summary), allelic variants, references, and contributors. When different mutations of a single gene cause distinct disorders, there are separate OMIM entries for each disease, but only one contains a list of disease-associated alleles ("allelic variants" field). For example, mutations in the L1CAM gene result in one of at least three MR disorders (WELLER and GARTNER 2001): MASA syndrome (mental retardation, aphasia, shuffling gait, and adducted thumbs), HSAS (hydrocephalus due to congenital stenosis of the aqueduct of Sylvius), or SPG1 (spastic paraplegia 1). There is a separate OMIM entry for each of these disorders and a fourth entry for the L1CAM gene. There is some text redundancy among the four entries, but only the LICAM entry includes the allelic variants field. On the basis of this organizational scheme, OMIM searches restricted to entries containing the allelic variants field should eliminate redundant results. However, this strategy would 
cause false negatives because entries that list allelic variants do not necessarily contain complete phenotype descriptions. For example, entry 600514, which lists the allelic variants of reelin $(R E L N)$, does not contain the phrase "mental retardation," whereas entry 257320 for Norman-Roberts type lissencephaly syndrome due to RELN mutations contains the search phrase but does not list allelic variants. In principle, the "clinical synopsis" field could offer a useful search strategy for disease phenotypes, but some are incomplete (e.g., the clinical synopsis for Norman-Roberts lissencephaly does not include MR although it is a consistent phenotype of this disorder) and many entries have no clinical synopsis at all.

Errors in the clinical synopsis fields also contributed to the many $(\sim 15 \%)$ false-positive entries (see Table 1 ). For example, entries 167200 and 167210 for pachyonychia congenita types 1 and 2 include MR in their clinical synopses, but the only evidence for MR is in the much rarer type 4 (FEInstein et al. 1988). Other false positives result from statements such as "neither [patient] had evidence of mental retardation" (entry 243605). In other entries MR is not a feature of the disorder being described, but some atypical patients are mentally retarded due to deletion of adjacent genes (e.g., entry 312865). Finally, MR may be mentioned because related disorders have a MR phenotype. For instance, MR is a phenotype of a subset of hereditary spastic paraplegias, so it is mentioned in the text of the entries for most forms. BoyADJIEV and JABS (2000) noted similar difficulties in extracting information from OMIM. To obtain complete information from OMIM, one must search in a manner that yields redundant and irrelevant entries. This minimizes false negatives, but, to interpret the search results accurately, one must be willing to review individual entries carefully. Even using a broad OMIM search strategy, we missed $45 \mathrm{MR}$ genes that were revealed through various literature search strategies.

Functional classification of human mental retardation genes: We searched for the 282 MR gene products in the molecularfunction category of the GO database and used information from the literature to classify those not yet in the database. The GO database is composed of three parallel schemes for classifying gene function: biological process, cellular component, and molecular function (GENE ONTOLOGY Consortium 2001). Each ontology is a hierarchical classification scheme (directed acyclic graph) of structured vocabulary terms that differs from a simple hierarchical tree, such as a pedigree, in that each term may be a "child" of multiple independent "parents." There are 24 occupied top-level terms in the molecular-function ontology, i.e., terms that do not have parents themselves. When GO assigned gene products to multiple molecular functions, we chose the most specific term for each. For example, we classified the $\alpha$-subunit of Gs, the adenylate cyclase-stimulating guanine nucleotide-binding protein (GNAS), as a "nucleotide-binding protein" rather than as a "hydrolase," the other GO assignment. For genes considered by GO to have "unknown function," we found that most could be provisionally classified on the basis of data in the literature.

The "biological function(s)" assignments were based on literature reviews for each gene, including neuroimaging, gene expression, and neuropathological data from human patients, as well as studies of wild-type and mutant mice. We first designated the basic cellular process in which the gene is primarily involved, e.g., cytoskeleton or chromosome structure. We then identified the site of primary organ system function, relative to MR: endocrine system, central nervous system, or neither. For those genes that directly impact central nervous system (CNS) development and/or function, we ascertained the tissue type (neuron, glia, or blood vessel) and the specific cellular process affected (e.g., cell identity or differentiation). We also considered whether MR caused by mutation of the gene is secondary to toxicity or secondary to energy or fuel deficiency.
Identifying Drosophila orthologs of human mental retardation genes: We used bioinformatics tools to determine if the human MR genes have likely functional orthologs in D. melanogaster. For MR genes encoding tRNAs, we aligned the human and fly tRNA homologs using LALIGN and calculated the percentage identity. For each protein-coding MR gene, we searched the D. melanogaster sequences of the NCBI nonredundant database with NCBI's BLASTP. We used an $E$-value cutoff of $1 \times 10^{-10}(1 e-10)$, a threshold commonly used for humanfly gene comparisons (ForTini et al. 2000; LlOYD et al. 2000; ReITer et al. 2001). The Homophila database (Reiter et al. 2001) is designed for such comparisons but, due to its organizational features and infrequent updates, we found it easier and more reliable to do our own BLAST searches. For one MR gene, we concluded that Drosophila does not have a biologically meaningful homolog despite a published claim of one. Grunge (FBgn0010825) is the most similar fly gene to human DRPLA (ZHANG et al. 2002), but has a BLASTP $E$-value of 5E-2, which does not meet our threshold. Moreover, sequence similarity is limited to the extreme $\mathrm{C}$ terminus and the Grunge protein does not possess the same domain organization as DRPLA.

For protein-coding MR genes, we also conducted a "reverse" BLASTP search using the top-scoring Drosophila BLASTP result as a query against the human sequences of the NCBI nonredundant database. A Drosophila gene was considered an ortholog of a human MR gene only if this reverse analysis (sometimes supplemented with dot-matrix plot and proteindomain comparison; see below) revealed that it was more similar to the human MR gene (or a paralog) than to another gene. For example, the Drosophila proteins most similar to human glial fibrillary acidic protein $(G F A P)$ are the products of Lamin and Lamin C. A reverse BLASTP search revealed that, although these two proteins share a single common domain with GFAP, they are more similar over their full lengths to members of the human lamin family. In addition, both human and Drosophila lamins are localized to the nucleus (GoldmAN et al. 2002), whereas GFAP is cytoplasmic (ENG et al. 2000). Hence, GFAP does not have an ortholog in Drosophila.

When compared with mammals, Drosophila has relatively few duplicated genes (DURAND 2003), so in some cases a Drosophila gene is the single ortholog of a paralogous set of human genes. For example, FMR1, which causes fragile $\mathrm{X}$ syndrome, is a member of a gene family that also includes FXR1 and FXR2, the autosomal fragile X-related genes. Drosophila dfmrl is the only homologous fly gene, sharing significant sequence similarity and domain structure with all three human genes, suggesting that it is the sole ortholog.

To determine if orthologous genes are likely to share the same molecular and biological functions in humans and flies, we used dot matrix plots (GCG DotPlot) to assess the extent of protein sequence similarity and searched the InterPro database for known functional domains in each protein. GCG TransMem was used to predict transmembrane regions in the human and fly proteins. If the proteins share sequence similarity over most of their lengths and have similar organization of known functional domains, we considered them to be candidate functional orthologs. In some cases we also considered expression patterns, mutant phenotypes, and subcellular localization. In cases of "computed genes" predicted from the Drosophila genome sequence, the absence of experimental data made the evaluation of ortholog status more difficult.

\section{RESULTS AND DISCUSSION}

The 282 mental retardation genes have been molecularly identified: Analysis of OMIM and literature search 


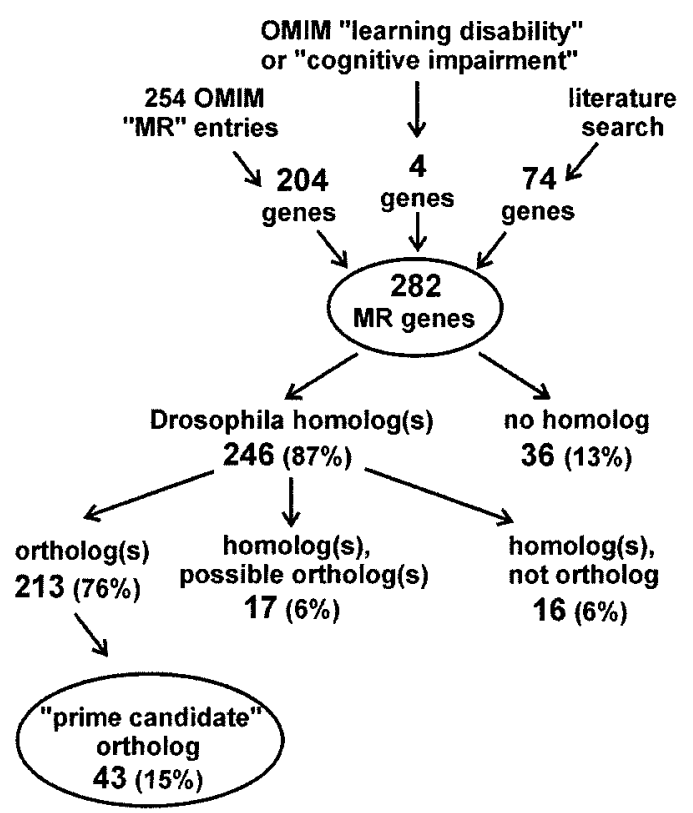

FIGURE 1.-Diagram of the identification of human mental retardation genes and their comparison to D. melanogaster genes. The OMIM searches were performed on February 21, 2002. The literature search was completed on September 30, 2003.

results allows us to present a status report on the genetics of MR. From the 1010 OMIM "mental retardation" entries obtained on February 21, 2002, we found 204 human genes that cause MR either in isolation or as part of a syndrome. Through literature searches we found 45 additional MR genes whose OMIM entries did not contain the search phrase "mental retardation." About a quarter of these "false-negative" entries contained the phrases "psychomotor retardation" and/or "developmental delay." To include disorders causing very mild MR, we also searched OMIM for entries containing "cognitive impairment" or "learning disability" but not "mental retardation." Most of these 38 entries describe adultonset, progressive cognitive impairment disorders, but literature review identified 4 of them as MR genes. Finally, literature searches between March 2002 and September 30, 2003 revealed 29 recently identified MR genes for a total of 282 human genes known to cause MR (Figure 1). On the basis of these and subsequent publications, we estimate that new MR genes are being identified at a rate of 1-2 per month. The APPENDIX lists the 282 MR genes in alphabetical order by their gene symbols, along with their associated MR disorders, chromosomal locations, OMIM numbers, and other information explained below. As will be discussed in later sections, the MR genes control an extraordinary range of molecular and cellular functions.

We classified the 1010 OMIM "mental retardation" entries, based on data available in spring 2002, according to the following scheme (Table 1):

Category 1: The disorder has been mapped to a specific
TABLE 1

OMIM mental retardation entries

\begin{tabular}{|c|c|c|c|}
\hline Category & Description & $\begin{array}{l}\text { No. of } \\
\text { entries }\end{array}$ & $\begin{array}{l}\% \text { of } \\
\text { entries }\end{array}$ \\
\hline 1 & Known gene & 254 & 25.1 \\
\hline 2 & Candidate gene & 55 & 5.4 \\
\hline 3 & Chromosomal region & 98 & 9.7 \\
\hline 4 & Candidate chromosome & 26 & 2.6 \\
\hline 5 & Not mapped & 416 & 41.2 \\
\hline 6 & Chromosomal abnormality & 9 & 0.9 \\
\hline 7 & No MR phenotype & 149 & 14.8 \\
\hline \multirow[t]{2}{*}{8} & Nonexistent disorder & 3 & 0.3 \\
\hline & Total: & 1010 & 100 \\
\hline
\end{tabular}

This table is based on analysis of a search done on February 21, 2002.

gene and allelic variants have been identified (this category includes OMIM entries for the MR disorders as well as separate entries describing the genes themselves).

Category 2: The disorder has been mapped to one or more candidate genes in a chromosomal region (contiguous gene deletion syndromes, e.g., Prader-Willi, are in this category).

Category 3: The disorder has been mapped to a chromosomal region.

Category 4: The disorder has been mapped to a candidate chromosome.

Category 5: The disorder has not yet been mapped to a chromosome.

Category 6: The disorder is caused by a gross chromosomal abnormality and no single gene determines the MR phenotype (Down syndrome is one example).

Category 7: MR is not a phenotype of the disorder.

Category 8: The disorder does not exist.

The number of OMIM entries in category 1 ("known gene"), 254, is greater than the number of genes, 204, because of OMIM database redundancy (see MATERIALS AND METHODS). The nearly 600 OMIM entries in categories 2-5 represent MR disorders in which the causative genes were unknown (see below). Of the 29 recently discovered MR genes, half had "advanced" from "candidate gene" (1 gene), "chromosomal region" (9 genes), or "unmapped" (5 genes) categories. Thirteen represent new loci that can cause a known disorder. One (FKRP) causes a form of muscular dystrophy, not previously associated with MR, that had been in category 7 .

Entries in category 6 ("chromosomal abnormality") describe bon a fide MR disorders, but we have not considered them further in this analysis because they appear to involve many genes (e.g., SHAPIro 1999). It remains to be determined whether individual genes that contribute to MR in cases of aneuploidy or other chromosomal defects can mutate to an MR phenotype individually. The 149 OMIM entries in category 7 ("no MR pheno- 
type") represent false positives in which MR is not a phenotype (see MATERIALS AND METHODS). Most of these false-positive errors could be eliminated by the adoption of a controlled vocabulary for OMIM clinical synopses, with the previously mentioned caveat that MR definitions vary. The three entries in category 8 ("nonexistent disorders") do not represent distinct clinical entities, and one was subsequently removed from the OMIM database.

With $\sim 600$ OMIM MR entries in categories 2-5 (Table 1), it is obvious that many more MR genes remain to be identified-but how many? Some of these disorders, particularly those in categories 4 ("candidate chromosome") and 5 ("not mapped"), are likely to represent MR genes that are already known. This is because of both practical difficulties in mapping human phenotypes and the phenomenon of phenotypic divergence; i.e., different mutant alleles of the same gene cause distinct MR disorders (e.g., different DKC1 mutations result in dyskeratosis congenita or Hoyeraal-Hreidarsson syndrome). Similarly, novel MR genes that remain to be identified may each explain more than one disorder, especially within the large unmapped group. Hence, this set of OMIM entries is likely to represent $<595$ genes.

On the other hand, what MR disorders might be "missing" from our analysis? First, we know that some genes, or their corresponding disorders, are present in the OMIM database but fail to appear in MR-related search results because of inconsistent use of terminology in the medical literature, curatorial errors, or differing opinions on what constitutes mental retardation (see MATERIALS AND METHODS). Second, MR mutations occurring in small families likely represent a large number of genes not yet listed in OMIM. Some families never reach the attention of medical genetics research teams. Small pedigrees represent significant challenges for gene mapping, even on the $\mathrm{X}$ chromosome (Ropers et al. 2003). The X-Linked Mental Retardation Genes Update Site (http://xlmr.interfree.it/home.htm; Chiurazzi et al. 2001) lists 57 nonspecific MR families and 110 X-linked MR syndromes for which the genes remain elusive. However, only 80 OMIM entries described X-linked MR disorders (syndromes and nonspecific) for which genes have not been identified (Table 1, X-linked entries in categories 2-4).

A third "missing" or underrecognized category is composed of essential genes of which most deleterious mutations cause early prenatal lethality and only exceptional alleles with specific molecular consequences permit viability along with an MR phenotype. In genetic model systems, complementation testing can easily show that a viable "memory mutation" is allelic to mutations causing early death with profound neuroanatomical defects (e.g., Pinto et al. 1999), but comparable mapping studies are much more difficult in humans.
Fourth, mutations in genes controlling thyroid development or function rarely cause MR in industrialized societies because of neonatal screening and treatment for hypothyroidism (GruTERs et al. 2002). Hence, while a dozen known genes have been associated with MR secondary to hypothyroidism (APPENDIX), mutations in other similar genes may not have had the "opportunity" to reveal whether they would cause MR in untreated patients. Finally, syndromal MR genes for which the MR phenotype has very low penetrance present a significant ascertainment challenge. For example, eight DNA repair genes/disorders are associated with MR in a modest fraction of patients. It seems likely that more such disorders (e.g., the rarer Fanconi anemia complementation groups) have MR as a bona fide phenotype, but, presumably because the phenotype depends on chance somatic mutations during brain development (GILMORE et al. 2000), it is difficult to confidently assign MR to their clinical descriptions.

Given all these considerations, predicting the true number of human MR genes is difficult. A complete and accurate count may be beyond the capacity of medical science to determine directly. We believe that 282 represents substantially less than half of the total. It is easy to imagine that human MR genes could number $\sim 1000$.

$\mathrm{X}$-linked mental retardation genes: To date, eight $\mathrm{X}$-linked genes are known to cause exclusively nonspecific MR (MRX genes), and $31 \mathrm{X}$-linked genes cause exclusively syndromal forms of MR (Table 2). Nonspecific MR has been the focus of much attention, in part because of the idea that genes with "pure" behavioral phenotypes, unaccompanied by gross brain abnormalities or other organ system defects, may provide greater insight into the molecular basis of cognition than the syndromal MR genes (Chelly 1999; Toniolo 2000). Indeed, several MRX genes figure prominently in Rhotype G-protein pathways (ARHGEF6, GDI1, OPHN1, PAK3, FGD1; RAMAKERS 2002) or are regulated by neuronal activity (PAK3, IL1RAPL1, RSK2, TM4SF2; BoDA et al. 2002). However, with the discovery that mutations of five MR genes can cause either nonspecific or syndromal MR (Table 2), the distinction between the two categories may not be as meaningful as originally proposed (see discussion in Frints et al. 2002).

For RSK2 (RPS6KA3), the phenotype difference is explained by allele type and severity. The R383W mutation that causes MRX19 is a partial loss-of-function allele, encoding a protein with $20 \%$ of wild-type kinase activity (MERIENNE et al. 1999). In contrast, null mutations of RSK2 cause Coffin-Lowry syndrome with prominent skeletal and connective tissue involvement (Hanauer and Young 2002). For several genes, the structure-function relationships are inferred but not directly demonstrated. The T1621M mutation of ATRX (also known as $\mathrm{XH} 2$ or $\mathrm{XNP}$ ) causes nonspecific MR in the mild-to-moderate range (YNTEMA et al. 2002). Although residue 1621 is within the highly conserved 
TABLE 2

$\mathrm{X}$-linked mental retardation genes

\begin{tabular}{lccl}
\hline $\begin{array}{l}\text { Type of MR } \\
\text { disorder }\end{array}$ & $\begin{array}{c}\text { No. of XLMR } \\
\text { genes }\end{array}$ & $\begin{array}{c}\text { \% of XLMR } \\
\text { genes }\end{array}$ & \multicolumn{1}{c}{ Gene symbols (see also APPENDIx) } \\
\hline Nonspecific only & 8 & 18.2 & ARHGEF6, FACL4, FMR2, GDI1, IL1RAPL1, OPHN1, PAK3, TM4SF2 \\
Syndromal only & 31 & 70.5 & All other X-linked genes in the APPENDIX \\
Both & 5 & 11.4 & ARX, ATRX, FGD1, MECP2, RSK2 \\
Total & $\mathbf{4 4}$ & $\mathbf{1 0 0}$ & \\
\hline
\end{tabular}

XLMR, X-linked mental retardation.

SNF2-related domain, it is not conserved, suggesting that some alterations at that site are compatible with partial function of this nuclear protein involved in chromatin structure and transcription regulation. Missense mutations just 7 and 12 residues upstream, however, cause a more severe, syndromal phenotype with hematologic, skeletal, and genital defects (GibBons et al. 1995), suggesting greater disruption of ATRX function. A variety of FGD1 mutations, most of which truncate the encoded putative Rho GEF, cause Aarskog-Scott syndrome, which includes highly penetrant skeletal and genital anomalies but infrequent, and only mild, MR. In contrast, one particular missense mutation in a region of unknown function, P312L, causes severe, fully penetrant nonspecific MR (LEBEL et al. 2002).

Genotype-phenotype relationships are even more complex for MECP2 and ARX. Within and among Rett syndrome families, females with $M E C P 2$ mutations show great clinical heterogeneity, with X-inactivation patterns and mutation sites believed to explain the severity differences (Cheadle et al. 2000; Hammer et al. 2002). In addition, at least seven different missense mutations in $M E C P 2$, scattered over the length of the protein, cause nonspecific MR (OrRICO et al. 2000; Couvert et al. 2001); several of these are very close to sites of Rettsyndrome-causing missense mutations (CHEAdLe et al. 2000; Hammer et al. 2002). For ARX, identical mutations, resulting in polyalanine tract expansion of this homeodomain protein, caused nonspecific MR in one family, but distinct neurological syndromes (West or Partington or MR with hypsarrhythmia) in various other families (Stromme et al. 2002). This suggests a major effect of genetic background on ARX phenotypes. Other $A R X$ mutations cause a unique lissencephaly syndrome with abnormal genitalia (Kitamura et al. 2002).

Complex genotype-phenotype relationships are also a feature of some autosomal MR disorders (e.g., FGFR1, GLI3, PEX1, PTEN, PTPN11). On the basis of X-linked $\mathrm{MR}$, it is possible that some alleles of the one known autosomal nonspecific MR gene (PRSS12; MolinaRI et $a l$. 2002) will be found to cause a syndromal MR phenotype. Conversely, autosomal genes presently known to cause MR syndromes may be able to mutate to a nonspecific MR phenotype.
Chromosomal distribution of human mental retardation genes: Of the 282 human MR genes, 11 are encoded by the mitochondrial genome. Figure $2 \mathrm{~A}$ shows the chromosomal distribution of the 271 nuclear MR genes compared to the chromosomal distribution of all known and predicted human genes based on the human genome sequence (VENTER et al. 2001). While $\sim 4 \%$ of known and predicted genes are on the $\mathrm{X}$ chromosome, $\sim 16 \%$ of the MR genes reside there-a fourfold overrepresentation. In contrast, the distribution of MR genes among the autosomes roughly parallels their relative gene contents (Figure 2A). An even greater X-chromosome overrepresentation is found among the MR disorders mapped to candidate loci (6-fold), chromosomal regions (14-fold), and chromosomes (15-fold), which correspond to categories 2, 3, and 4, respectively, of Table 1 .

It has been proposed that the human X chromosome contains a disproportionately high density of genes for cognitive ability (Lehrke 1972; Turner and PartingTON 1991). This proposal generated controversy as well as speculation concerning possible underlying evolutionary mechanisms, including the intriguing suggestion that female mate selection for high male intelligence helped accelerate the rapid rise of human cognitive abilities (Turner 1996; Zechner et al. 2001). The identification of numerous MRX genes and X-linked MR syndromes (Chiurazzi et al. 2001) seemed to support the proposal. Opponents, however, argued that all X-linked recessive mutations are simply easier to map and identify because their phenotypes are revealed in hemizygous males (Morton 1992; Lubs 1999). Countering this view is an OMIM-based analysis (ZECHNER et al. 2001) showing a 7.2-fold X-chromosome bias for MR genes, whereas genes causing common morphological phenotypes (polydactyly, cleft palate, facial dysplasia, skeletal dysplasia, and growth retardation) have, on average, only a 2.4-fold X-chromosome bias. [ZECHNER et al. (2001) did not take OMIM errors, such as false positives and negatives, into consideration, but such errors may be comparable across phenotypes.]

To take this question one step further, we asked whether the apparent X-chromosome overrepresentation among the molecularly identified human MR genes 

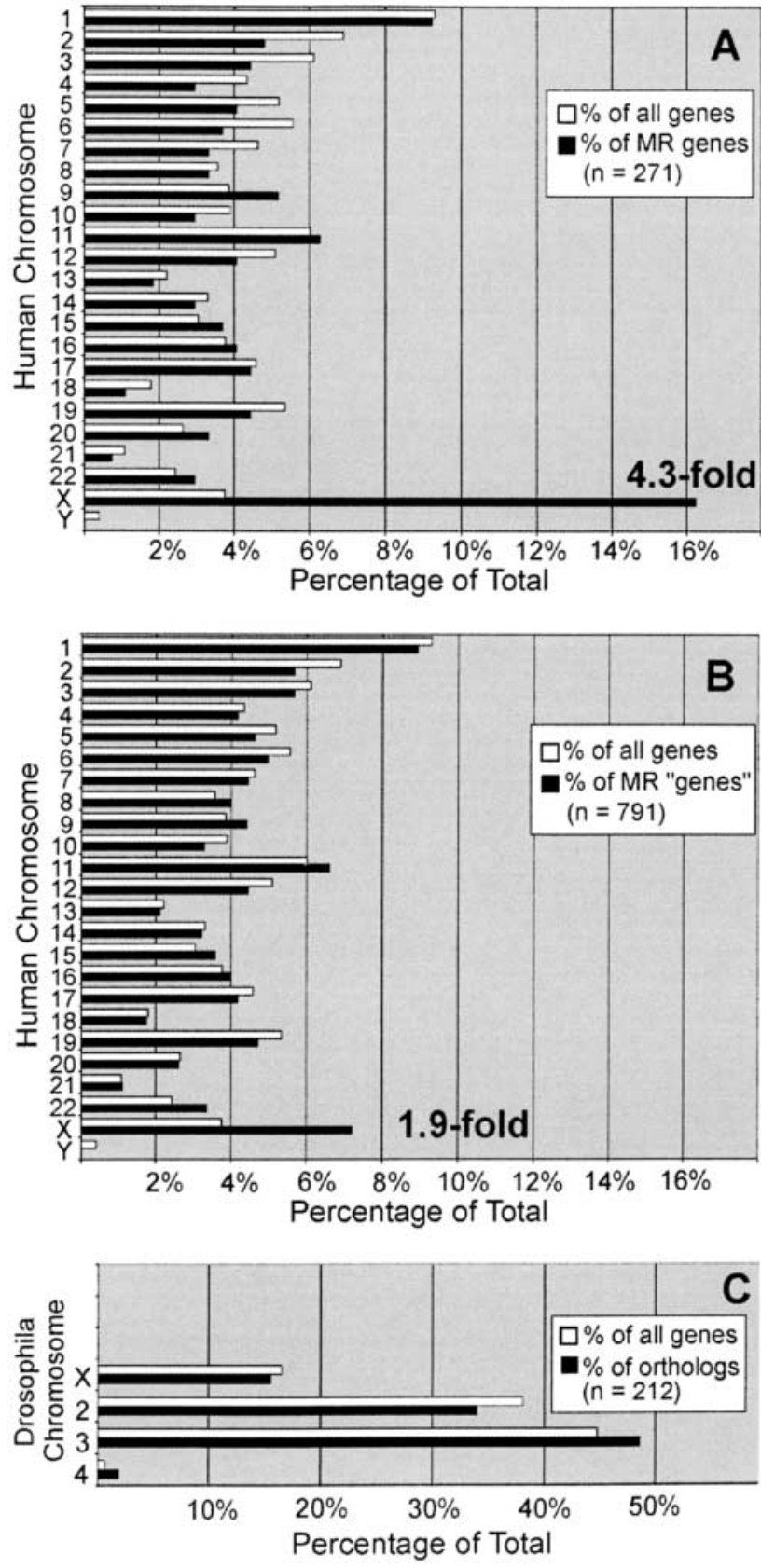

FIGURE 2.-Chromosomal distribution of human mental retardation genes and D. melanogaster orthologs. (A) The chromosomal distribution of the 271 molecularly identified nuclear MR genes is compared to the chromosomal distribution of all nuclear, protein-coding human genes based on human genome sequence analysis (Venter et al. 2001). Note the striking overrepresentation of X-linked MR genes. (B) The predicted chromosomal distribution of known and potential MR genes based on maximizing the assignment of genes to autosomes (see RESULTS and DISCUSSION), compared to all nuclear human genes as in A. The X-chromosome overrepresentation has been reduced, but remains almost twofold. (C) The chromosomal distribution of the Drosophila MR gene orthologs is compared to the chromosomal distribution of all nuclear, protein-coding Drosophila genes on the basis of Drosophila genome sequence analysis (ADAMs et al. 2000; see FlyBase at http://flybase.bio.indiana.edu/ for Release 3). Drosophila homologs of human MR genes that are not orthologs were not included in this analysis.
(Figure 2A) would disappear if we accounted for the plausible possibility that numerous autosomal loci are "hiding" among the unmapped MR genes (represented by the OMIM entries in category 5, Table 1). We attempted to overcome the ascertainment bias that favors identification of X-linked genes by making simplifying assumptions that maximize the estimate of autosomal MR genes and minimize the estimate of X-linked MR genes. First, we assumed that one OMIM entry equals one gene. Second, for the unmapped MR disorders (category 5, Table 1), we assumed that each represents a different, novel autosomal gene and that these are distributed in proportion to the overall gene distribution on those chromosomes (VENTER et al. 2001). Third, for those disorders whose genes map to chromosomal regions and candidate chromosomes (categories 3 and 4, Table 1), we assumed that there will be no new $\mathrm{X}$-linked genes, i.e., that each potential $\mathrm{X}$-linked gene is identical to an X-linked gene already known to cause MR. However, all candidate genes (category 2, Table 1 ), including the X-linked genes, were assumed to be new MR genes.

Even when these very conservative (i.e., biased toward autosomal) assumptions are used to estimate the chromosomal distribution of the unknown MR genes, a 1.9fold overrepresentation of MR genes on the X chromosome remains (Figure 2B). This result supports the hypothesis that the $\mathrm{X}$ chromosome contains a disproportionately high density of genes influencing cognitive ability. One caveat is the possibility discussed above that many autosomal MR genes may be so rare or difficult to study that they never appear in the medical literature and, hence, in OMIM. We also agree with the suggestion of Lubs (1999) that resolution of this issue would be enhanced by analyzing genome-wide brain expression data and by searching for allelic variation in single genes responsible for the high end of the intelligence spectrum.

D. melanogaster homologs of human mental retardation genes: We found that $87 \%$ of known MR genes (246/282) have at least one Drosophila homolog with a BLASTP E-value of $1 \times 10^{-10}$ or better (Figure 1; APPENDIX). Similarly, ReITer et al. (2001) found that $75 \%$ of $\sim 1400$ human disease genes, representing all major disease categories, have Drosophila homologs at this level of sequence similarity. More important, $76 \%$ (213) of the MR genes, including syndromal and nonsyndromal types, have at least one Drosophila ortholog (see MATERIALS AND METHODS and APPENDIX). In fact, a handful of the human genes were named for their Drosophila orthologs, in most cases prior to their identification as MR genes (ASPM: abnormal spindle-like, microcephaly-associated; EMX2: homolog 2 of empty spiracles; PTCH: homolog of patched; PTCH2: homolog 2 of patched; SHH: sonic hedgehog; SIX3: homolog 3 of sine oculis).

The APPENDIX lists the Drosophila homologs and orthologs of the MR genes, their FlyBase accession num- 
bers, and the BLASTP E-values (see also Figure 1 for overview). As discussed below, several dozen Drosophila orthologs (designated "I" in the APPENDIX) are prime candidates for cellular and molecular study of MR. Seventeen MR genes (6\%; designated with asterisk) have one or more homolog(s) that may be orthologs, but it is not possible to make a determination on the basis of sequence analysis in the absence of experimental data. Another $16 \mathrm{MR}$ genes (6\%; in brackets) have one or more Drosophila homolog(s) that are not orthologs on the basis of reverse BLAST results or other sequence analysis (see MATERIALS AND METHODS). There are 36 MR genes (13\%) with no Drosophila homolog, although this number may decline as final gene identification for the Drosophila genome is completed.

Some of the Drosophila genes are functional orthologs of human MR genes on the basis of experimental data. For instance, mutations of $d f m r 1$, the Drosophila ortholog of fragile X mental retardation 1 (FMR1; WAN et al. 2000), cause specific disruptions of neuronal morphology (Zhang et al. 2001; Morales et al. 2002; Lee et al. 2003; C. Michel, R. Kraft, B. Hassan and L. REstifo, unpublished results) and behavioral defects (DockendorfF et al. 2002; INOUE et al. 2002). Genetic and biochemical data suggest that Drosophila dFMR1 is a regulator of translation (ZHANG et al. 2001; IsHIZUKA et al. 2002), as has been shown for mammalian FMRP (KAyTOR and OrR 2001; LAgGerbauer et al. 2001; MAZROUI et al. 2002; ZALFA et al. 2003). Although learning phenotypes of $d f m r l$ mutant flies have not yet been reported, four of the fruit fly MR gene orthologs are "learning and memory genes" on the basis of behavioral data: $G$ protein sa60A (ConNolly et al. 1996), the ortholog of GNAS; Neurofibromin 1 (GuO et al. 2000), the ortholog of NF1; cheerio (see DuBNAU et al. 2003, online supplement), the ortholog of FLNA; and S6kII or ignorant (G. Putz, T. Zars, and M. HeisenberG, personal communication), the ortholog of RSK2. Additional Drosophila learning and memory genes have been proposed as candidates for MR disorders that are not yet mapped (Morley and Montgomery 2001).

The Drosophila orthologs of the human MR genes do not have a skewed chromosomal distribution (Figure 2C). Approximately $16 \%$ of all fly genes and $16 \%$ of MR gene orthologs are on the $\mathrm{X}$ chromosome. Of the first two dozen Drosophila "learning and memory genes" identified, almost $50 \%$ are X-linked (reviewed in Dubnau and Tully 1998; Morley and Montgomery 2001). However, the recent isolation of 60 new autosomal memory genes (DuBNAU et al. 2003) indicates that the older results reflect the previous tendency to design X-chromosome screens for behavioral and neuroanatomical phenotypes.

Molecular functions of mental retardation genes: Each of the 282 MR genes was classified in a single molecular-function category, primarily on the basis of the GO database (Figure 3; APPENDIX; see MATERIALS AND METHODS). The MR genes are distributed over a broad range of functions, indicating that disruption of any of a wide array of molecular processes can impair brain function so as to cause MR. Several categories are prominently represented, such as enzymes (143 genes; $51 \%$ ), mediators of signal transduction (32 genes; $12 \%$ ) and transcription regulation (19 genes; 7\%), binding proteins (23 genes; 8\%), and transporters (21 genes; $8 \%$ ). Enzymes, especially those expressed in accessible peripheral tissues, make gene identification easier than that for many other proteins, so their relative representation may decline as new MR genes are discovered. Other categories with smaller numbers of MR genes include cell adhesion molecule, structural molecule, motor protein, tRNAs, apoptosis regulator, chaperone, and enzyme regulator. GO classifies $\sim 9 \%$ of the MR genes (25) in the "unknown function" category, but published data suggest functions for all but 10 of them (see APPENDIX).

Within the GO molecular-function ontology, top-level categories include fundamental molecular functions (e.g., binding activity, of which there are many subcategories), as well as others related to a specific cellular process (e.g., cell adhesion molecule), and in many cases, genes could be assigned to more than one. This makes classification, analysis, and comparison to other sets of genes somewhat difficult. We did not classify any MR gene products as "defense/immunity proteins," but $I K B K G$ encodes a subunit of a signal transducer (our category choice) that regulates NF- $\mathrm{B}$ in the immune and inflammatory response pathway (WALLACH et al. 2002). We also did not use the "translation regulator" category, but EIF $2 A K 3$ encodes a kinase (our category choice) that indirectly regulates translation by phosphorylating eukaryotic translation initiation factor-2 (MA et al. 2002). Similarly, we classified FMR1 as "RNA binding," but considerable data demonstrate that it regulates translation (JIN and WARREN 2003). In addition, we could have classified some genes in the "protein stabilization" (e.g., PPGB), cytoskeletal regulator (e.g., $T B C E$ ), or "protein tagging" (e.g., UBE3A) categories. However, anticoagulant, antifreeze, antioxidant, chaperone regulator, nutrient reservoir, and toxin are toplevel categories in which none of the 282 MR genes could be placed.

Figure 3 indicates the Drosophila-homolog status of the MR genes in each molecular-function category. The 213 MR genes with Drosophila ortholog(s) (solid bars) are distributed among the GO categories in roughly the same pattern as that of all the MR genes, with two exceptions. More than half of the "receptor binding" genes ( 4 of 7 ) and $36 \%$ (9 of 25) of the "unknown function" MR genes have no Drosophila homolog.

Biological functions of mental retardation genes: We devised a "biological function(s)" classification scheme for the 282 MR genes that considers both cellular- and 


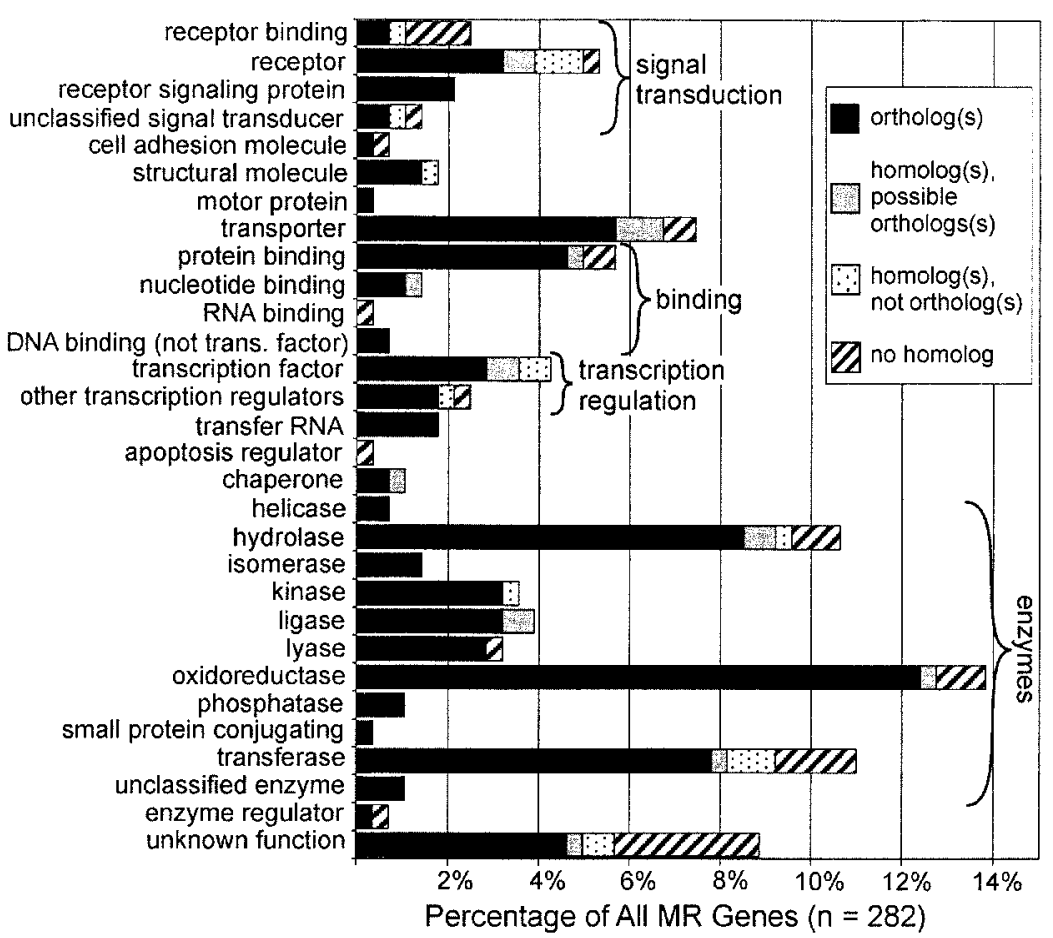

FigURE 3.-Molecular function classification of mental retardation genes. Genes were classified on the basis of GO categories (see MATERIALS AND METHODS). In cases where the top-level parent terms include large numbers of genes (signal transduction, binding, transcription regulation, enzyme), we show the distribution of genes among the children terms. For many of the genes that have not yet been classified by the GO Consortium, we used information from the literature to assign them to a GO term. For some of the genes designated "unknown function" by GO, we were able to assign provisional functions on the basis of published literature (see APPENDIX), but these genes are included in the "unknown function" category of this figure. As indicated by the boxed legend, each bar indicates classification of the human MR genes based on the degree of similarity to Drosophila genes. systems-level perspectives (Figure 4; APPENDIX; see MATERIALS AND METHODS). The basic cellular processes controlled by MR genes take place in the nucleus, in the cytoplasm (including within organelles), and at the interface among cells, cell compartments, and the extracellular milieu. In the nucleus, MR genes affect chromosome structure (e.g., DNMT3B), DNA repair (e.g., NBS1), basal and regulated transcription (e.g., ERCC2 and SIX3, respectively), as well as rRNA processing (e.g., DKC1).

In the cytoplasm, many MR genes have metabolic functions (see also KAHLER and FAHEY 2003), involving a wide range of pathways [citric acid cycle (e.g., $F H)$, gluconeogenesis (e.g., GK), glycolysis (e.g., PDHA1), oxidation (e.g., the $P E X$ genes), oxidative phosphorylation (e.g., MTCO1), urea cycle (e.g., OTC), and general cell integrity (e.g., GSS)] and biologically critical compounds [amine (e.g., MAOA), amino acid (e.g., OAT), carbohydrate (e.g., GALE), cholesterol (e.g., SC5DL), creatine (e.g., GATM), fatty acid (e.g., ALDH3A2), heme (e.g., PPOX), lipid (e.g., DIA), methionine (e.g., MAT1A), purine (e.g., HPRT), pyrimidine (e.g., DPYD), and cofactors (e.g., TC2) ]. MR genes involved in macromolecular synthesis and modification include those required for mitochondrial translation (e.g., MTTK), translation regulation (e.g., FMR1), protein folding (e.g., $B B S 6$ ), protein stability (e.g., $P P G B)$, protein glycosylation (e.g., PPM2), and lipid synthesis (FACL4). Macromolecular degradation in lysosomal (e.g., HEXA) and proteasomal (e.g., UBE3A) pathways is also commonly disrupted by mutations in MR genes. MR genes have major effects on the cytoskeleton, including its actin (e.g., FLNA), microtubule (e.g., DCX), and intermediate filament (e.g., GFAP) components.
The major signaling pathways are represented among the MR genes, including those regulated by Sonic Hedgehog (e.g., $S H H)$, the TGF- $\beta$ family of growth factors (e.g., GPC3), Notch (e.g., JAG1), and calcium (e.g., $A T P 2 A 2)$. MR-related signaling cascades are mediated by diverse cell surface proteins, such as integrins (e.g., ITGA7), G protein-coupled receptors (e.g., AGTR2), receptor tyrosine kinases (e.g., NTRK1), and intracellular proteins, including small G proteins (e.g., GDI1), heterotrimeric G proteins (e.g., GNAS), and phosphatidylinositol (e.g., PTEN). Moreover, genes in a common pathway can share MR as a phenotype. SHH (Ming et al. 1998), through its receptors encoded by PTCH and PTCH2, regulates $G L I 3$, some of whose targets are also regulated by $G P C 3$.

MR genes also control communication and transport across cell and organelle membranes. These include cation-chloride cotransporters (SLC12A1, SLC12A6) that may be critical for inhibitory neurotransmission (PAYNe et al. 2003). The transmembrane linkage (ITGA7, TM4SF2) between the extracellular matrix (LAMA2) and the cytoskeleton is strongly implicated in MR, as is cell adhesion ( $L 1 C A M)$.

The overlap between MR and muscle disease is striking and appears to arise from at least three distinct mechanisms: reduced membrane/cytoskeletal stability (DMD, ITGA 7, LAMA2); glycosylation defects associated with abnormal neuronal migration (FCMD, FKRP, LARGE, POMGNT1, POMT1); and mitochondrial dysfunction (MTCO3 and many others). The biological basis of myotonic dystrophy (DM1) is unknown.

An integrative view of MR biology: The hereditary MR disorders can be approached from two somewhat 


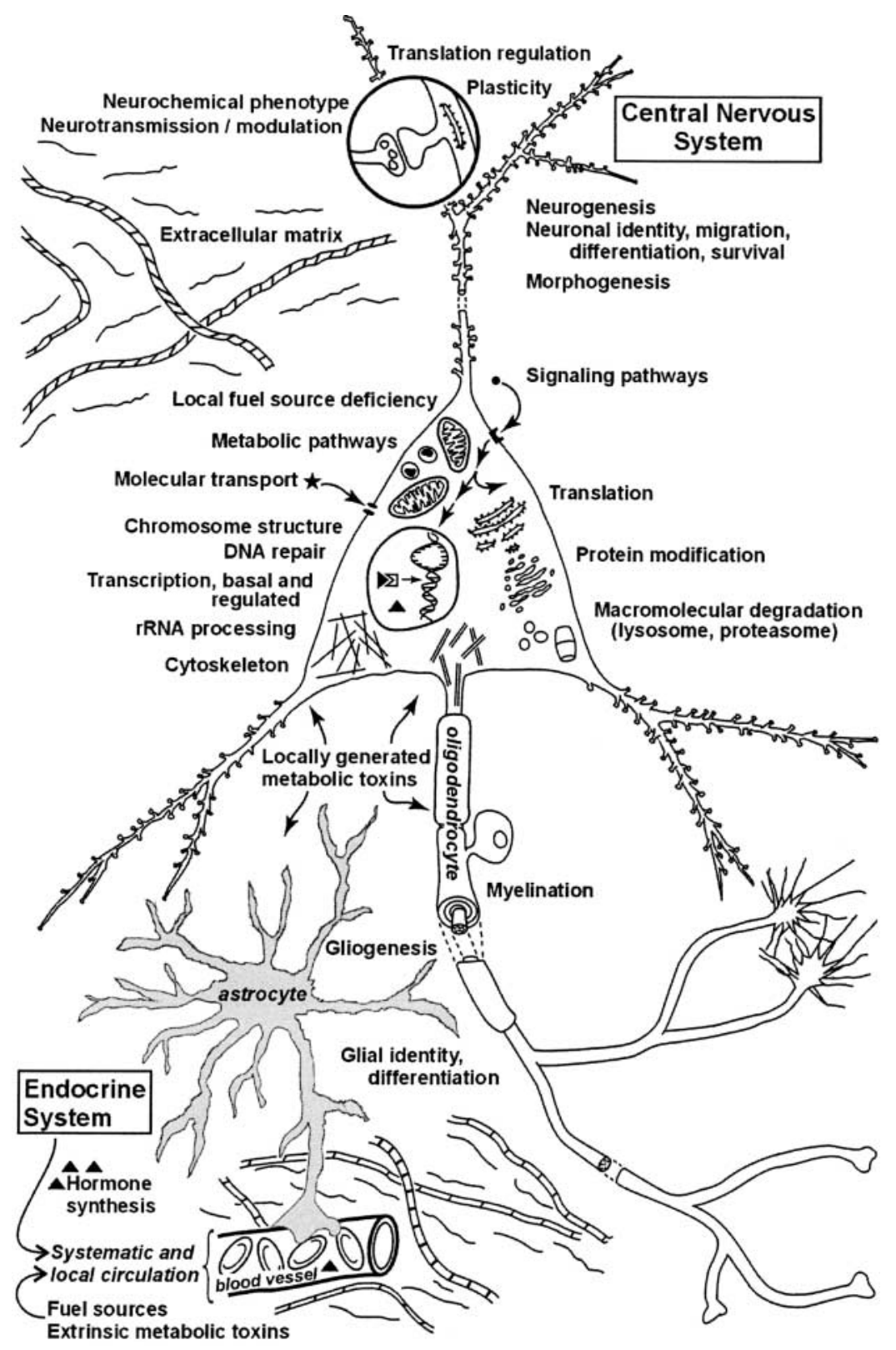

FIgURE 4.-Biological functions that underlie mental retardation. Diagram of a mammalian cortical neuron and associated structures in the central nervous system. The physiological connection to the endocrine system via the bloodstream is indicated in the bottom left. Sizes are not to scale. Solid triangles represent hormone molecules. Each of the unboxed terms, in roman type, is a biological function regulated by one or more MR genes or results from mutation of an MR gene (see APPENDIX). independent perspectives: (i) where the genes are expressed and function and (ii) the relationship between the mutation and pathogenesis of the MR phenotype. Genes may act selectively within the brain ("intrinsic or selective function") or primarily outside the CNS ("extrinsic or generalized function"). MR may result from fundamental cellular defects that impair many tissues ("generic effect"), with the brain sometimes having a higher sensitivity, or MR can result from selective impairment of unique features of brain development or physiology ("selective effect"). With the caveat that MR pathogenesis is incompletely understood and that spatial expression data are limited, we consider examples of MR genes in these major categories.

Extrinsic or generalized function/generic effect: $A B C C 8$ (SUR1) and KCNJ11 gene products work together in the pancreas to regulate ATP-dependent, exocytotic insulin secretion. Mutations in either gene cause excess insulin release and hypoglycemia which, if inadequately treated, disrupts brain development and function due to systemic fuel deficiency (VANNUCCI and VANNUCCI 2001; Huopio et al. 2002). Similarly, the brain's energy requirements make it very sensitive to genetic disruptions of mitochondrial function (CHOW and THORBURN 2000). Mutations in mitochondrial genes (MTATP6, MTCO1, MTCO2, MTCO3, MTCYB, MTTE, MTTK, MTTL1, MTTS1) or in nuclear genes encoding mitochondrial proteins (BCS1L,SCO2, SURF1, TIMM8A) cause MR due to local energy (ATP) deficiency in neurons and glia (SERvidei 2001).

Extrinsic or generalized function/selective effect: In the endocrine system, locally synthesized hormones enter the 
circulation and affect distant organs. MR genes include several tissue-specific regulators of thyroid gland development (TTF2, PAX8) or thyroid hormone synthesis (DUOX2, TG, TPO; Kopp 2002). Mutations in these cause congenital hypothyroidism, and mutations in a receptor $(T H R B)$ cause thyroid hormone resistance. In either case, brain cells cannot initiate the transcriptional cascade that controls neuronal size, migration, and dendritic morphology, as well as oligodendrocyte differentiation (Thompson and PotTer 2000). Hence, neuronal circuitry and myelination are disrupted.

Many metabolic MR genes fall into this category as well. AASS is expressed in most tissues and encodes a key enzyme in lysine metabolism (SACKSTEDER et al. 2000). In patients lacking AASS function, lysine accumulates and inhibits arginase, causing excess circulating ammonia, which interferes with neuronal and glial functions (Felipo and Butterworth 2002). Similarly, PAH is expressed mainly in nonneural tissues (LichterKONECKI et al. 1999), with mutations causing elevated circulating phenylalanine. This systemic toxin impairs myelination, synaptogenesis (BAUMAN and KeMPER 1982; Huttenlocher 2000), and possibly aminergic neurotransmission (SURTEEs and BlaU 2000). The lysosomal storage disorders, which cause macromolecules to accumulate in many tissues, may also belong to this category. Most represent degradative enzyme deficiencies, but some of the genes encode transport, stabilizer, or activator proteins (WISNIEwski et al. 2001). They are classified by the compounds that accumulate in lysosomes, such as sphingolipidoses (e.g., ARSA), neuronal ceroid lipofuscinoses (e.g., CLN1), glyoproteinoses (e.g., $P P G B$ ), and mucolipidoses (e.g., NEU1). The traditional view that the progressive brain phenotypes result "simply" from local toxicity is countered by reports of specific neurodevelopmental defects (Walkley 1998; AltaRESCU et al. 2002).

Intrinsic function/selective effect: For genes with selective expression or function within the CNS, the consequences of mutations are also primarily CNS selective, with variation in cell-type involvement and severity (Pomeroy and Kim 2000). The coexistence of neuropathology and cognitive deficits supports the view of MR as a disorder of brain development or plasticity. At one end of the spectrum are MR disorders with gross brain malformations. Holoprosencephaly, a failure of the right and left brain halves to form distinct hemispheres, results from mutations in genes controlling cellular identity of forebrain neuronal precursors (PTCH, SHH, SIX3, TDGF1, TGIF, ZIC2; WALLIS and Muenke 2000). Schizencephaly ("cleft brain") is due to dominant missense mutations in EMX2, which encodes a homeodomain-containing transcription factor (FAIELLA et al. 1997). Abnormal neuronal migration in the rostral forebrain (the region of EMX2 expression) causes gross morphogenetic as well as more subtle lamination defects. Neuronal migration defects also cause lissenceph- aly ("smooth brain") due to mutations in LIS1, DCX, and RELN, as well as ARX (some alleles) and FLNA (Olson and Walsh 2002). Agenesis (partial or complete) and dysgenesis of the interhemispheric corpus callosum (Davila-Gutierrez 2002) are relatively common MR-associated phenotypes (e.g., CXORF5, GLI3, OCRL, SLC12A6, TSC1, TSC2) and may be isolated or accompany holoprosencephaly and other abnormalities.

A handful of MR genes and their primary cellular phenotypes are glia specific. Dominant missense mutations in GFAP cause Alexander disease due to astrocytic accumulation of abnormal intermediate filaments and secondary demyelination (JoHNsON 2002). In contrast, PLP1 is expressed solely in oligodendrocytes and encodes the most abundant CNS myelin protein. Myelin integrity is very sensitive to $P L P 1$ gene dosage, with duplications, deletions, and missense mutations all causing Pelizaeus-Merzbacher disease (Koeppen and RobiTAILLE 2002).

At the other end of the spectrum are the many hereditary MR disorders for which routine neuropathological data are unavailable or fail to show consistent defects. Higher-resolution Golgi staining has revealed dendritic abnormalities of cortical neurons in fragile-X (FMR1; Irwin et al. 2000) and Rett syndromes (MECP2; ARMSTRONG 2001) and possibly in Rubinstein-Taybi syndrome (CREBBP; Kaufmann and Moser 2000). All three likely result from misregulated gene expression in the brain, but which target genes are responsible for the dendritic defects remain to be determined.

For MR disorders with no known anatomical lesions, such as nonsyndromal MRX, gene function in the CNS is inferred from molecular analyses. For example, GDI1 (MRX41, MRX48; BIENVENU et al. 1998) encodes a brain-specific regulator of Rab-type $\mathrm{G}$ proteins. One of its targets is believed to be Rab3A, which controls activity-dependent synaptic vesicle recruitment to axon terminals (LEENDERs et al. 2001). Given the structure-function relationships underlying developmental synaptic plasticity (COHEN-Cory 2002), it seems likely that neuroanatomical phenotypes for this and other MRX disorders will eventually be found.

Regardless of the scheme used, many disorders defy straightforward classification. For example, the role of homocysteine in CNS development and function (Mattson and Shea 2003) belies the "metabolic" classification of the MR genes CBS, MTHFR, MTR, MTRR, and TC2. The MR genes SC5DL and DHCR7 encode enzymes in cholesterol biosynthesis, making them also primarily "metabolic." However, because Sonic Hedgehog protein function is absolutely dependent on covalent linkage to cholesterol (Ingham and McMaHon 2001), the enzymatic deficiencies may impair SHH signaling. It may be that, with sufficient research on molecular and cellular pathogenesis, few if any MR genes will be considered "just metabolic." 


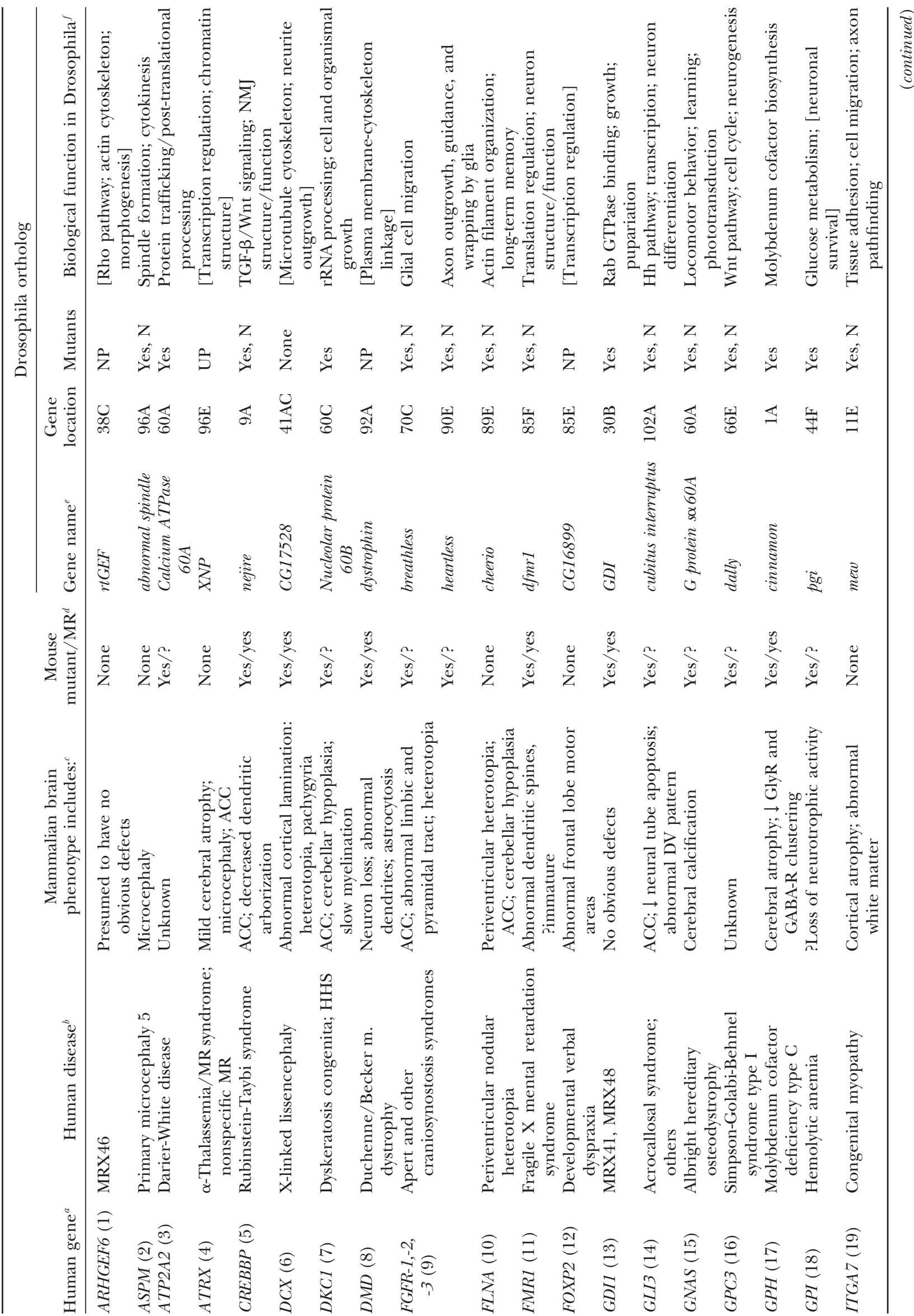




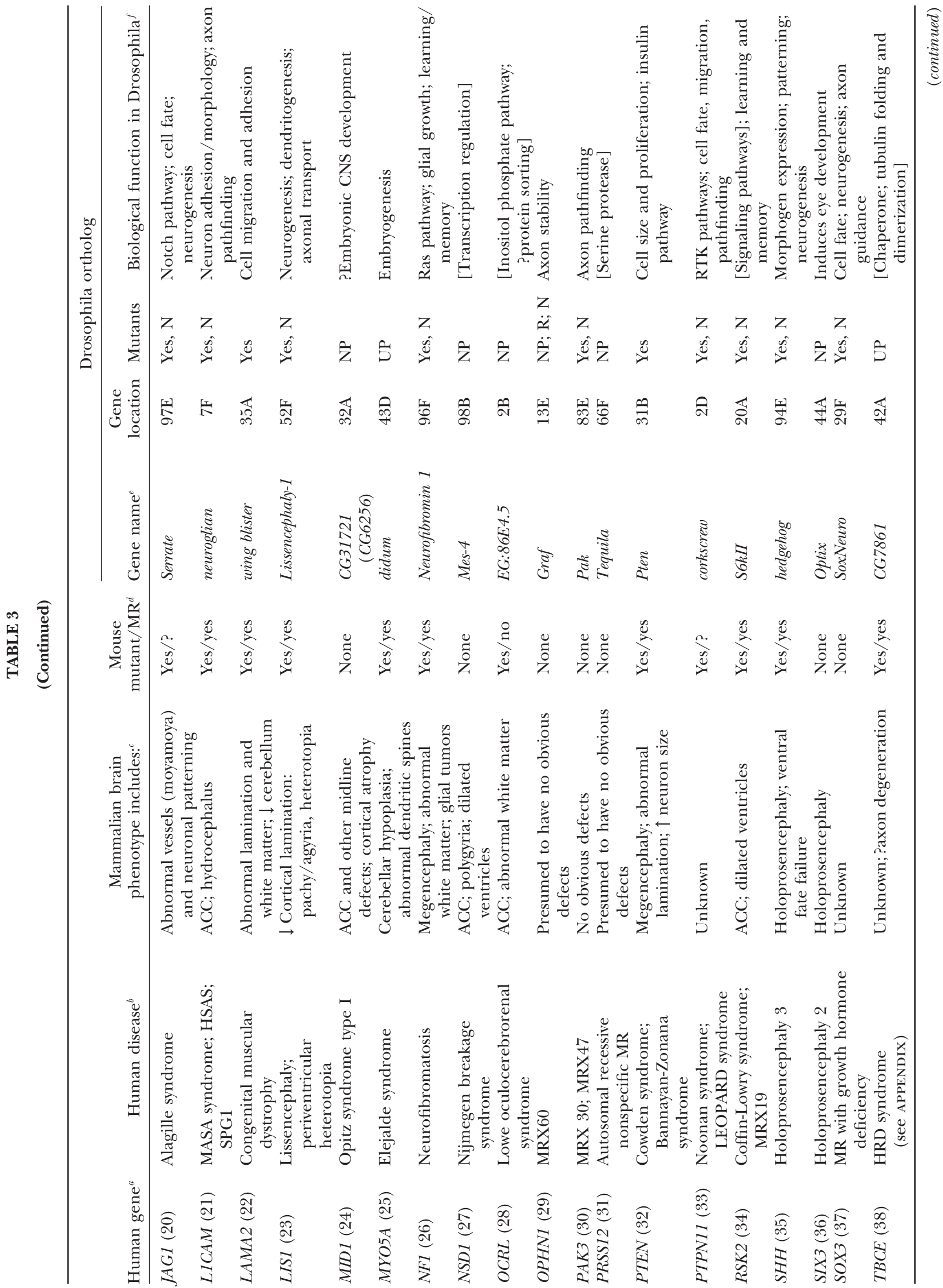




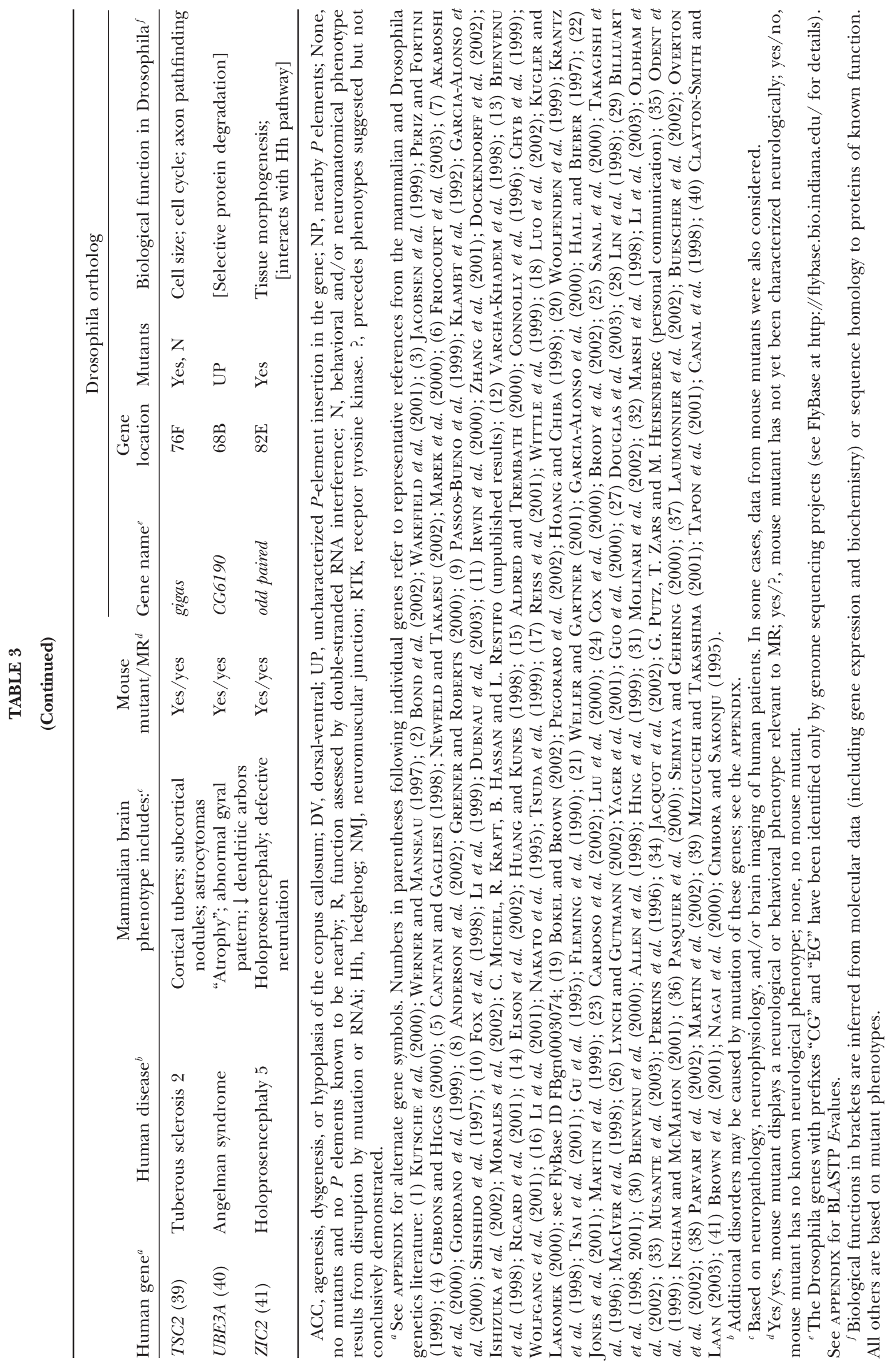


The role of $\boldsymbol{D}$. melanogaster in MR research: In terms of primary amino acid sequence and protein-domain organization, the degree of MR gene conservation between humans and Drosophila is remarkable (Figure 1; APPENDIX). Not only individual genes but also whole pathways have been retained through $\sim 700$ million years of evolution. These include protein glycosylation (ALG3, ALG6, B4GALT1, DPM1, FUCT1, GCS1, MGAT2, MPDU1, PMI, $P P M 2)$, as well as signaling pathways, notably the Hedgehog pathway (SHH, PTCH, PTCH2, GLI3, GPC3) and those mediated by small G proteins (ARHGEF6, GDI1, OPHN1, $P A K 3$, FGD1, GPH, RSK2, and others).

Given this remarkable conservation of MR genes, we propose that Drosophila genetics can be used in a systematic manner to study MR. We have selected $42 \mathrm{fly}$ genes (the orthologs of 43 human MR genes) as "prime candidates" for such analyses (Table 3). These genes most likely act selectively within the brain during development to establish the anatomical and physiological substrates for experience-dependent plasticity. The majority of prime-candidate orthologs currently have fly mutants available (about the same fraction as have mouse mutants available) and the rest can be mutagenized through the mobilization of nearby transposable elements or studied using RNA interference methods (Adams and Sekelsky 2002). About half are already known to have neural phenotypes, behavioral or anatomical, in Drosophila (Table 3 and references therein). The anatomical defects involve neurons (e.g., cubitus interruptus), glia (e.g., Neurofibromin 1), and neural precursor cells (e.g., division abnormally delayed) and result from problems with proliferation (e.g., hedgehog), migration (e.g., breathless), and process extension or arborization (e.g., Pak, dfmrl). For a few genes, neuronal defects in the mushroom bodies, an arthropod learning and memory center (ZARs 2000), have been demonstrated (e.g., Lissencephaly 1; Drosophila fragile-X mental retardation 1).

How will the Drosophila developmental neurogenetics system contribute to the understanding and treatment of these challenging human disorders? First, cellular phenotypes, including those detected in primary neuronal culture (KRAFT et al. 1998; R. KrAFT, J. KuRTIS and L. Restifo, unpublished results), could provide bioassays for drug testing. Second, genetic interaction studies will likely identify novel MR genes, as well as reveal the interconnected structure of MR gene pathways.

The degree to which fly mutant phenotypes "match" those of human patients remains to be seen, but it may not matter nearly as much as the genetic pathways involved, as these are likely to guide targeted drug discovery. For example, the fly ortholog of the MR gene ATP2A2 was identified in a screen for enhancers of Notch (Periz and Fortini 1999). The role of the Notch pathway in MR is revealed by Alagille syndrome due to mutations in JAG1 (Krantz et al. 1998), which encodes a ligand of Notch (the Drosophila ligand is Serrate). The biological relevance of genetic interactions in human MR is well demonstrated by some of the BardetBiedl syndromes ( $B B S 2$ and BBS6; see APPENDIX) in which clinical manifestations result from "triallelic inheritance," homozygosity at one locus and heterozygosity at another (KATSANIS et al. 2001). Genetic interaction tests in Drosophila could help clarify the functional relevance of the physical interaction between mammalian ZIC2 and GLI3 proteins (KoyABU et al. 2001).

The number of MR genes is very large, but they may be involved in a relatively small number of interconnected pathways. If so, a modest number of pharmacological treatment strategies might be effective for many MR patients. In fact, some types of acquired MR might benefit from the same drugs. Diagnoses of hereditary MR are typically made early in life at a time when developmental brain plasticity provides an opportunity for therapeutic intervention. The widespread functional conservation of MR genes in Drosophila indicates that this genetic model system could play a critical role in the discovery of novel treatment strategies for MR.

The authors thank Brian Blood for recent literature searches and BLAST analyses to update the list of human MR genes and their Drosophila homologs. The authors are grateful to colleagues David Mount for advice on bioinformatics methods, Terrill Yuhas and Nirav Merchant for computer support, Charles Hedgecock for assistance with computer graphics, and John Meaney and Robert Erickson for helpful discussions about human genetic disease. This work was funded by the National Institutes of Health (grant no. P01 NS028495).

Note added in proof: Evaluation of recently updated OMIM entries revealed three more MR genes whose molecular identifications were published prior to September 30, 2003. They are AAAS (OMIM 605378), COH1 (OMIM 607817), and MLC1 (OMIM 605908).

\section{LITERATURE CITED}

Adams, M. D., and J. J. Sekelsky, 2002 From sequence to phenotype: reverse genetics in Drosophila melanogaster. Nat. Rev. Genet. 3: 189-198.

Adams, M. D., S. E. Celniker, R. A. Holt, C. A. Evans, J. D. Gocayne et al., 2000 The genome sequence of Drosophila melanogaster. Science 287: 2185-2195.

Aicardi, J., 1998 The etiology of developmental delay. Semin. Pediatr. Neurol. 5: 15-20.

Akaboshi, S., M. Yoshimura, T. Hara, H. Kageyama, K. Nishikwa et al., 2000 A case of Hoyeraal-Hreidarsson syndrome: delayed myelination and hypoplasia of corpus callosum are other important signs. Neuropediatrics 31: 141-144.

Aldred, M. A., and R. C. Trembath, 2000 Activating and inactivating mutations in the human GNAS1 gene. Hum. Mutat. 16: 183189.

Allen, K. M., J. G. Gleeson, S. Bagrodia, M. W. Partington, J. C. MacMillan et al., 1998 PAK3 mutation in nonsyndromic X-linked mental retardation. Nat. Genet. 20: 25-30.

Altarescu, G., M. Sun, D. F. Moore, J. A. Smith, E. A. Wiggs et al., 2002 The neurogenetics of mucolipidosis type IV. Neurology 59: 306-313.

Altschul, S. F., T. L. Madden, A. A. Schaffer, J. Zhang, Z. Zhang et al., 1997 Gapped BLAST and PSI-BLAST: a new generation of protein database search programs. Nucleic Acids Res. 25: 33893402 .

Anderson, J. L., S. I. Head, C. Rae and J. W. Morley, 2002 Brain function in Duchenne muscular dystrophy. Brain 125: 4-13. 
Apweiler, R., T. K. Attwood, A. Bairoch, A. Bateman, E. Birney et al., 2001 The InterPro database, an integrated documentation resource for protein families, domains and functional sites. Nucleic Acids Res. 29: 37-40.

Armstrong, D. D., 2001 Rett syndrome neuropathology review 2000. Brain Dev. 23 (Suppl. 1): S72-S76.

BAt-HAEe, M. A., 2001 A longitudinal study of active treatment of adaptive skills of individuals with profound mental retardation. Psychol. Rep. 89: 345-354.

Bauman, M. L., and T. L. Kemper, 1982 Morphologic and histoanatomic observations of the brain in untreated human phenylketonuria. Acta Neuropathol. 58: 55-63.

Bienvenu, T., V. des Portes, A. Saint Martin, N. McDonell, P. Billuart et al. 1998 Non-specific X-linked semidominant mental retardation by mutations in a Rab GDP-dissociation inhibitor. Hum. Mol. Genet. 7: 1311-1315.

Bienvenu, T., V. des Portes, N. McDonell, A. Carrie, R. Zemni, et al. 2000 Missense mutation in PAK3, R67C, causes X-linked nonspecific mental retardation. Am. J. Med. Genet. 93: 294-298.

Billuart, P., T. Bienvenu, N. Ronce, V. Des Portes, M. C. Vinet, et al. 1998 Oligophrenin-1 encodes a rhoGAP protein involved in X-linked mental retardation. Nature 392: 923-926.

Billuart, P., C. G. Winter, A. Maresh, X. Zhao and L. Luo, 2001 Regulating axon branch stability: the role of p190 RhoGAP in repressing a retraction signaling pathway. Cell 107: 195-207.

Boda, B., C. Mas and D. Muller, 2002 Activity-dependent regulation of genes implicated in X-linked non-specific mental retardation. Neuroscience 114: 13-17.

Bokel, C., and N. H. Brown, 2002 Integrins in development: moving on, responding to, and sticking to the extracellular matrix. Dev. Cell 3: 311-321.

Bond, J., E. Roberts, G. H. Mochida, D. J. Hampshire, S. Scott et al., 2002 ASPM is a major determinant of cerebral cortical size. Nat. Genet. 32: 316-320.

Bonini, N. M., Q. T. Bui, G. L. Gray-Board and J. M. Warrick, 1997 The Drosophila eyes absent gene directs ectopic eye formation in a pathway conserved between flies and vertebrates. Development 124: $4819-4826$.

Boyadjiev, S. A., and E. W. Jabs, 2000 Online Mendelian Inheritance in Man (OMIM) as a knowledge base for human developmental disorders. Clin. Genet. 57: 253-266.

Brody, T., C. Stivers, J. Nagle and W. F. Odenwald, 2002 Identification of novel Drosophila neural precursor genes using a differential embryonic head cDNA screen. Mech. Dev. 113: 41-59.

Brown, L. Y., S. Odent, V. David, M. Blayau, C. Dubourg et al., 2001 Holoprosencephaly due to mutations in ZIC2: alanine tract expansion mutations may be caused by parental somatic recombination. Hum. Mol. Genet. 10: 791-796.

Buescher, M., F. S. Hing and W. ChiA, 2002 Formation of neuroblasts in the embryonic central nervous system of Drosophila melanogaster is controlled by SoxNeuro. Development 129: 4193-4203.

Butler, F. M., S. P. Miller, K. H. Lee and T. Pierce, 2001 Teaching mathematics to students with mild-to-moderate mental retardation: a review of the literature. Ment. Retard. 39: 20-31.

Canal, I., A. Acebes and A. Ferrus, 1998 Single neuron mosaics of the Drosophila gigas mutant project beyond normal targets and modify behavior. J. Neurosci. 18: 999-1008.

Cantani, A., and D. Gagliesi, 1998 Rubinstein-Taybi syndrome. Review of 732 cases and analysis of the typical traits. Eur. Rev. Med. Pharmacol. Sci. 2: 81-87.

Cardoso, C., R. J. Leventer, J. J. Dowling, H. L. Ward, J. Chung et al., 2002 Clinical and molecular basis of classical lissencephaly: mutations in the LIS1 gene (PAFAH1B1). Hum. Mutat. 19: 4-15.

Cheadle, J. P., H. Gill, N. Fleming, J. Maynard, A. Kerr et al., 2000 Long-read sequence analysis of the $M E C P 2$ gene in Rett syndrome patients: correlation of disease severity with mutation type and location. Hum. Mol. Genet. 9: 1119-1129.

Chelly, J., 1999 Breakthroughs in molecular and cellular mechanisms underlying X-linked mental retardation. Hum. Mol. Genet. 8: $1833-1838$.

Chiurazzi, P., B. C. Hamel and G. Neri, 2001 XLMR genes: update 2000. Eur. J. Hum. Genet. 9: 71-81.

Chow, C. W., and D. R. Thorburn, 2000 Morphological correlates of mitochondrial dysfunction in children. Hum. Reprod. 15 (Suppl. 2): 68-78.

Chyb, S., W. Hevers, M. Forte, W. J. Wolfgang, Z. Selinger et al.,
1999 Modulation of the light response by cAMP in Drosophila photoreceptors. J. Neurosci. 19: 8799-8807.

Cimbora, D. M., and S. SAKonju, 1995 Drosophila midgut morphogenesis requires the function of the segmentation gene odd-paired. Dev. Biol. 169: 580-595.

Clayton-Smith, J., and L. LaAn, 2003 Angelman syndrome: a review of the clinical and genetic aspects. J. Med. Genet. 40: 87-95.

Cohen-Cory, S., 2002 The developing synapse: construction and modulation of synaptic structures and circuits. Science 298: 770776.

Connolly, J. B., I. J. Roberts, J. D. Armstrong, K. Kaiser, M. FORTE et al., 1996 Associative learning disrupted by impaired Gs signaling in Drosophila mushroom bodies. Science 274: 2104 2107.

Couvert, P., T. Bienvenu, C. Aquaviva, K. Poirier, C. Moraine et al., 2001 MECP2 is highly mutated in X-linked mental retardation. Hum. Mol. Genet. 10: 941-946.

Cox, T. C., L. R. Allen, L. L. Cox, B. Hopwood, B. Goodwin et al., 2000 New mutations in MID1 provide support for loss of function as the cause of X-linked Opitz syndrome. Hum. Mol. Genet. 9: 2553-2562.

DAily, D. K., H. H. Ardinger and G. E. Holmes, 2000 Identification and evaluation of mental retardation. Am. Fam. Physician 61: 1059-1067.

Dashman, T., and C. SANSARICQ, 1993 Nutrition in the management of inborn errors of metabolism. Clin. Lab. Med. 13: 407-432.

Davila-Gutierrez, G., 2002 Agenesis and dysgenesis of the corpus callosum. Semin. Pediatr. Neurol. 9: 292-301.

Dearborn, R., Q. He, S. Kunes and Y. Dai, 2002 Eph receptor tyrosine kinase-mediated formation of a topographic map in the Drosophila visual system. J. Neurosci. 22: 1338-1349.

DockendorfF, T. C., H. S. Su, S. M. McBride, Z. YAng, C. H. Chol et al., 2002 Drosophila lacking dfmrl activity show defects in circadian output and fail to maintain courtship interest. Neuron 34: 973-984.

Dosen, A., and K. DAy (Editors), 2001 Treating Mental Illness and Behavior Disorders in Children and Adults with Mental Retardation. American Psychiatric Press, Washington, DC.

Douglas, J., S. Hanks, I. K. Temple, S. Davies, A. Murray et al., 2003 NSD1 mutations are the major cause of Sotos syndrome and occur in some cases of Weaver syndrome but are rare in other overgrowth phenotypes. Am. J. Hum. Genet. 72: 132-143.

Dubnau, J., and T. Tully, 1998 Gene discovery in Drosophila: new insights for learning and memory. Annu. Rev. Neurosci. 21: 407444.

Dubnau, J., A. S. Chiang, L. Grady, H. Barditch, S. Gossweiler et al., 2003 The staufen/pumilio pathway is involved in Drosophila long-term memory. Curr. Biol. 13: 286-296.

DurAND, D., 2003 Vertebrate evolution: doubling and shuffling with a full deck. Trends Genet. 19: 2-5.

Elson, E., R. Perveen, D. Donnai, S. Wall and G. C. M. Black, 2002 De novo GLI3 mutation in acrocallosal syndrome: broadening the phenotypic spectrum of GLI3 defects and overlap with murine models. J. Med. Genet. 39: 804-806.

ENG, L. F., R. S. GHirnikar and Y. L. Lee, 2000 Glial fibrillary acidic protein: GFAP-thirty-one years (1969-2000). Neurochem. Res. 25: 1439-1451.

Faiella, A., S. Brunelli, T. Granata, L. D'Incerti, R. Cardini et $a l ., 1997$ A number of schizencephaly patients including two brothers are heterozygous for germline mutations in the homeobox gene EMX2. Eur. J. Hum. Genet. 5: 186-190.

FeAny, M. B., and W. W. Bender, 2000 A Drosophila model of Parkinson's disease. Nature 404: 394-398.

Feinstein, A., J. Friedman and M. Schewach-Millet, 1988 Pachyonychia congenita. J. Am. Acad. Dermatol. 19: 705-711.

Felipo, V., and R. F. Butterworth, 2002 Neurobiology of ammonia. Prog. Neurobiol. 67: 259-279.

Fleming, R. J., T. N. Scottgale, R. J. Diederich and S. ArtavanisTsakonas, 1990 The gene Serrate encodes a putative EGF-like transmembrane protein essential for proper ectodermal development in Drosophila melanogaster. Genes Dev. 4: 2188-2201.

FlyBase Consortium, 2002 The FlyBase database of the Drosophila genome projects and community literature. Nucleic Acids Res. 30: $106-108$.

Fortini, M. E., M. P. Skupski, M. S. Boguski and I. K. Hariharan, 
2000 A survey of human disease gene counterparts in the Drosophila genome. J. Cell Biol. 150: F23-F30.

Fox, J. W., E. D. Lamperti, Y. Z. Eksioglu, S. E. Hong, Y. Feng et al., 1998 Mutations in filamin 1 prevent migration of cerebral cortical neurons in human periventricular heterotopia. Neuron 21: $1315-1325$.

Frints, S., G. Froyen, P. Marynen and J. P. Fryns, 2002 X-linked mental retardation: vanishing boundaries between non-specific (MRX) and syndromic (MRXS) forms. Clin. Genet. 62: 423-432.

Friocourt, G., A. Koulakoff, P. Chafey, D. Boucher, F. FaucherEAU et al., 2003 Doublecortin functions at the extremities of growing neuronal processes. Cereb. Cortex 13: 620-626.

Garcia-Alonso, L., S. Romani and F. Jimenez, 2000 The EGF and FGF receptors mediate neuroglian function to control growth cone decisions during sensory axon guidance in Drosophila. Neuron 28: 741-752.

Gene Ontology Consortium, 2001 Creating the gene ontology resource: design and implementation. Genome Res. 11: 14251433.

Gibbons, R. J., and D. R. Higgs, 2000 Molecular-clinical spectrum of the ATR-X syndrome. Am. J. Med. Genet. 97: 204-212.

Gibbons, R. J., D. J. Picketts, L. Villakd and D. R. Higgs, 1995 Mutations in a putative global transcriptional regulator cause X-linked mental retardation with alpha-thalassemia (ATR-X syndrome). Cell 80: 837-845.

Gilmore, E. C., R. S. Nowakowski, V. S. Caviness and K. Herrup, 2000 Cell birth, cell death, cell diversity and DNA breaks: How do they all fit together? Trends Neurosci. 23: 100-105.

Giordano, E., I. Peluso, S. Senger and M. Furia, 1999 minifly, a Drosophila gene required for ribosome biogenesis. J. Cell Biol. 144: 1123-1133.

Goldman, R. D., Y. Gruenbaum, R. D. Moir, D. K. Shumaker and T. P. SPANN, 2002 Nuclear lamins: building blocks of nuclear architecture. Genes Dev. 16: 533-547.

Greener, M. J., and R. G. Roberts, 2000 Conservation of components of the dystrophin complex in Drosophila. FEBS Lett. 482: $13-18$.

Gruters, A., A. Jenner and H. Krude, 2002 Long-term consequences of congenital hypothyroidism in the era of screening programmes. Best Pract. Res. Clin. Endocrinol. Metab. 16: 369382.

Gu, Y., N. A. Hukriede and R. J. Fleming, 1995 Serrate expression can functionally replace Delta activity during neuroblast segregation in the Drosophila embryo. Development 121: 855-865.

Guo, H. F., J. Tong, F. Hannan, L. Luo and Y. Zhong, 2000 A neurofibromatosis-1-regulated pathway is required for learning in Drosophila. Nature 403: 895-898.

Hall, S. G., and A. J. Bieber, 1997 Mutations in the Drosophila neuroglian cell adhesion molecule affect motor neuron pathfinding and peripheral nervous system patterning. J. Neurobiol. 32: $325-340$.

Hammer, S., N. Dorrani, J. Dragich, S. Kudo and C. Schanen, 2002 The phenotypic consequences of MECP2 mutations extend beyond Rett syndrome. Ment. Retard. Dev. Disabil. Res. Rev. 8: 94-98.

Hamosh, A., A. F. Scott, J. Amberger, C. Bocchini, D. Valle et al., 2002 Online Mendelian Inheritance in Man (OMIM), a knowledge base of human genes and genetic disorders. Nucleic Acids Res. 30: 52-55.

Hanauer, A., and I. D. Young, 2002 Coffin-Lowry syndrome: clinical and molecular features. J. Med. Genet. 39: 705-713.

Hing, H., J. Xiao, N. Harden, L. Lim and S. L. Zipursky, 1999 Pak functions downstream of Dock to regulate photoreceptor axon guidance in Drosophila. Cell 97: 853-863.

Hoang, B., and A. Chiba, 1998 Genetic analysis on the role of integrin during axon guidance in Drosophila. J. Neurosci. 18: $7847-7855$

Huang, X., and W. Miller, 1991 A time-efficient, linear-space local similarity algorithm. Adv. Appl. Math. 12: 337-357.

HuAng, Z., and S. Kunes, 1998 Signals transmitted along retinal axons in Drosophila: hedgehog signal reception and the cell circuitry of lamina cartridge assembly. Development 125: 37533764.

Huopio, H., S.-L. Shyng, T. Otonkoski and C. G. Nichols, 2002 $\mathrm{K}_{\mathrm{ATP}}$ channels and insulin secretion disorders. Am. J. Physiol. Endocrinol. Metab. 283: E207-E216.
HutTenlocher, P. R., 2000 The neuropathology of phenylketonuria: human and animal studies. Eur. J. Pediatr. 159 (Suppl. 2): S102-S106.

Ingham, P. W., and A. P. McMahon, 2001 Hedgehog signaling in animal development: paradigms and principles. Genes Dev. 15: 3059-3087.

Inoue, S. B., M. Shimoda, I. Nishinokubi, M. C. Siomi, M. Okamura et al., 2002 A role for the Drosophila fragile X-related gene in circadian output. Curr. Biol. 12: 1331-1335.

Irwin, S. A., R. Galvez and W. T. Greenough, 2000 Dendritic spine structural anomalies in fragile-X mental retardation syndrome. Cereb. Cortex 10: 1038-1044.

Ishizuka, A., M. C. Siомı and H. Siomi, 2002 A Drosophila fragile $\mathrm{X}$ protein interacts with components of RNAi and ribosomal proteins. Genes Dev. 16: 2497-2508.

Jackson, G. R., I. Salecker, X. Dong, X. Yao, N. Arnheim et al., 1998 Polyglutamine-expanded human huntingtin transgenes induce degeneration of Drosophila photoreceptor neurons. Neuron 21: 633-642.

Jacobsen, N. J. O., I. Lyons, B. Hoogendoorn, S. Burge, P.-Y. Kwok et al., 1999 ATP2A2 mutations in Darier's disease and their relationship to neuropsychiatric phenotypes. Hum. Mol. Genet. 8: 1631-1636.

Jacouot, S., M. Zeniou, R. Touraine and A. Hanauer, 2002 X-linked Coffin-Lowry syndrome (CLS, MIM 303600, RPS6KA3 gene, protein product known under various names: pp90 $0^{\text {rk2 }}$, RSK2, ISPK, MAPKAP1). Eur. J. Hum. Genet. 10: 2-5.

Jin, P., and S. T. WARREN, 2003 New insights into fragile X syndrome: from molecules to neurobehaviors. Trends Biochem. Sci. 28: $152-158$.

Johnson, A., 2002 Alexander disease: a review and the gene. Int. J. Dev. Neurosci. 20: 391-394.

Johnston, S. H., C. Rauskolb, R. Wilson, B. Prabhakaran, K. D. IRVINE et al., 1997 A family of mammalian Fringe genes implicated in boundary determination and the Notch pathway. Development 124: 2245-2254.

Jones, K. J., G. Morgan, H. Johnston, V. Tobias, R. A. Ouvrier et al., 2001 The expanding phenotype of laminin $\alpha 2$ chain (merosin) abnormalities: case series and review. J. Med. Genet. 38: 649-657.

Kabra, M., and S. Gulati, 2003 Mental retardation. Indian J. Pediatr. 70: $153-158$

Kahler, S. G., and M. C. Fahey, 2003 Metabolic disorders and mental retardation. Am. J. Med. Genet. 117C: 31-41.

Katsanis, N., S. J. Ansley, J. L. Badano, E. R. Eichers, R. A. Lewis et al., 2001 Triallelic inheritance in Bardet-Biedl syndrome, a Mendelian recessive disorder. Science 293: 2256-2259.

Kaufmann, W. E., and H. W. Moser, 2000 Dendritic anomalies in disorders associated with mental retardation. Cereb. Cortex 10: 981-991.

Kaytor, M. D., and H. T. OrR, 2001 RNA targets of the fragile X protein. Cell 107: 555-557.

Kazantsev, A., H. A. Walker, N. Slepko, J. E. Bear, E. Preisinger et al., 2002 A bivalent Huntingtin binding peptide suppresses polyglutamine aggregation and pathogenesis in Drosophila. Nat. Genet. 30: 367-376.

Kinsbourne, M., and W. D. Graf, 2000 Disorders of mental development, pp. 1155-1211 in Child Neurology, edited by J. H. Menkes and H. B. Sarnat. Lippincott Williams \& Wilkins, Philadelphia.

Kitamura, K., M. Yanazawa, N. Sugiyama, H. Miura, A. IizukaKogo et al., 2002 Mutation of ARX causes abnormal development of forebrain and testes in mice and X-linked lissencephaly with abnormal genitalia in humans. Nat. Genet. 32: 359-369.

Klambt, C., L. Glazer and B. Z. Shilo, 1992 breathless, a Drosophila FGF receptor homolog, is essential for migration of tracheal and specific midline glial cells. Genes Dev. 6: 1668-1678.

Koeppen, A. H., and Y. Robitaille, 2002 Pelizaeus-Merzbacher disease. J. Neuropathol. Exp. Neurol. 61: 747-759.

Kopp, P., 2002 Perspective: genetic defects in the etiology of congenital hypothyroidism. Endocrinology 143: 2019-2024.

Koyabu, Y., K. Nakata, K. Mizugishi, J. Aruga and K. Mikoshiba, 2001 Physical and functional interaction between Zic and Gli proteins. J. Biol. Chem. 276: 6889-6892.

Kraft, R., R. B. Levine and L. L. Restifo, 1998 The steroid hormone 20-hydroxyecdysone enhances neurite growth of Drosophila mushroom body neurons isolated during metamorphosis. J. Neurosci. 18: 8886-8899. 
Krantz, I. D., R. P. Colliton, A. Genin, E. B. Rand, L. Li et al., 1998 Spectrum and frequency of jagged1 (JAG1) mutations in Alagille syndrome patients and their families. Am. J. Hum. Genet. 62: 1361-1369.

Kugler, W., and M. LAKomek, 2000 Glucose-6-phosphate isomerase deficiency. Bailliere's Best Pract. Res. Clin. Haematol. 13: 89-101.

Kutsche, K., H. Yntema, A. Brandt, I. Jantke, H. G. Nothwang et al., 2000 Mutations in ARHGEF6, encoding a guanine nucleotide exchange factor for Rho GTPases, in patients with X-linked mental retardation. Nat. Genet. 26: 247-250.

Laggerbauer, B., D. Ostareck, E.-M. Keidel, A. Ostareck-Lederer and U. Fischer, 2001 Evidence that fragile X mental retardation protein is a negative regulator of translation. Hum. Mol. Genet. 10: 329-338.

Laumonnier, F., N. Ronce, B. C. Hamel, P. D. Thomas, J. Lespinasse et al., 2002 Transcription factor SOX3 is involved in X-linked mental retardation with growth hormone deficiency. Am. J. Hum. Genet. 71: 1450-1455.

Lebel, R. R., M. May, S. Pouls, H. A. Lubs, R. E. Stevenson et al., 2002 Non-syndromic X-linked mental retardation associated with a missense mutation (P312L) in the FGD1 gene. Clin. Genet. 61: $139-145$.

Lee, A., L. Wenjun, K. Xu, B. A. Bogert, K. Su et al., 2003 Control of dendritic development by the Drosophila fragile X-related gene involves the small GTPase Rac1. Development 130: 5543-5552.

Leenders, A. G., F. H. Lopes da Silva, W. E. Ghijsen and M. VerHAGE, 2001 Rab3a is involved in transport of synaptic vesicles to the active zone in mouse brain nerve terminals. Mol. Biol. Cell 12: 3095-3102.

LeHrke, R., 1972 Theory of X-linkage of major intellectual traits. Am. J. Ment. Defic. 76: 611-619.

LEONARD, H., and X. WEN, 2002 The epidemiology of mental retardation: challenges and opportunities in the new millennium. Ment. Retard. Dev. Disabil. Res. Rev. 8: 117-134.

Leuzinger, S., F. Hirth, D. Gerlich, D. Acampora, A. Simeone et al., 1998 Equivalence of the fly orthodenticle gene and the human OTXgenes in embryonic brain development of Drosophila. Development 125: 1703-1710.

Levy, H. L., 1999 Phenylketonuria: old disease, new approach to treatment. Proc. Natl. Acad. Sci. USA 96: 1811-1813.

LI, L., F. LIU and A. H. Ross, 2003 PTEN regulation of neural development and CNS stem cells. J. Cell. Biochem. 88: 24-28.

Li, M., M. Serr, K. Edwards, S. Ludmann, D. Yamamoto et al., 1999 Filamin is required for ring canal assembly and actin organization during Drosophila oogenesis. J. Cell Biol. 146: 1061-1073.

Li, M., C. Shuman, Y. L. Fei, E. Cutiongco, H. A. Bender et al., 2001 GPC3 mutation analysis in a spectrum of patients with overgrowth expands the phenotype of Simpson-Golabi-Behmel syndrome. Am. J. Med. Genet. 102: 161-168.

Lichter-Konecki, U., C. M. Hipke and D. S. Konecki, 1999 Human phenylalanine hydroxylase gene expression in kidney and other nonhepatic tissues. Mol. Genet. Metab. 67: 308-316.

Lin, T., B. M. Orrison, S. F. Suchy, R. A. Lewis and R. L. Nussbaum, 1998 Mutations are not uniformly distributed throughout the OCRL1 gene in Lowe syndrome patients. Mol. Genet. Metab. 64: 58-61.

LiU, Z., R. STEwARD and L. Luo, 2000 Drosophila Lis1 is required for neuroblast proliferation, dendritic elaboration and axonal transport. Nat.. Cell Biol. 2: 776-783.

Lloyd, T. E., P. Verstreken, E. J. Ostrin, A. Phillippi, O. LichTARGE et al., 2000 A genome-wide search for synaptic vesicle cycle proteins in Drosophila. Neuron 26: 45-50.

Long, E. S., and R. G. Miltenberger, 1998 A review of behavioral and pharmacological treatments for habit disorders in individuals with mental retardation. J. Behav. Ther. Exp. Psychiatry 29: 143156.

LuBs, H. A., 1999 The other side of the coin: a hypothesis concerning the importance of genes for high intelligence and evolution on the X chromosome. Am. J. Med. Genet. 85: 206-208.

Luckasson, R., D. L. Coulter, E. A. Polloway, S. Reiss, R. L. Schalock et al., 1992 MentalRetardation:Definition, Classification, and Systems of Support. American Association on Mental Retardation, Washington, DC.

Luo, Y., J. M. Long, C. Lu, S. L. Chan, E. L. Spangler et al., 2002 A link between maze learning and hippocampal expression of neuroleukin and its receptor gp78. J. Neurochem. 80: 354-361.
Lynch, T. M., and D. H. Gutmann, 2002 Neurofibromatosis 1 Neurol. Clin. 20: 841-865.

MA, K., K. M. VATtem and R. C. WeK, 2002 Dimerization and release of molecular chaperone inhibition facilitate activation of eukaryotic initiation factor-2 kinase in response to endoplasmic reticulum stress. J. Biol. Chem. 277: 18728-18735.

MacIver, B., A. McCormack, R. Slee and M. Bownes, 1998 Identification of an essential gene encoding a class-V unconventional myosin in Drosophila melanogaster. Eur. J. Biochem. 257: 529-537.

Maizel, J. V., JR., and R. P. Lenk, 1981 Enhanced graphic matrix analysis of nucleic acid and protein sequences. Proc. Natl. Acad. Sci. USA 78: 7665-7669.

Marek, K. W., N. Ng, R. Fetter, S. Smolik, C. S. Goodman et al., 2000 A genetic analysis of synaptic development: pre- and postsynaptic dCBP control transmitter release at the Drosophila NMJ. Neuron 25: 537-547.

Marsh, D. J., V. Coulon, K. L. Lunetta, P. Rocca-Serra, P. L. DAHiA et al., 1998 Mutation spectrum and genotype-phenotype analyses in Cowden disease and Bannayan-Zonana syndrome, two hamartoma syndromes with germline PTEN mutation. Hum. Mol. Genet. 7: 507-515.

Martin, D., S. Zusman, X. Li, E. L. Williams, N. Khare et al., 1999 wing blister, a new Drosophila laminin alpha chain required for cell adhesion and migration during embryonic and imaginal development. J. Cell Biol. 145: 191-201.

Martin, N., J. Jaubert, P. Gounon, E. Salido, G. Haase et al., 2002 A missense mutation in Tbce causes progressive motor neuropathy in mice. Nat. Genet. 32: 443-447.

Mattson, M. P., and T. B. Shea, 2003 Folate and homocysteine metabolism in neural plasticity and neurodegenerative disorders. Trends Neurosci. 26: 137-146.

Mazroui, R., M. E. Huot, S. Tremblay, C. Filion, Y. Labelle et al., 2002 Trapping of messenger RNA by fragile X mental retardation protein into cytoplasmic granules induces translational repression. Hum. Mol. Genet. 11: 3007-3017.

MCLAREN, J., and S. E. BRYSON, 1987 Review of recent epidemiological studies of mental retardation: prevalence, associated disorders and etiology. Am. J. Ment. Retard. 92: 243-254.

Merienne, K., S. Jacquot, S. Pannetier, M. Zeniou, A. Bankier et al., 1999 A missense mutation in RPS6KA3 (RSK2) responsible for non-specific mental retardation. Nat. Genet. 22: 13-14.

Ming, J. E., E. Roessler and M. Muenke, 1998 Human developmental disorders and the Sonic hedgehog pathway. Mol. Med. Today 4: 343-349.

Mizuguchi, M., and S. Takashima, 2001 Neuropathology of tuberous sclerosis. Brain Dev. 23: 508-515.

Molinari, F., M. Rio, V. Meskenaite, F. Encha-Razavi, J. Auge et al., 2002 Truncating neurotrypsin mutation in autosomal recessive nonsyndromic mental retardation. Science 298: 1779-1781.

Morales, J., P. R. Hiesinger, A. J. Schroeder, K. Kume, P. VerSTREKEN et al., 2002 Drosophila fragile X protein, DFXR, regulates neuronal morphology and function in the brain. Neuron 34: 961-972.

Morley, K. I., and G. W. Montgomery, 2001 The genetics of cognitive processes: candidate genes in humans and animals. Behav. Genet. 31: 511-531.

Morton, N. E., 1992 Genes for intelligence on the X chromosome. J. Med. Genet. 29: 71.

Musante, L., H. G. Kehl, F. Majewski, P. Meinecke, S. Schweiger et al., 2003 Spectrum of mutations in PTPN11 and genotypephenotype correlation in 96 patients with Noonan syndrome and five patients with cardio-facio-cutaneous syndrome. Eur. J. Hum. Genet. 11: 201-206.

Nagai, T., J. Aruga, O. Minowa, T. Sugimoto, Y. Ohno et al., 2000 Zic2 regulates the kinetics of neurulation. Proc. Natl. Acad. Sci. USA 97: 1618-1623.

Nagao, T., S. Leuzinger, D. Acampora, A. Simeone, R. Finkelstein et al., 1998 Developmental rescue of Drosophila cephalic defects by the human Otx genes. Proc. Natl. Acad. Sci. USA 95: 3737-3742.

Nakato, H., T. A. Futch and S. B. Selleck, 1995 The division abnormally delayed (dally) gene: a putative integral membrane proteoglycan required for cell division patterning during postembryonic development of the nervous system in Drosophila. Development 121: 3687-3702.

Newfeld, S. J., and N. T. TAKAesu, 2002 An analysis using the hobo genetic system reveals that combinatorial signaling by the Dpp 
and $\mathrm{Wg}$ pathways regulates dpp expression in leading edge cells of the dorsal ectoderm in Drosophila melanogaster. Genetics 161: $685-692$.

Odent, S., T. Attie-Bitach, M. Blayau, M. Mathieu, J. Auge et al., 1999 Expression of the Sonic hedgehog ( $\mathrm{SHH}$ ) gene during early human development and phenotypic expression of new mutations causing holoprosencephaly. Hum. Mol. Genet. 8: 16831689.

Oldham, S., H. Stocker, M. Laffargue, F. Wittwer, M. Wymann $e t$ al., 2002 The Drosophila insulin/IGF receptor controls growth and size by modulating PtdInsP(3) levels. Development 129: 4103-4109.

Olson, E. C., and C. A. WAlsh, 2002 Smooth, rough and upsidedown neocortical development. Curr. Opin. Genet. Dev. 12: 320327.

Orrico, A., C. Lam, L. Galli, M. T. Dotti, G. Hayek et al., 2000 $M E C P 2$ mutation in male patients with non-specific X-linked mental retardation. FEBS Lett. 481: 285-288.

Overton, P. M., L. A. Meadows, J. Urban and S. Russell, 2002 Evidence for differential and redundant function of the Sox genes Dichaete and SoxN during CNS development in Drosophila. Development 129: 4219-4228.

Padgett, R. W., J. M. Wozney and W. M. Gelbart, 1993 Human BMP sequences can confer normal dorsal-ventral patterning in the Drosophila embryo. Proc. Natl. Acad. Sci. USA 90: 2905-2909.

Parvari, R., E. Hershiovitz, N. Grossman, R. Gorodischer, B. LOEYs et al., 2002 Mutation of TBCE causes hypoparathyroidismretardation-dysmorphism and autosomal recessive Kenny-Caffey syndrome. Nat. Genet. 32: 448-452.

Pasquier, L., C. Dubourg, M. Blayau, L. Lazaro, B. Le Marec $e t$ al., 2000 A new mutation in the six-domain of $S I X 3$ gene causes holoprosencephaly. Eur. J. Hum. Genet. 8: 797-800.

Passos-Bueno, M. R., W. R. Wilcox, E. W. Jabs, A. L. Sertie, L. G. Alonso et al., 1999 Clinical spectrum of fibroblast growth factor receptor mutations. Hum. Mutat. 14: 115-125.

Payne, J. A., C. Rivera, J. Voipio and K. Kaila, 2003 Cation-chloride co-transporters in neuronal communication, development and trauma. Trends Neurosci. 26: 199-206.

Pegoraro, E., F. Cepollaro, P. Prandini, A. Marin, M. Fanin et al., 2002 Integrin alpha 7 beta 1 in muscular dystrophy/myopathy of unknown etiology. Am. J. Pathol. 160: 2135-2143.

Periz, G., and M. E. Fortini, $1999 \mathrm{Ca}^{2+}$-ATPase function is required for intracellular trafficking of the Notch receptor in Drosophila. EMBO J. 18: 5983-5993.

Perkins, L. A., M. R. Johnson, M. B. Melnick and N. Perrimon, 1996 The nonreceptor protein tyrosine phosphatase corkscrew functions in multiple receptor tyrosine kinase pathways in Drosophila. Dev. Biol. 180: 63-81.

Pinto, S., D. G. Quintana, P. Smith, R. M. Mihalek, Z. H. Hou et al., 1999 latheo encodes a subunit of the origin recognition complex and disrupts neuronal proliferation and adult olfactory memory when mutant. Neuron 23: 45-54.

Pomeroy, S. L., and J. Y. H. Kiм, 2000 Biology and pathobiology of neuronal development. Ment. Retard. Dev. Disabil. Res. Rev. 6: $41-46$.

RAmakers, G. J., 2002 Rho proteins, mental retardation and the cellular basis of cognition. Trends Neurosci. 25: 191-199.

Reiss, J., S. Gross-Hardt, E. Christensen, P. Schmidt, R. R. Mendel et al., 2001 A mutation in the gene for the neurotransmitter receptor-clustering protein gephyrin causes a novel form of molybdenum cofactor deficiency. Am. J. Hum. Genet. 68: 208-213.

Reiter, L.T ., L. Ротocki, S. Chien, M. Gribskov and E. Bier, 2001 A systematic analysis of human disease-associated gene sequences in Drosophila melanogaster. Genome Res. 11: 1114-1125.

Ricard, C. S., J. M. Jakubowski, J. W. Verbsky, M. A. Barbieri, W. M. Lewis et al., 2001 Drosophila rab GDI mutants disrupt development but have normal rab membrane extraction. Genesis 31: 17-29.

Roeleveld, N., G. A. Zielhuis and F. Gabreels, 1997 The prevalence of mental retardation: a critical review of recent literature. Dev. Med. Child Neurol. 39: 125-132.

Ropers, H.-H., M. Hoeltzenbein, V. Kalscheuer, H. Yntema, B. Hamel et al., 2003 Nonsyndromic X-linked mental retardation: Where are the missing mutations? Trends Genet. 19: 316-320.

Rulifson, E. J., S. K. Kim and R. Nusse, 2002 Ablation of insulin- producing neurons in flies: growth and diabetic phenotypes. Science 296: 1118-1120.

Sacksteder, K. A., B. J. Biery, J. C. Morrell, B. K. Goodman, B. V. GEISBRECHT et al., 2000 Identification of the alpha-aminoadipic semialdehyde synthase gene, which is defective in familial hyperlysinemia. Am. J. Hum. Genet. 66: 1736-1743.

Sanal, O., L. Yel, T. Kucukali, E. Gilbert-Barnes, M. Tardieu $e t$ al., 2000 An allelic variant of Griscelli disease: presentation with severe hypotonia, mental-motor retardation, and hypopigmentation consistent with Elejalde syndrome (neuroectodermal melanolysosomal disorder). J. Neurol. 247: 570-572.

Seimiya, M., and W. J. Gehring, 2000 The Drosophila homeobox gene optix is capable of inducing ectopic eyes by an eyeless-independent mechanism. Development 127: 1879-1886.

ServideI, S., 2001 Mitochondrial encephalomyopathies: gene mutation. Neuromuscul. Disord. 11: 332-337.

Shapiro, B. L., 1999 The Down syndrome critical region. J. Neural. Transm. 57 (Suppl.): 41-60.

Shishido, E., N. Ono, T. Kojima and K. Saigo, 1997 Requirements of DFR1/Heartless, a mesoderm-specific Drosophila FGF-receptor, for the formation of heart, visceral and somatic muscles, and ensheathing of longitudinal axon tracts in CNS. Development 124: 2119-2128.

Stevenson, R. E., C. E. Schwartz and R. J. Schroer, $2000 \quad$ X-Linked Mental Retardation. Oxford University Press, New York.

Stromme, P., M. E. Mangelsdorf, M. A. Shaw, K. M. Lower, S. M. Lewis et al., 2002 Mutations in the human ortholog of Aristaless cause X-linked mental retardation and epilepsy. Nat. Genet. 30: 441-445.

SurteEs, R., and N. Blau, 2000 The neurochemistry of phenylketonuria. Eur. J. Pediatr. 159 (Suppl. 2): S109-S113.

Takagishi, Y., S. Oda, S. Hayasaka, K. Dekker-Ohno, T. Shikata et al., 1996 The dilute-lethal $(d l)$ gene attacks a Ca2+ store in the dendritic spine of Purkinje cells in mice. Neurosci. Lett. 215: $169-172$.

Tapon, N., N. Ito, B. J. Dickson, J. E. Treisman and I. K. Hariharan, 2001 The Drosophila tuberous sclerosis complex gene homologs restrict cell growth and cell proliferation. Cell 105: 345-355.

Thompson, C. C., and G. B. PotTer, 2000 Thyroid hormone action in neural development. Cereb. Cortex 10: 939-945.

Toniolo, D., 2000 In search of the MRX genes. Am. J. Med. Genet. 97: 221-227.

Tsai, H., R. E. Hardisty, C. Rhodes, A. E. Kiernan, P. Roby et al., 2001 The mouse slalom mutant demonstrates a role for Jagged 1 in neuroepithelial patterning in the organ of Corti. Hum. Mol. Genet. 10: 507-512.

Tsuda, M., K. Kamimura, H. Nakato, M. Archer, W. Staatz et al., 1999 The cell-surface proteoglycan Dally regulates Wingless signaling in Drosophila. Nature 400: 213-215.

Turner, G., 1996 Intelligence and the X chromosome. Lancet 347: $1814-1815$.

Turner, G., and M. W. Partington, 1991 Genes for intelligence on the X chromosome. J. Med. Genet. 28: 429.

Vannucci, R. C., and S. J. Vannucci, 2001 Hypoglycemic brain injury. Semin. Neonatol. 6: 147-155.

Vargha-Khadem, F., K. E. Watkins, C. J. Price, J. Ashburner, K. J. Alcock et al., 1998 Neural basis of an inherited speech and language disorder. Proc. Natl. Acad. Sci. USA 95: 12695-12700.

Venter, J. C., M. D. Adams, E. W. Myers, P. W. Li, R. J. Mural et al., 2001 The sequence of the human genome. Science 291: 1304-1351.

Wakefield, J. G., S. Bonaccorsi and M. Gatti, 2001 The Drosophila protein Asp is involved in microtubule organization during spindle formation and cytokinesis. J. Cell Biol. 153: 637-647.

WALKLEY, S. U., 1998 Cellular pathology of lysosomal storage disorders. Brain Pathol. 8: 175-193.

Wallach, D., T. U. Arumugam, M. P. Boldin, G. Cantarella, K. A. Ganesh et al., 2002 How are the regulators regulated? The search for mechanisms that impose specificity on induction of cell death and NF-kappaB activation by members of the TNF/ NGF receptor family. Arthritis Res. 4: S189-S196.

Wallis, D., and M. MuENKe, 2000 Mutations in holoprosencephaly. Hum. Mutat. 16: 99-108.

Wan, L., T. C. DockendorfF, T. A. Jongens and G. Dreyfuss, 2000 Characterization of dFMR1, a Drosophila melanogaster homolog 
of the fragile X mental retardation protein. Mol. Cell. Biol. 20: $8536-8547$.

Warrick, J. M., H. L. Paulson, G. L. Gray-Board, Q. T. Bui, K. H. Fischвеск et al., 1998 Expanded polyglutamine protein forms nuclear inclusions and causes neural degeneration in Drosophila. Cell 93: 939-949.

Weller, S., and J. Gartner, 2001 Genetic and clinical aspects of X-linked hydrocephalus (L1 disease): mutations in the L1CAM gene. Hum. Mutat. 18: 1-12.

Werner, L. A., and L. J. Manseau, 1997 A Drosophila gene with predicted rhoGEF, pleckstrin homology and SH3 domains is highly expressed in morphogenic tissues. Gene 187: 107-114.

Wisniewski, K. E., N. Zhong and M. Philippart, 2001 Pheno/ genotypic correlations of neuronal ceroid lipofuscinoses. Neurology 57: 576-581.

Wittle, A. E., K. P. Kamdar and V. Finnerty, 1999 The Drosophila cinnamon gene is functionally homologous to Arabidopsis $c n x 1$ and has a similar expression pattern to the mammalian gephyrin gene. Mol. Gen. Genet. 261: 672-680.

Wolfgang, W. J., A. Hoskote, I. J. H. Roberts, S. Jackson and M. Forte, 2001 Genetic analysis of the Drosophila Gs $\alpha$ Gene. Genetics 158: 1189-1201.

Woolfenden, A. R., G. W. Albers, G. K. Steinberg, J. S. Hahn, D. C. C. Johnston et al., 1999 Moyamoya syndrome in children with Alagille syndrome: additional evidence of a vasculopathy. Pediatrics 103: 505-508.
Yager, J., S. Richards, D. S. Hekmat-Scafe, D. D. Hurd, V. SundareSAN et al., 2001 Control of Drosophila perineurial glial growth by interacting neurotransmitter-mediated signaling pathways. Proc. Natl. Acad. Sci. USA 98: 10445-10450.

Yntema, H. G., F. A. Poppelaars, E. Derksen, A. R. Oudakker, T. Van Roosmalen $e t$ al., 2002 Expanding phenotype of XNP mutations: mild to moderate mental retardation. Am. J. Med. Genet. 110: 243-247.

Zalfa, F., M. Giorgi, B. Primerano, A. Moro, A. Di Penta et al., 2003 The fragile X syndrome protein FMRP associates with $B C 1$ RNA and regulates translation of specific mRNAs at synapses. Cell 112: 317-327.

ZARs, T., 2000 Behavioral functions of the insect mushroom bodies. Curr. Opin. Neurobiol. 10: 790-795.

Zechner, U., M. Wilda, H. Kehrer-Sawatzki, W. Vogel, R. Fundele et al., 2001 A high density of X-linked genes for general cognitive ability: A run-away process shaping human evolution? Trends Genet. 17: 697-701.

Zhang, S., L. Xu, J. LeE and T. Xu, 2002 Drosophila atrophin homo$\log$ functions as a transcriptional corepressor in multiple developmental processes. Cell 108: 45-56.

Zhang, Y. Q., A. M. Bailey, H. J. Matthies, R. B. Renden, M. A. Sмiтн et al., 2001 Drosophila fragile X-related gene regulates the MAP1B homolog Futsch to control synaptic structure and function. Cell 107: 591-603.

Communicating editor: R. S. HAWLEY 


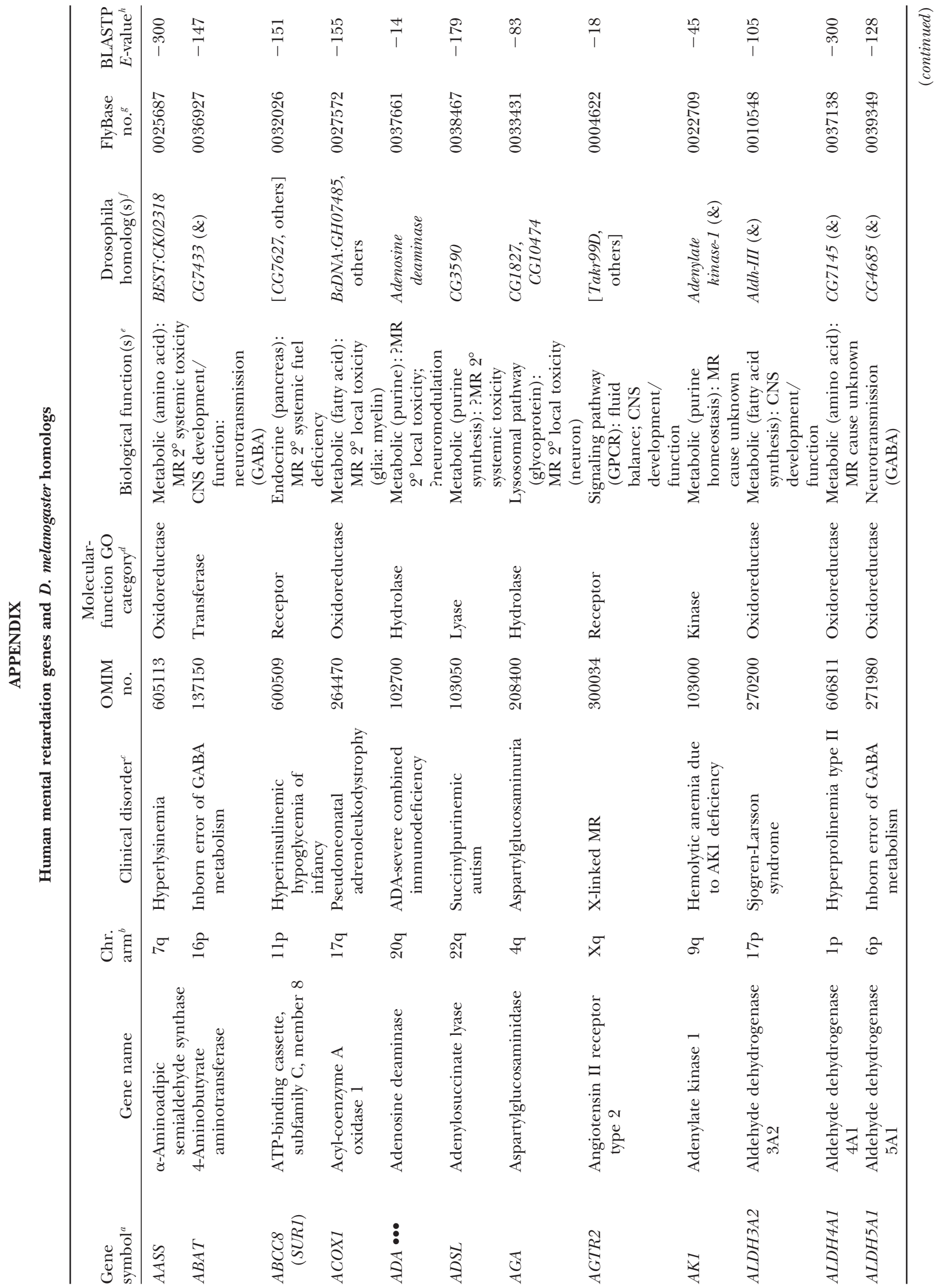




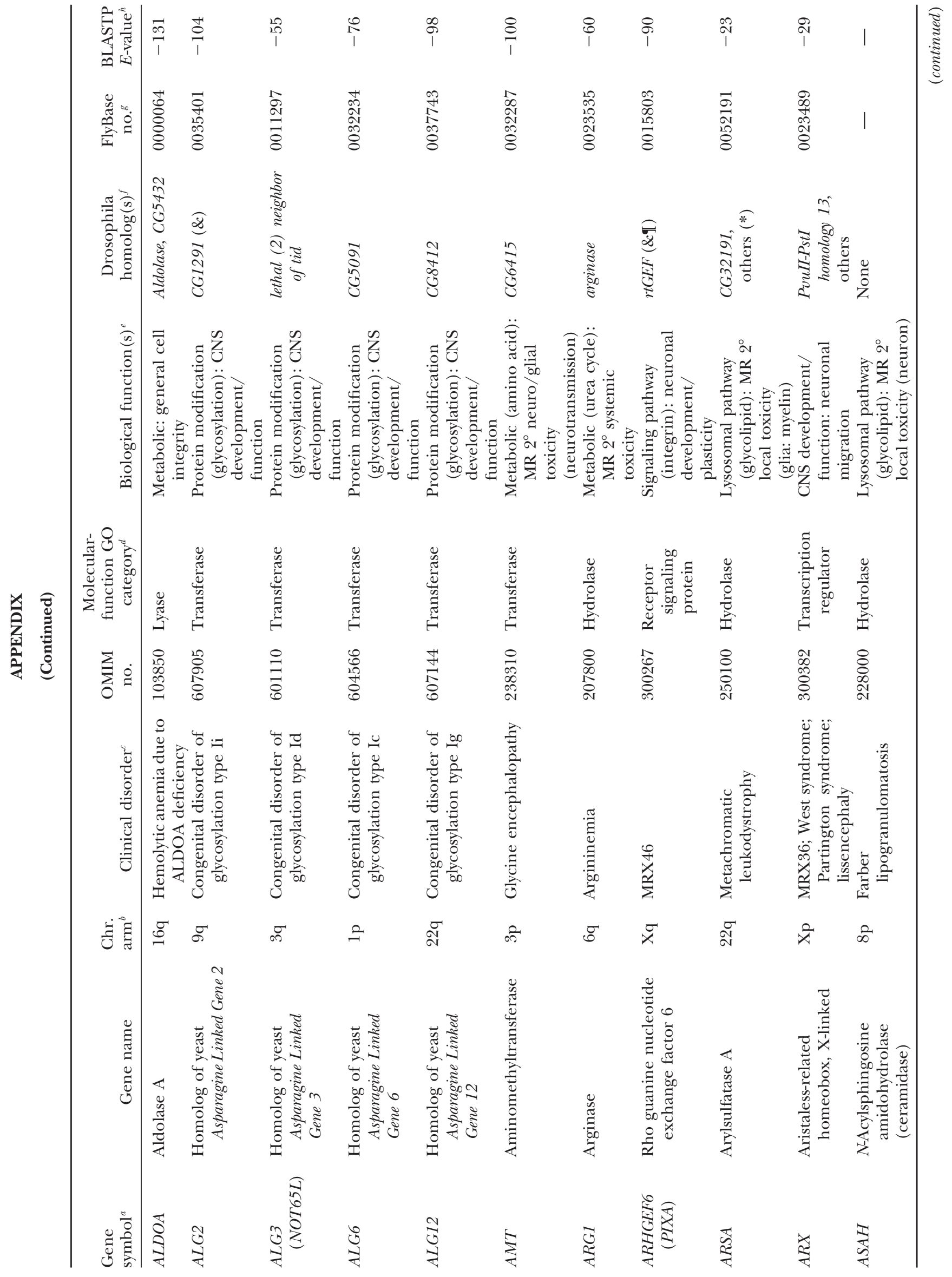




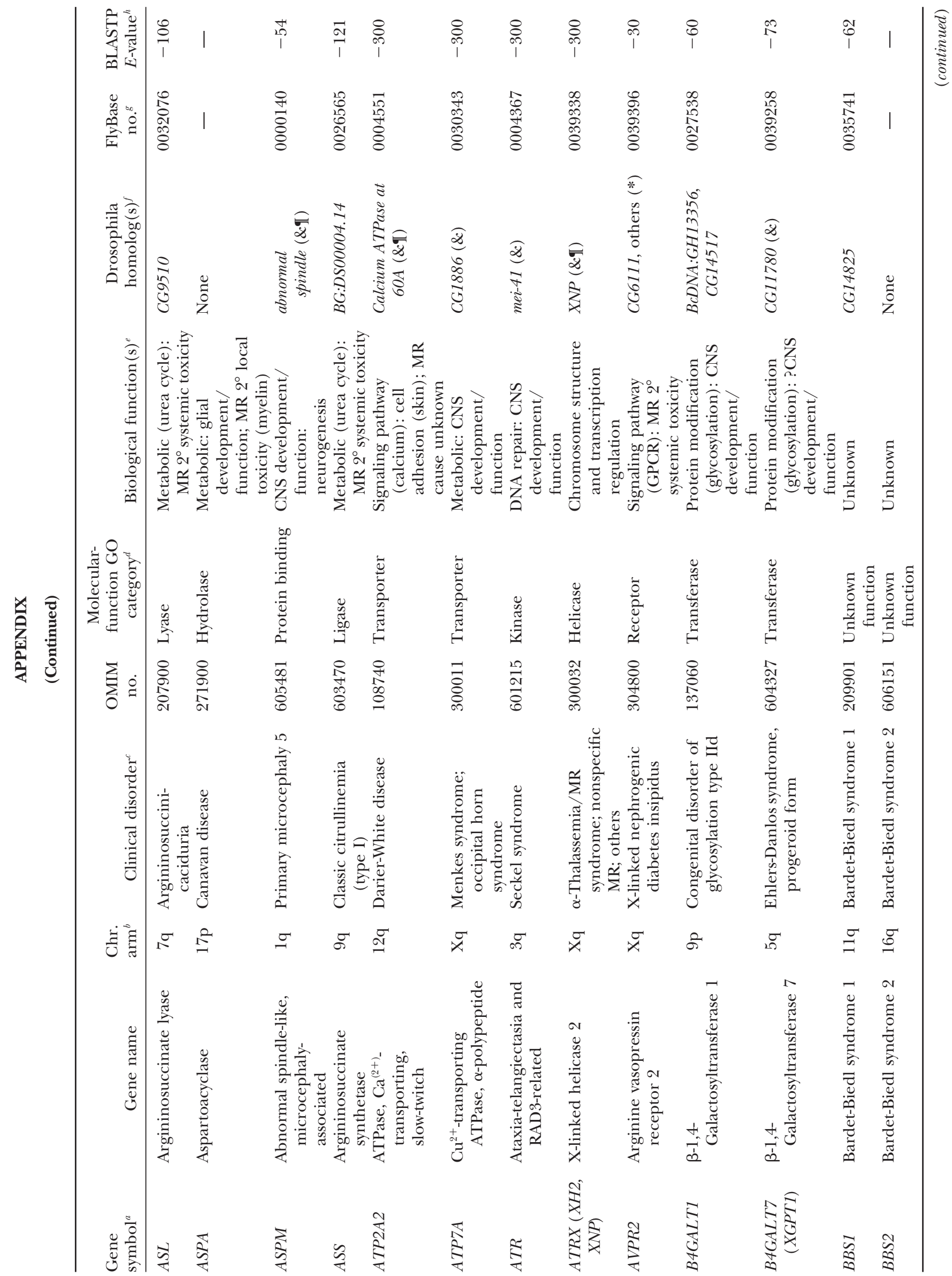




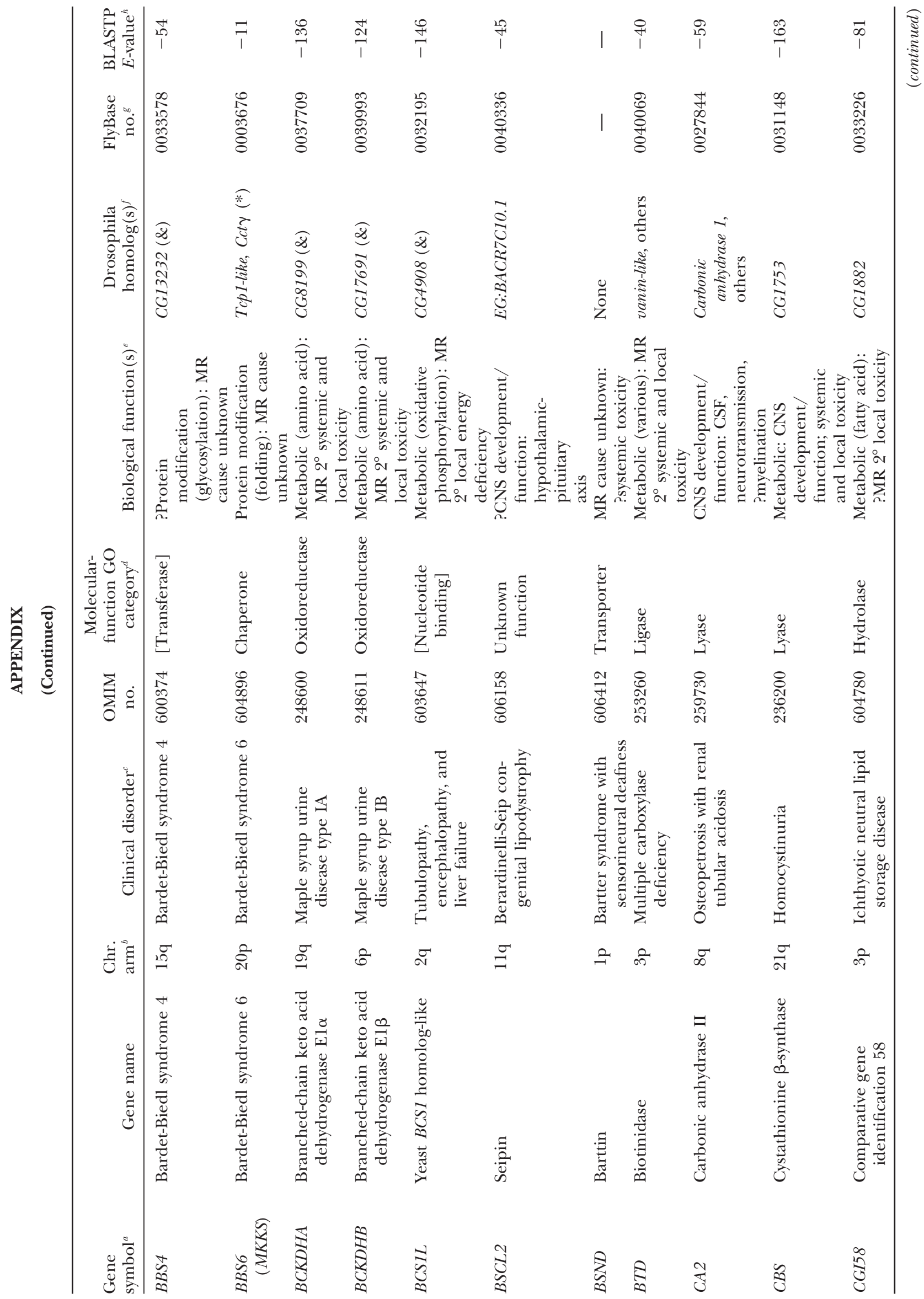




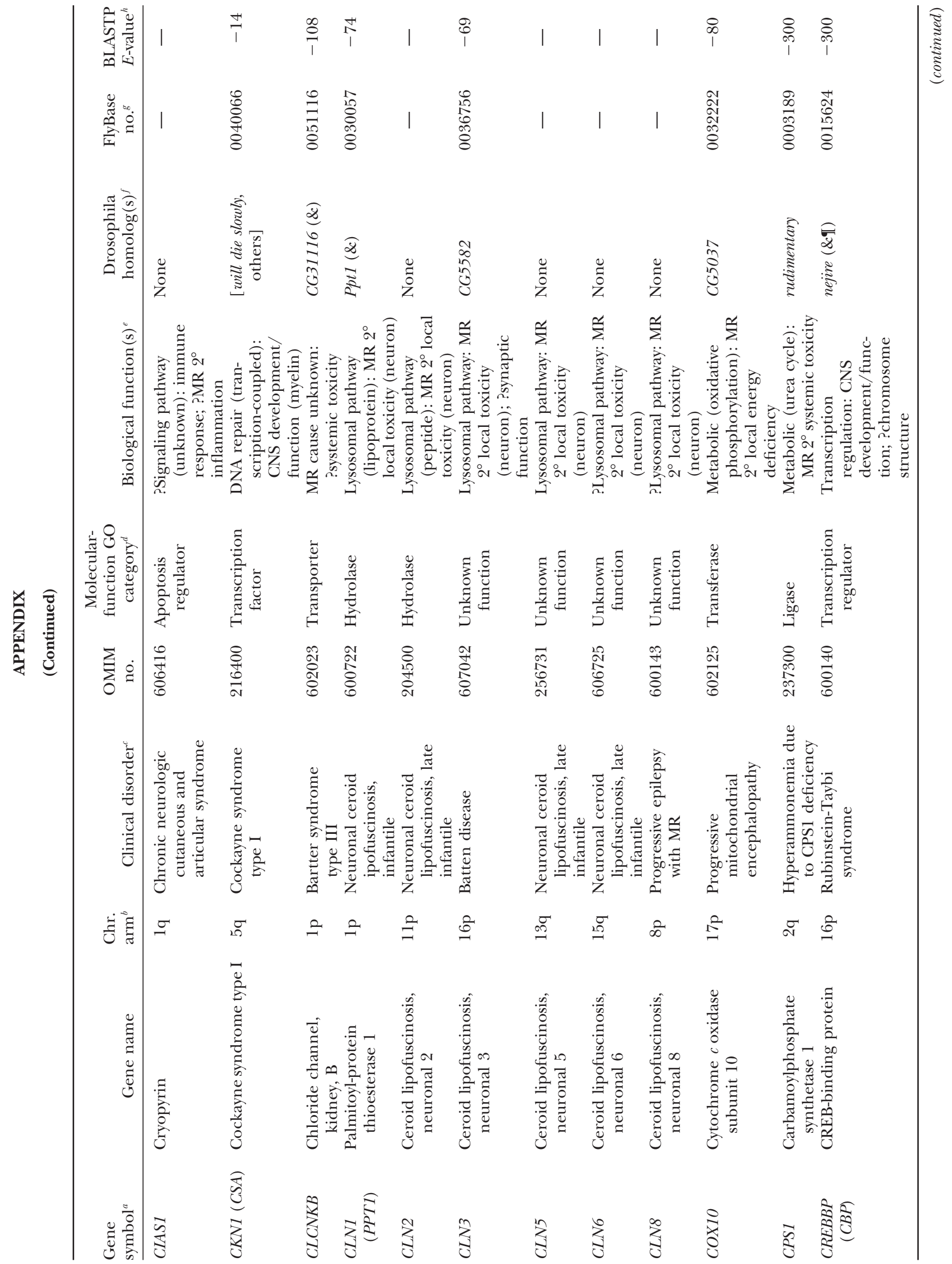




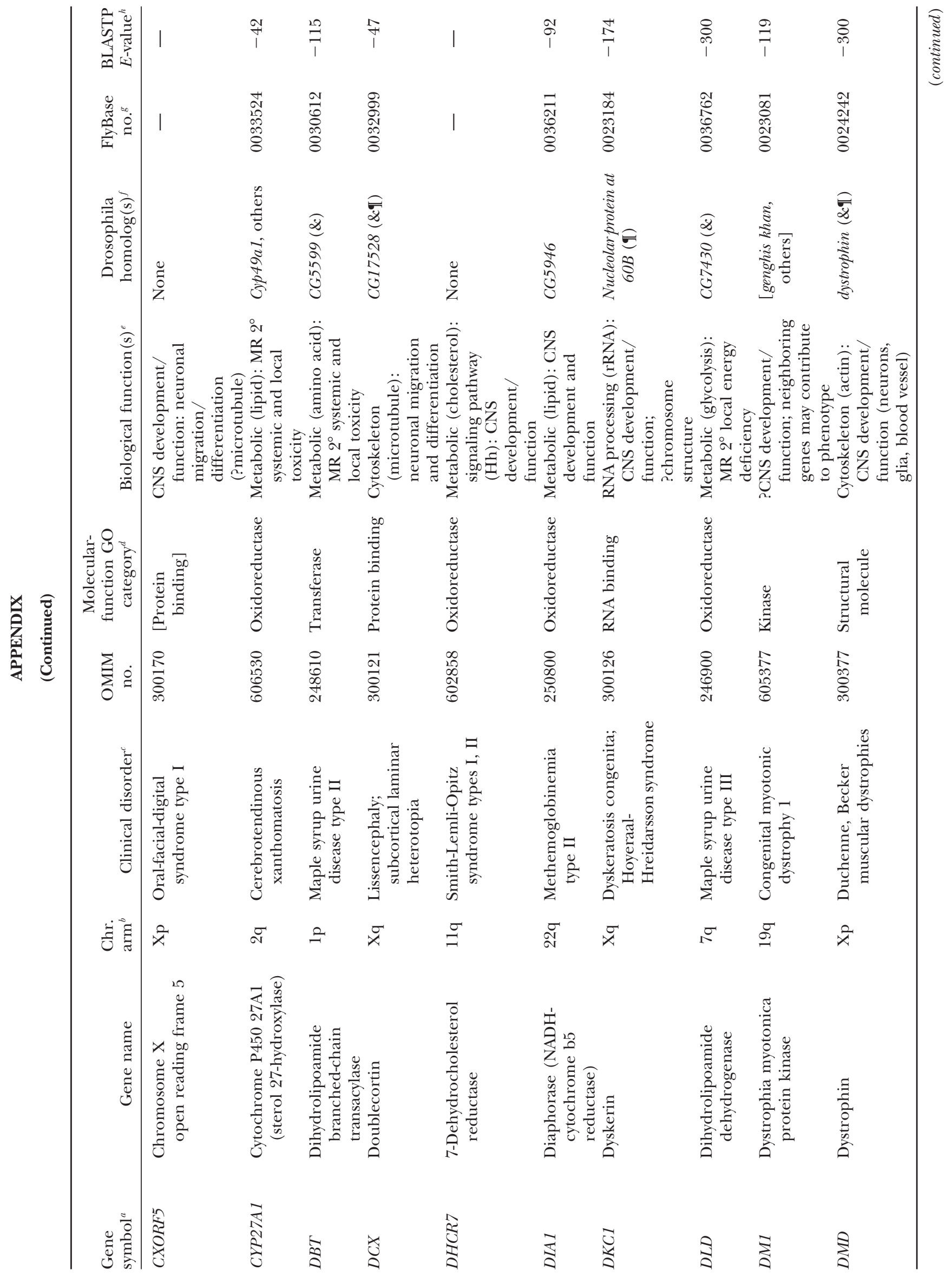




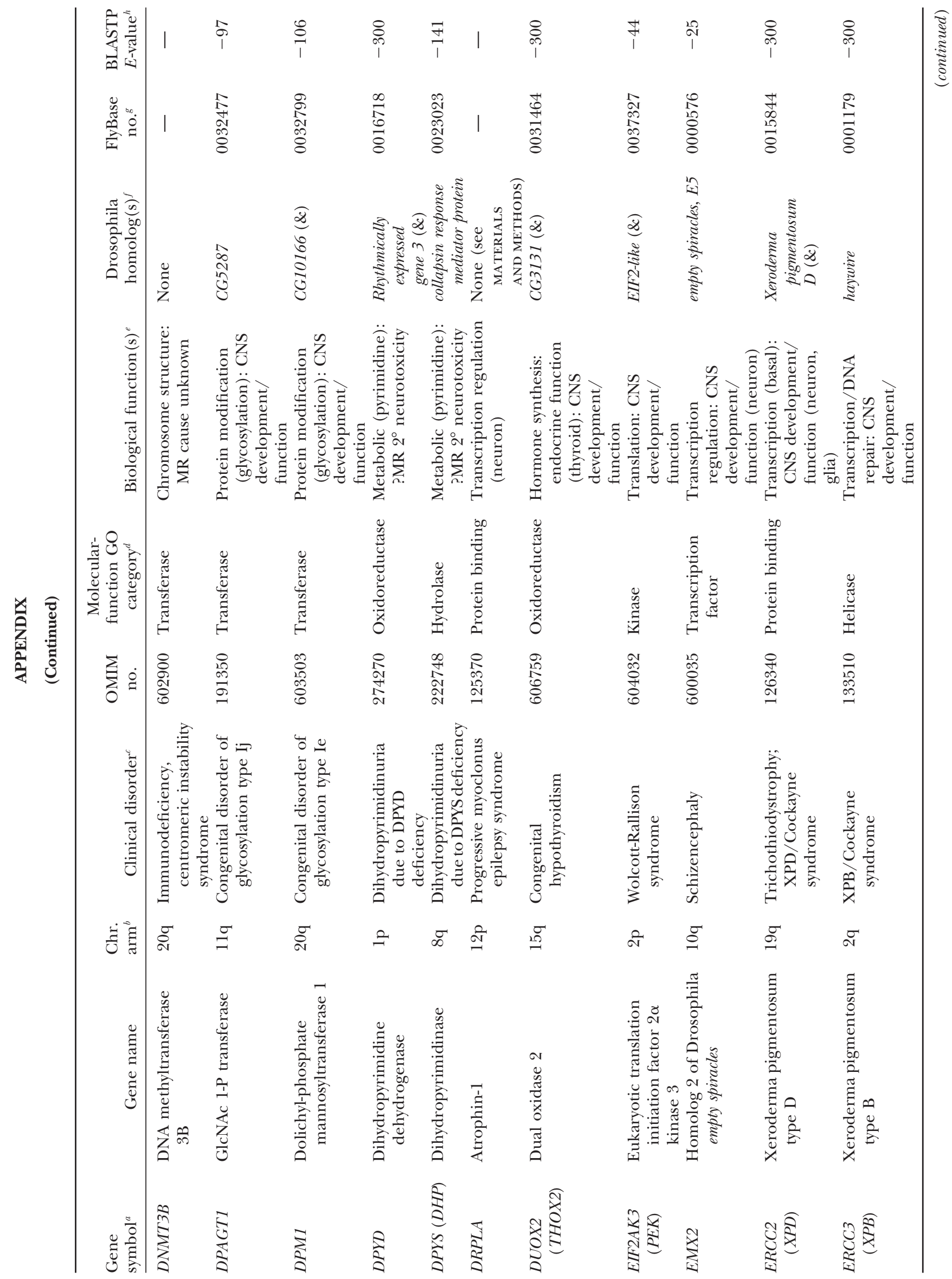




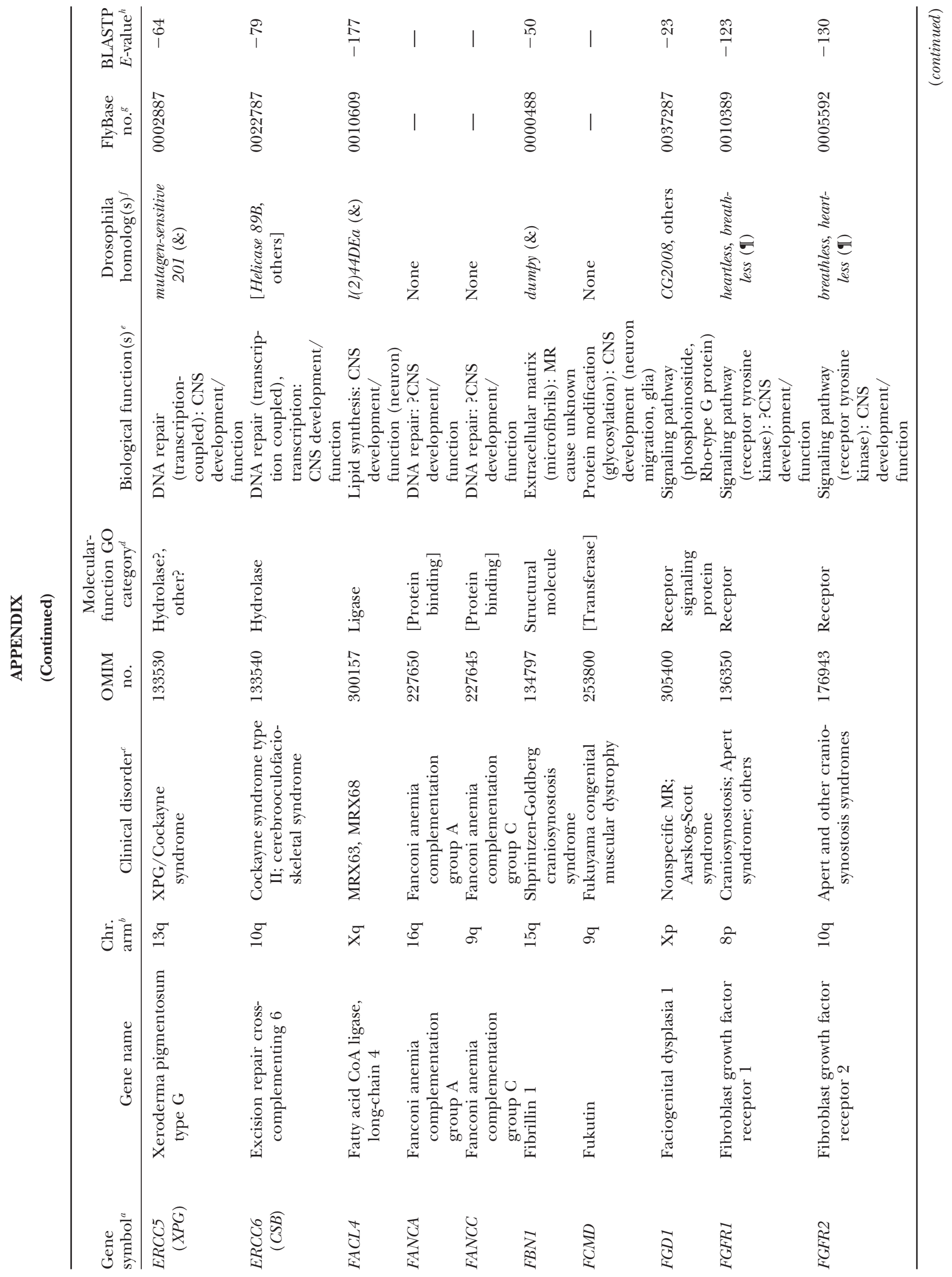




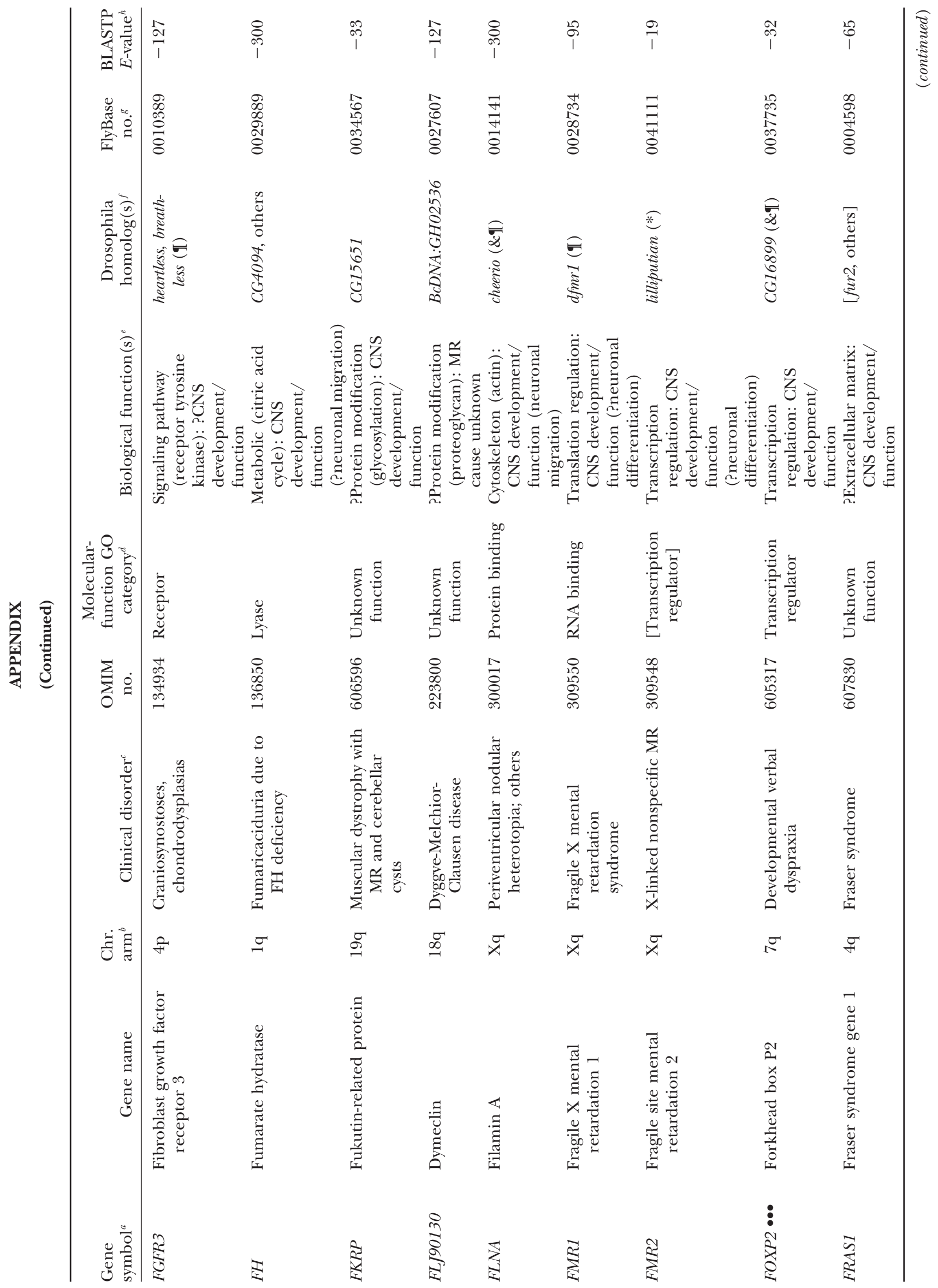




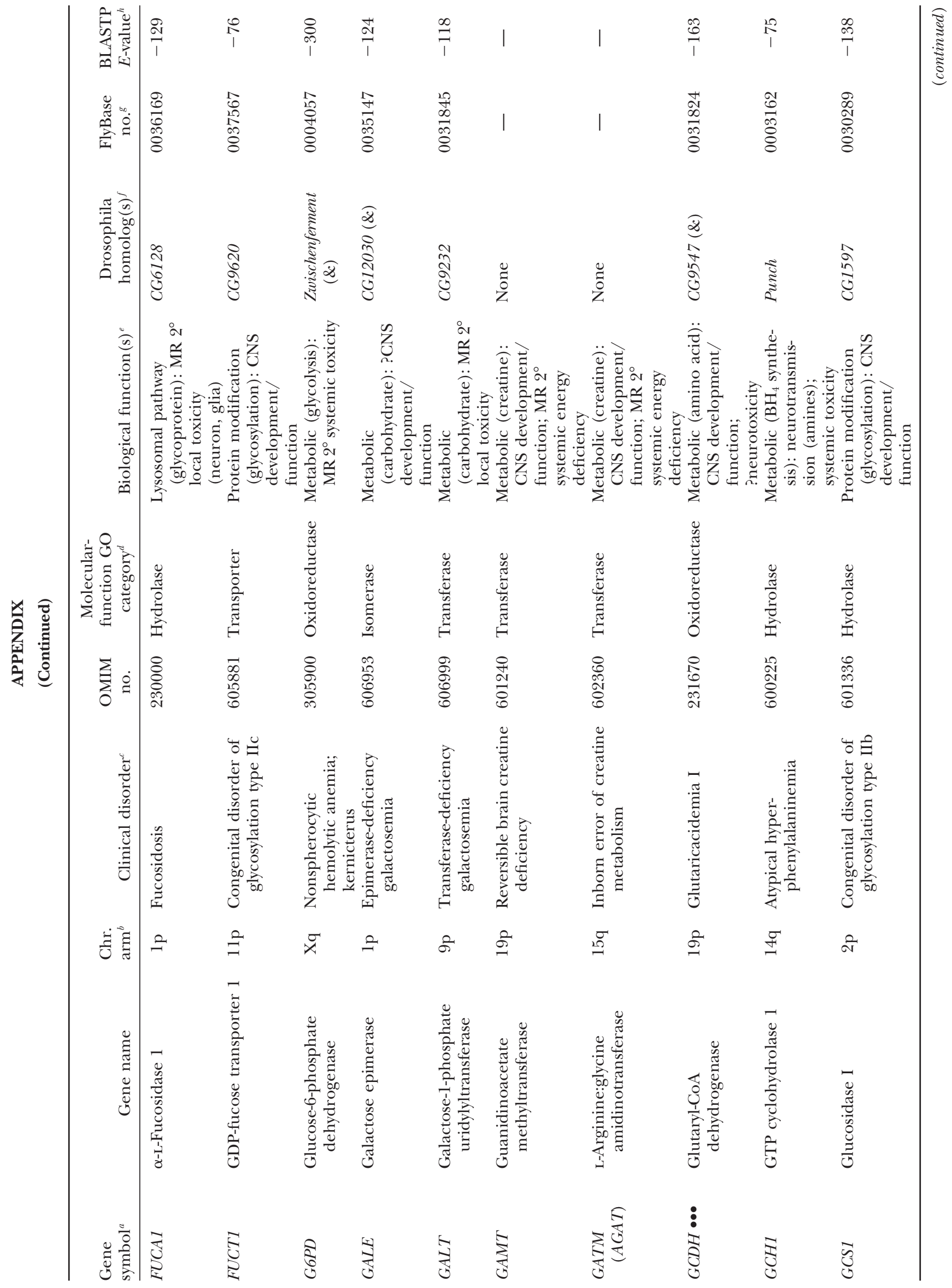




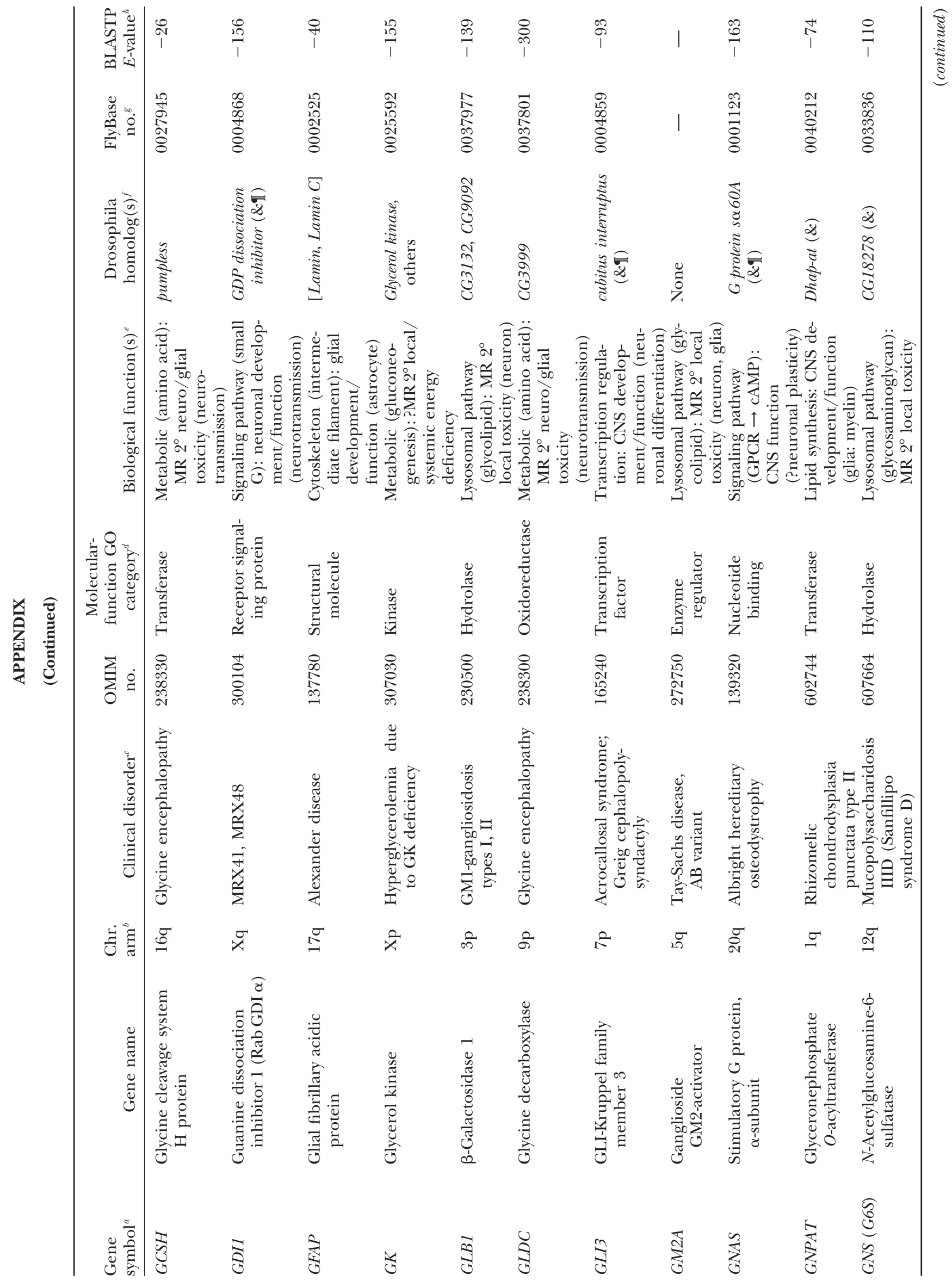




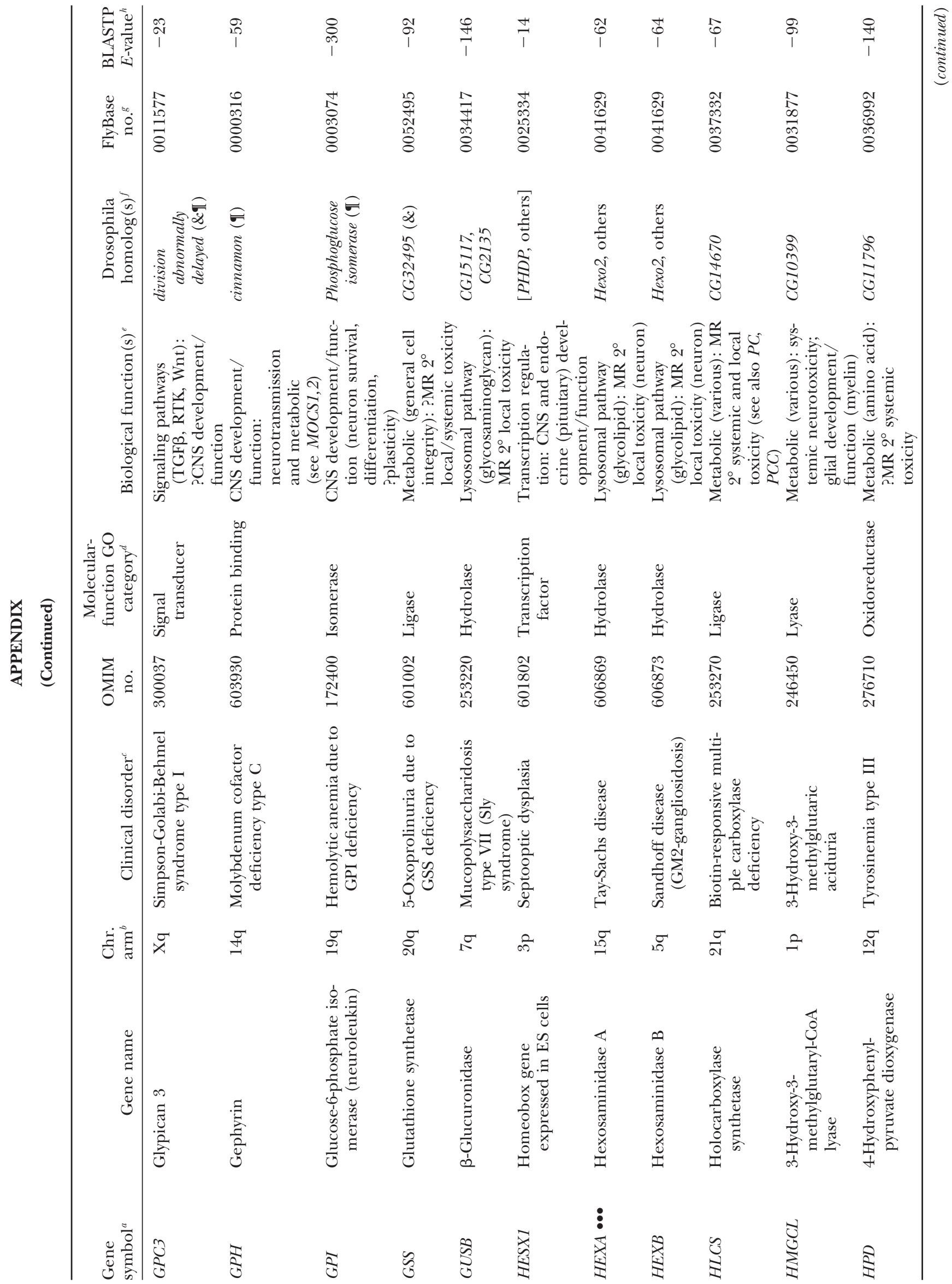




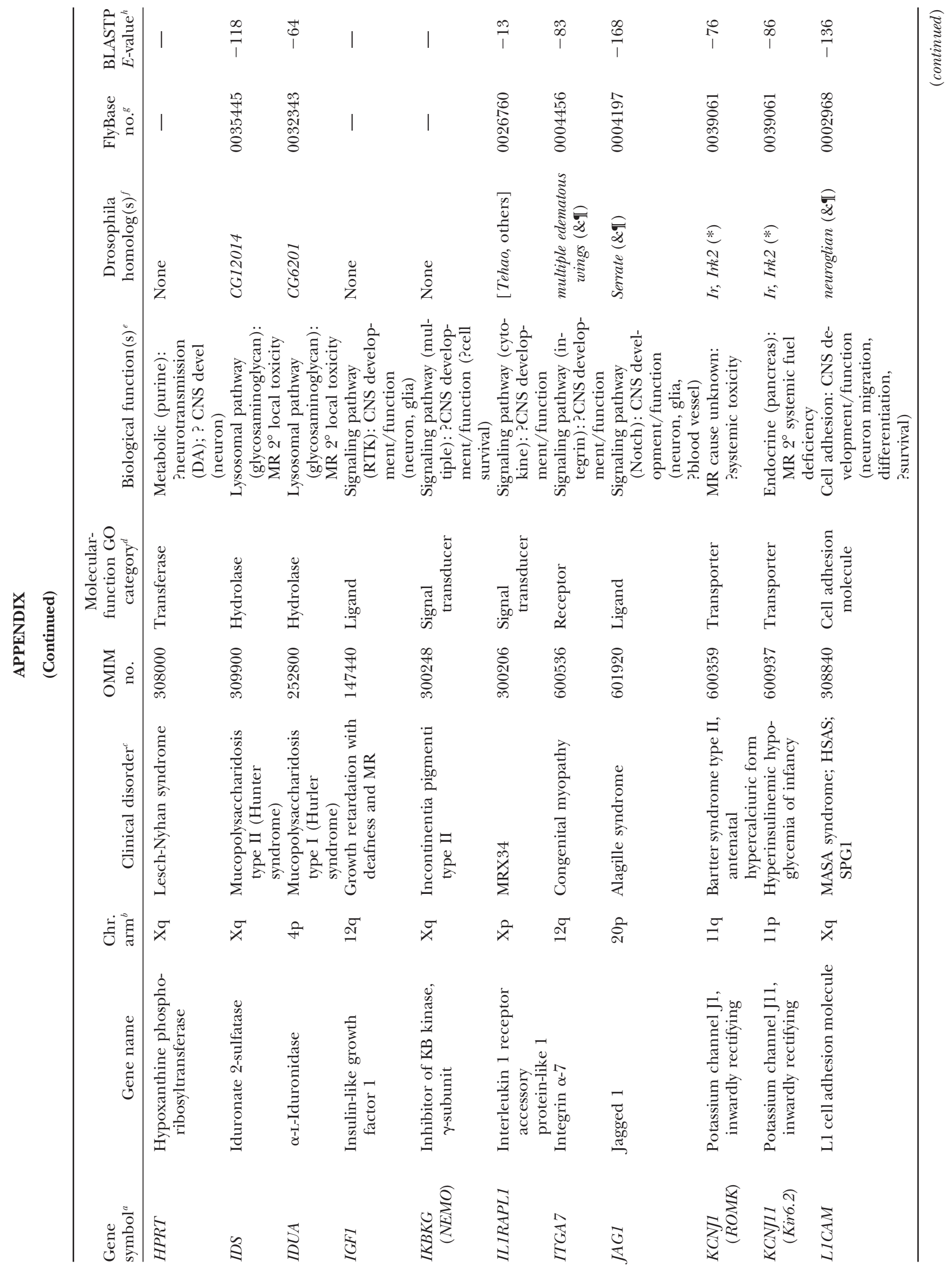




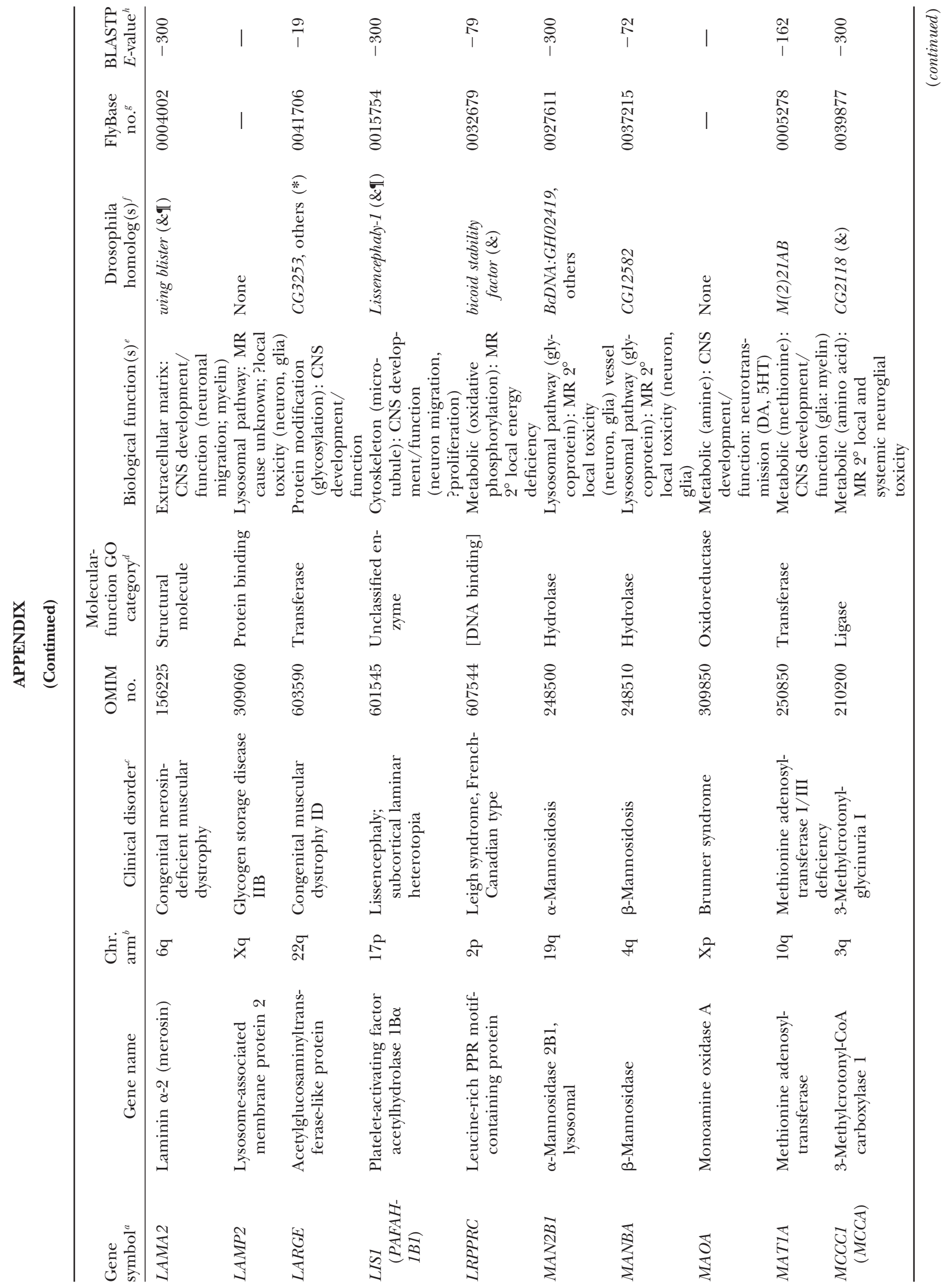




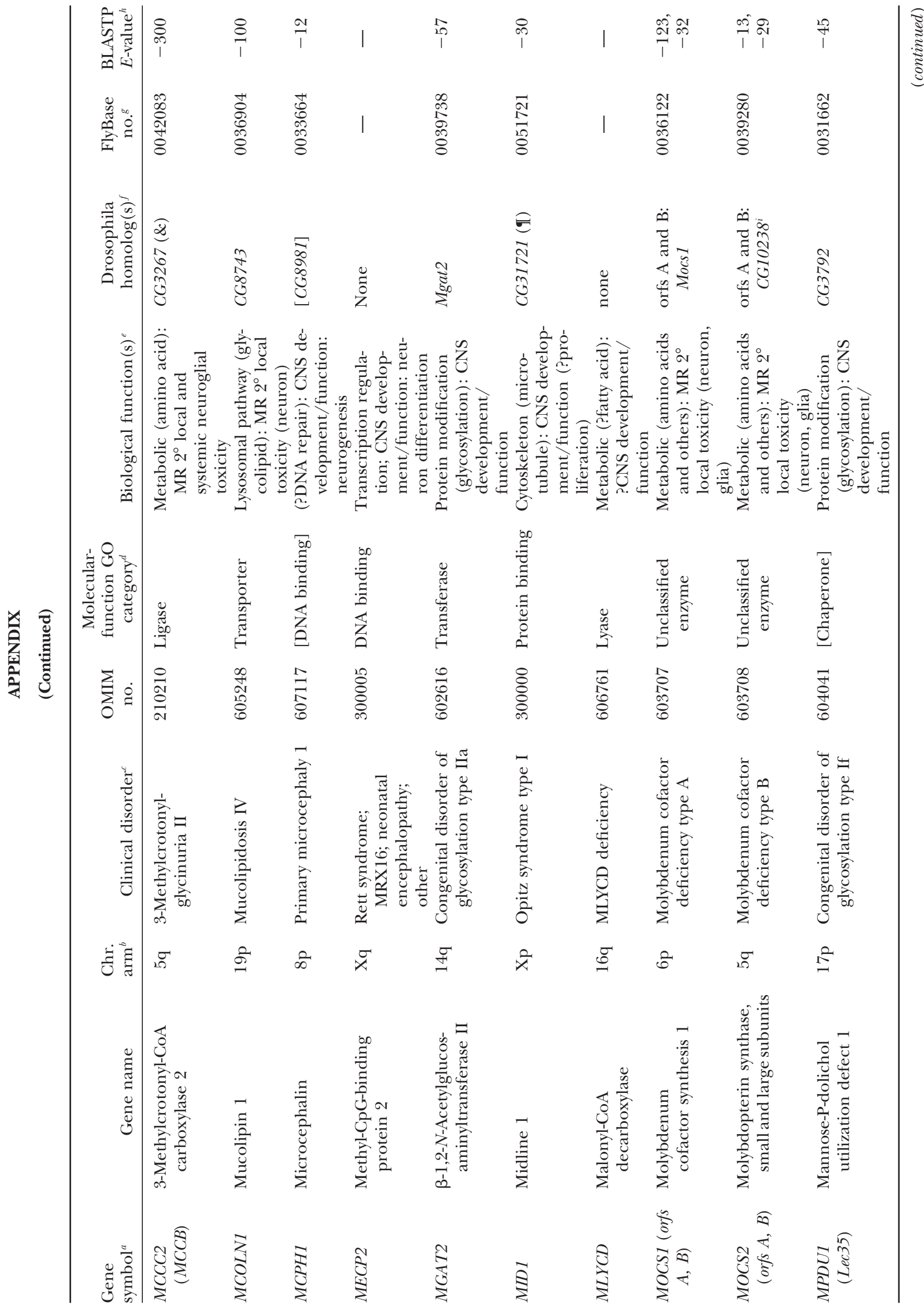




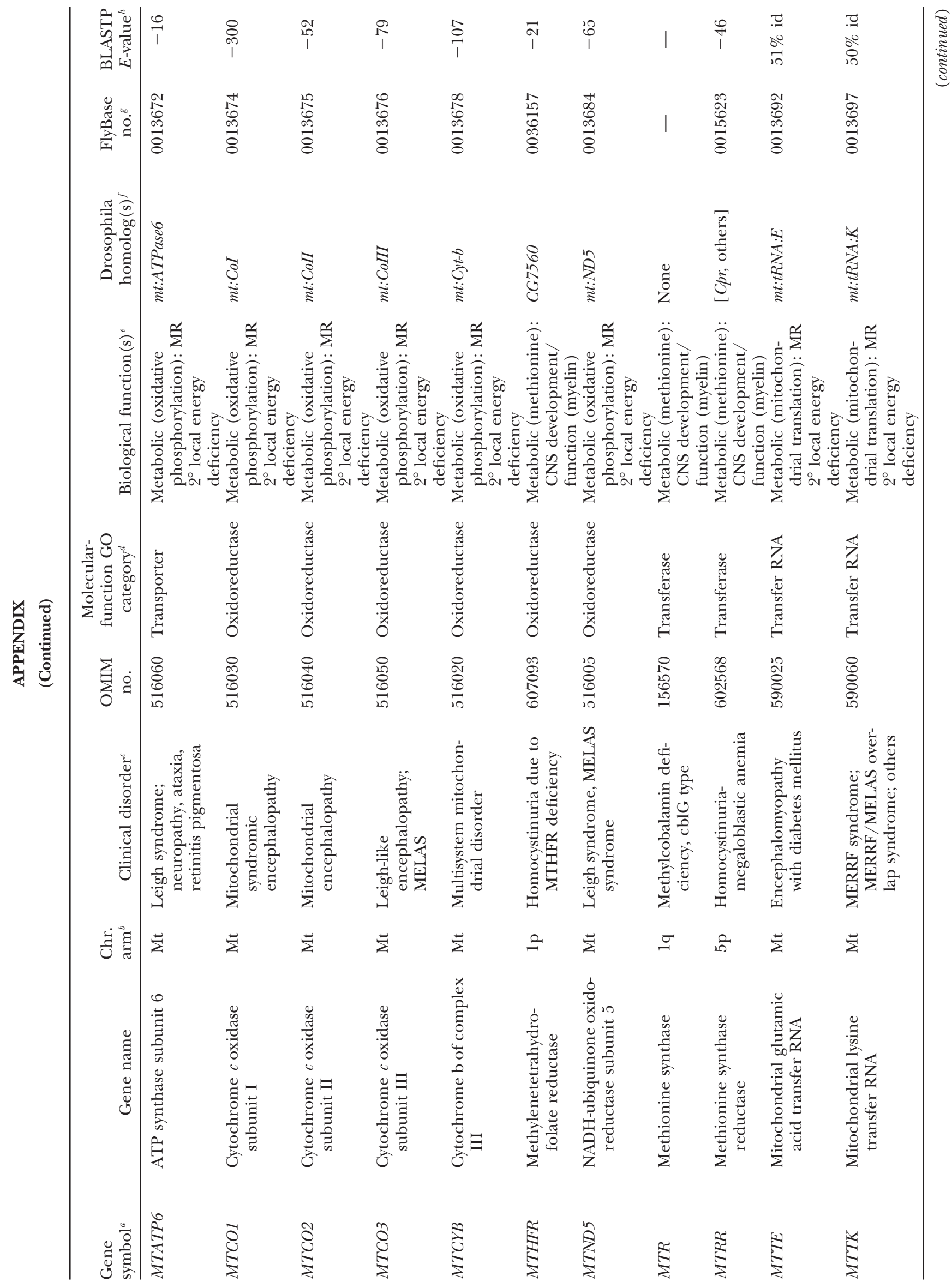




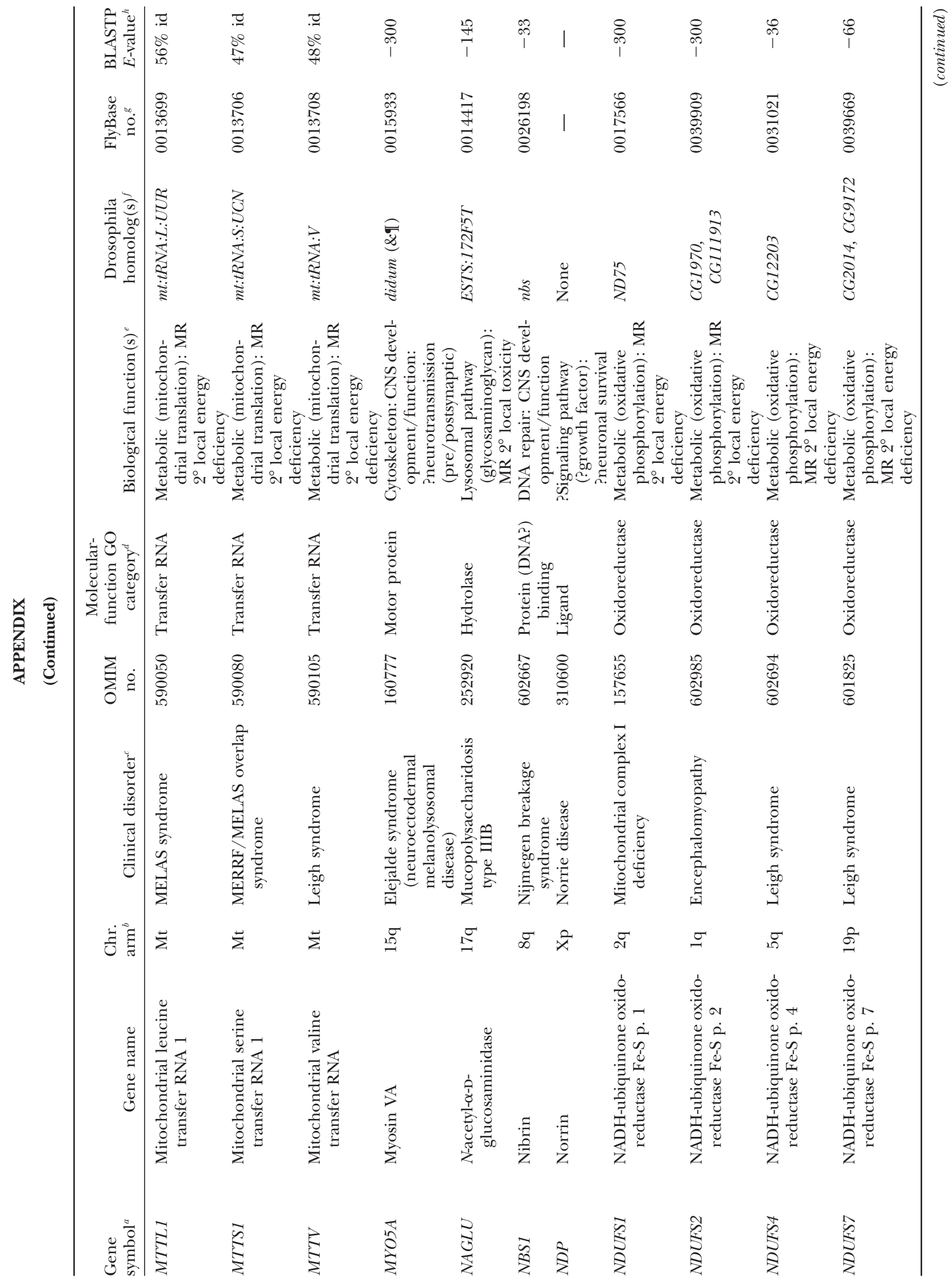




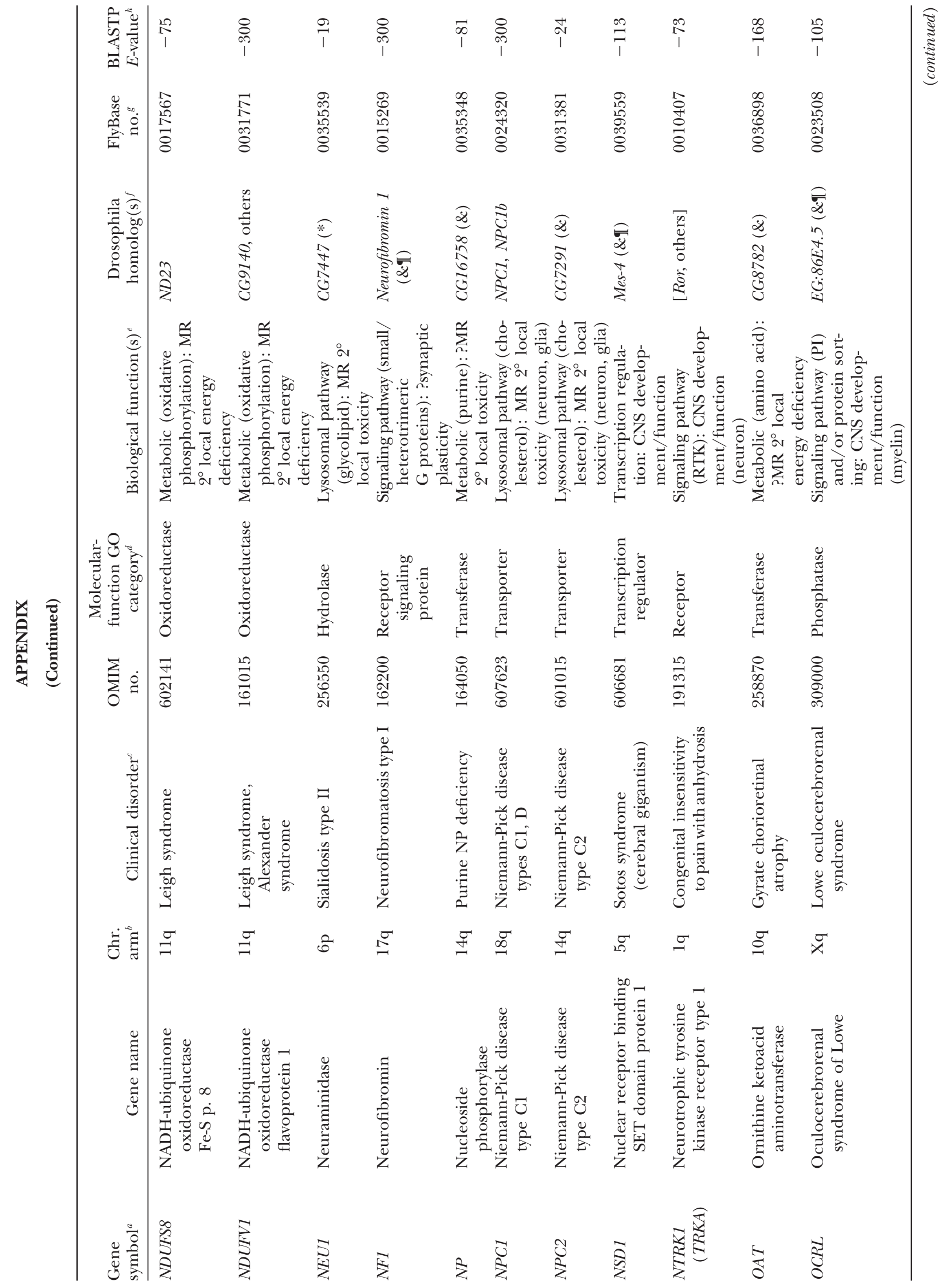




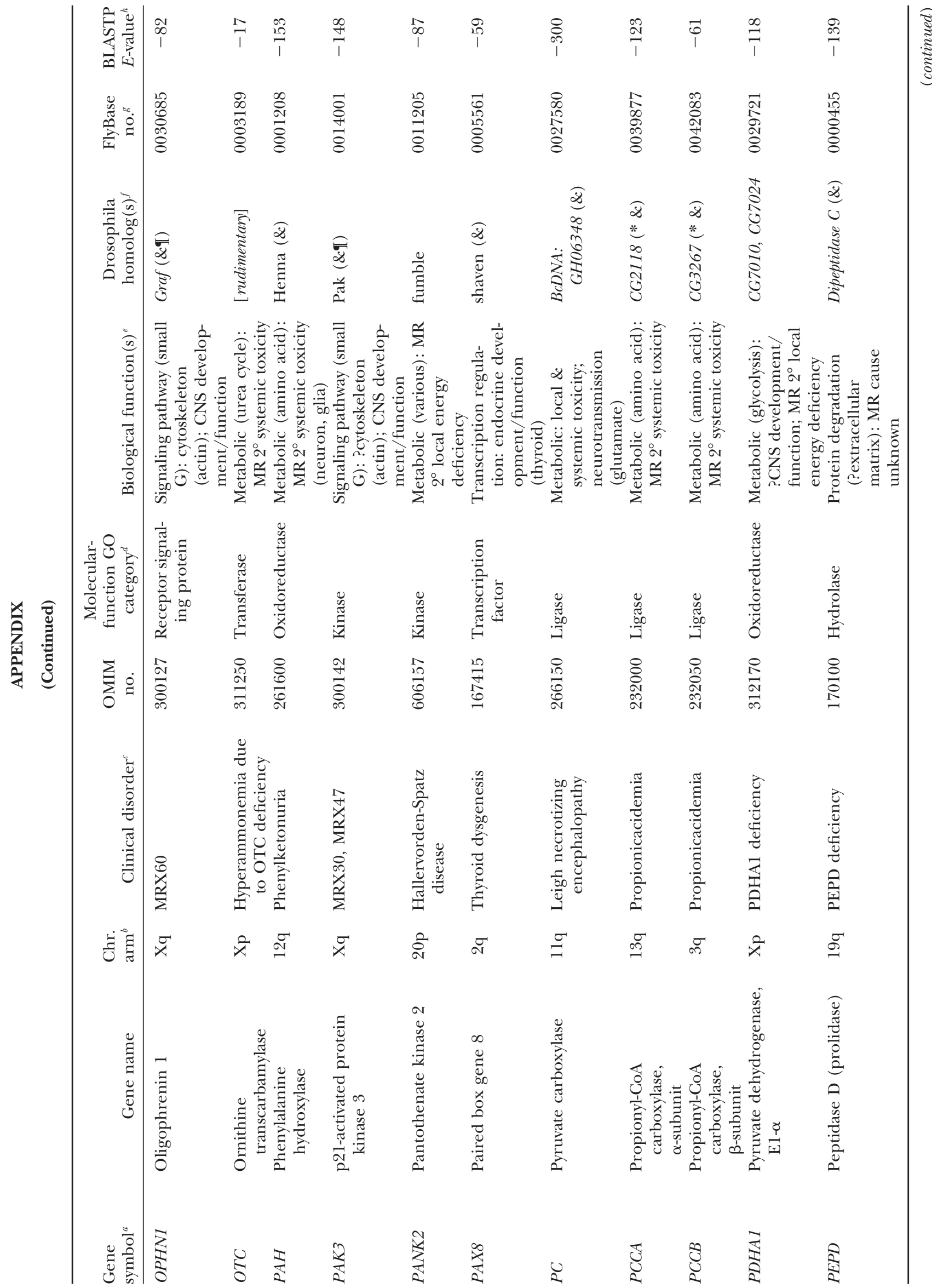




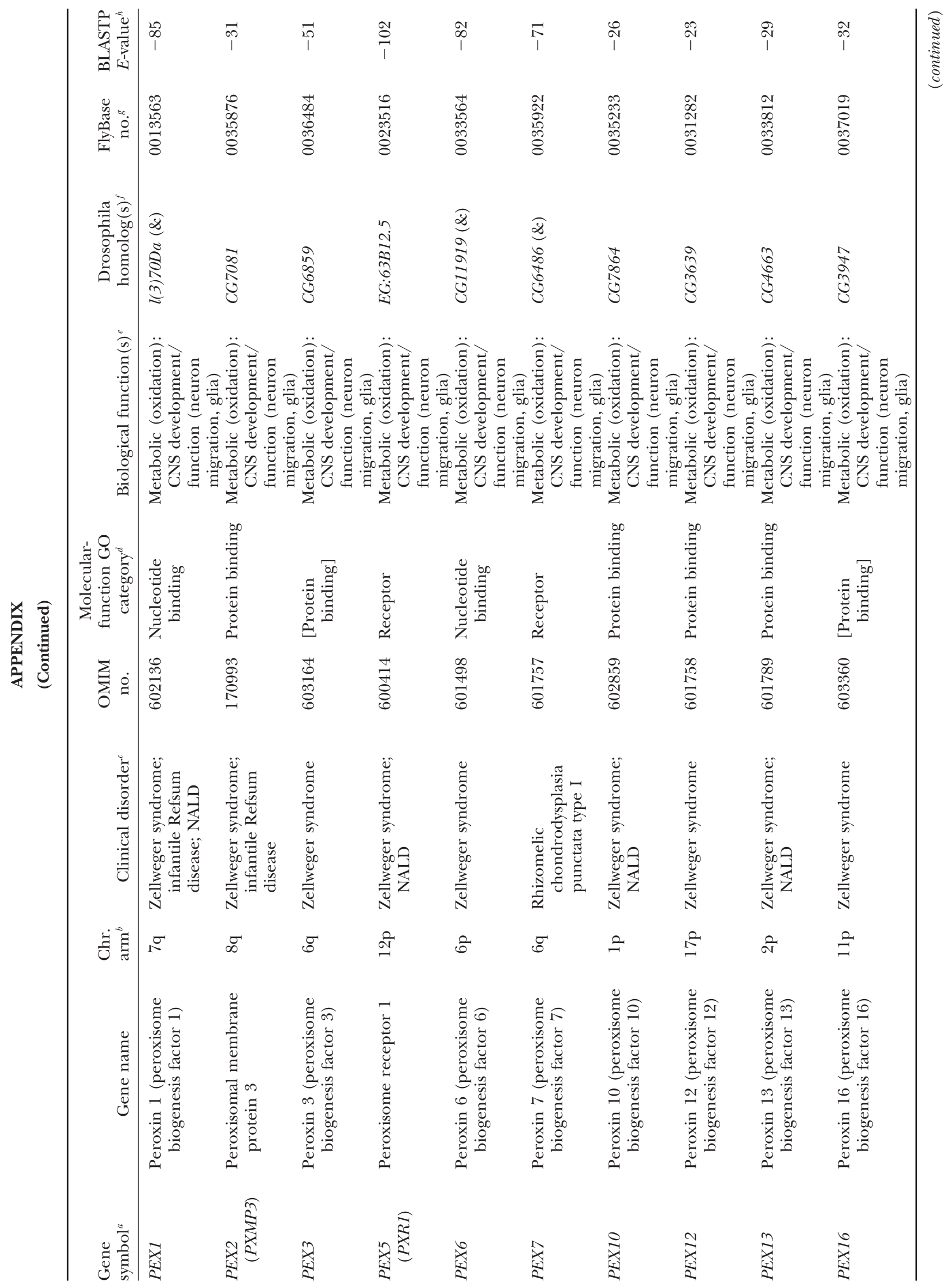




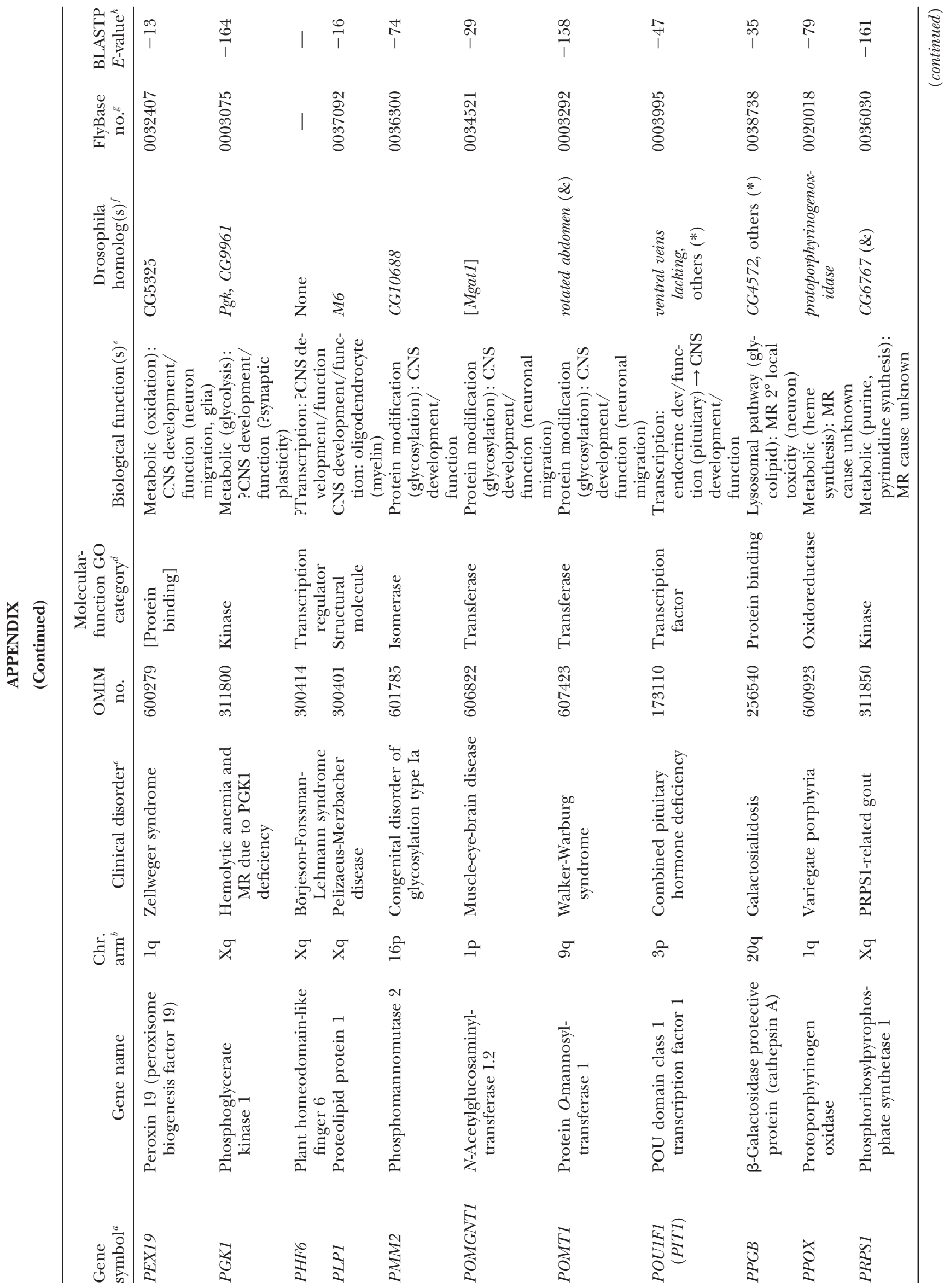




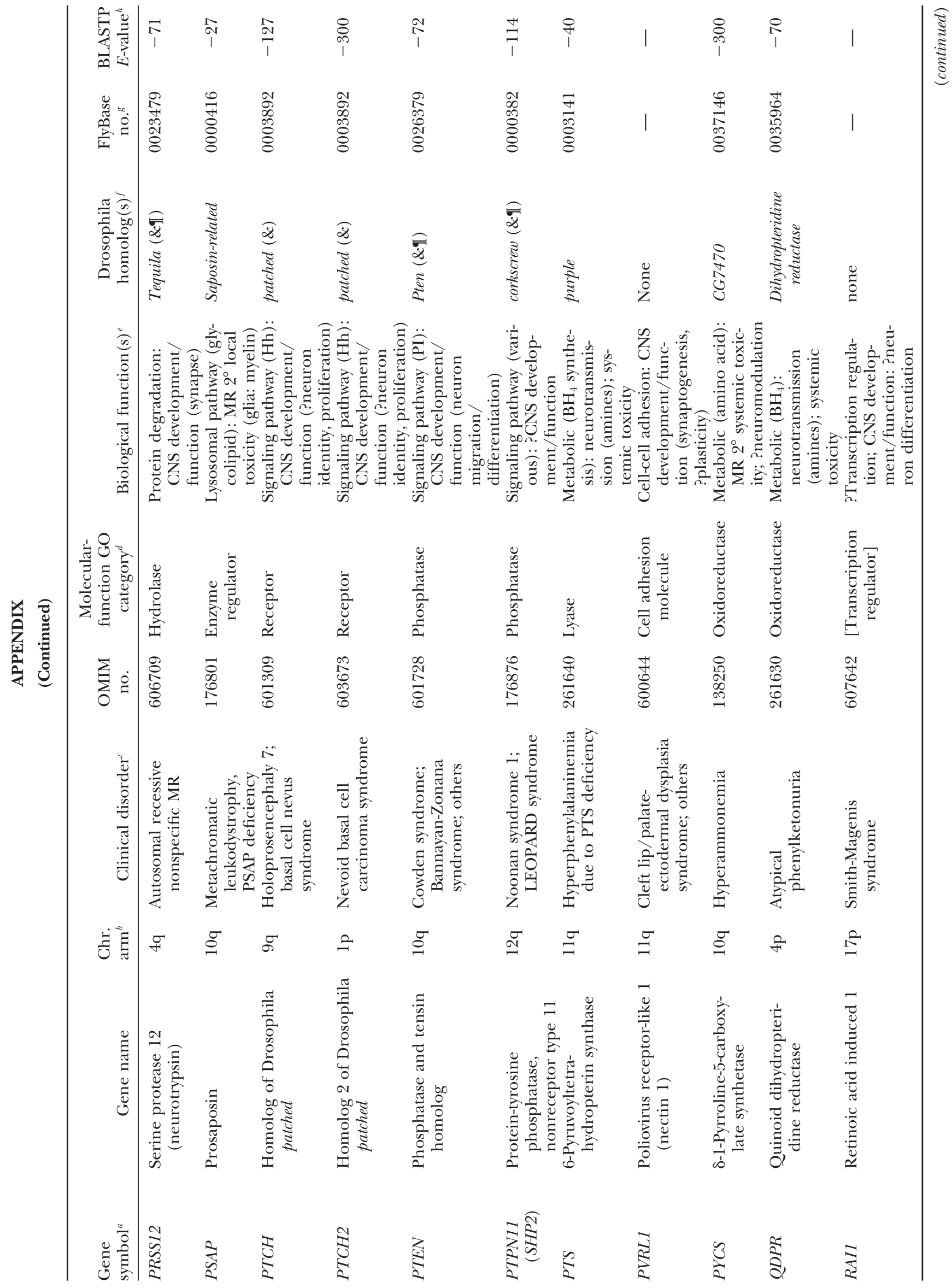




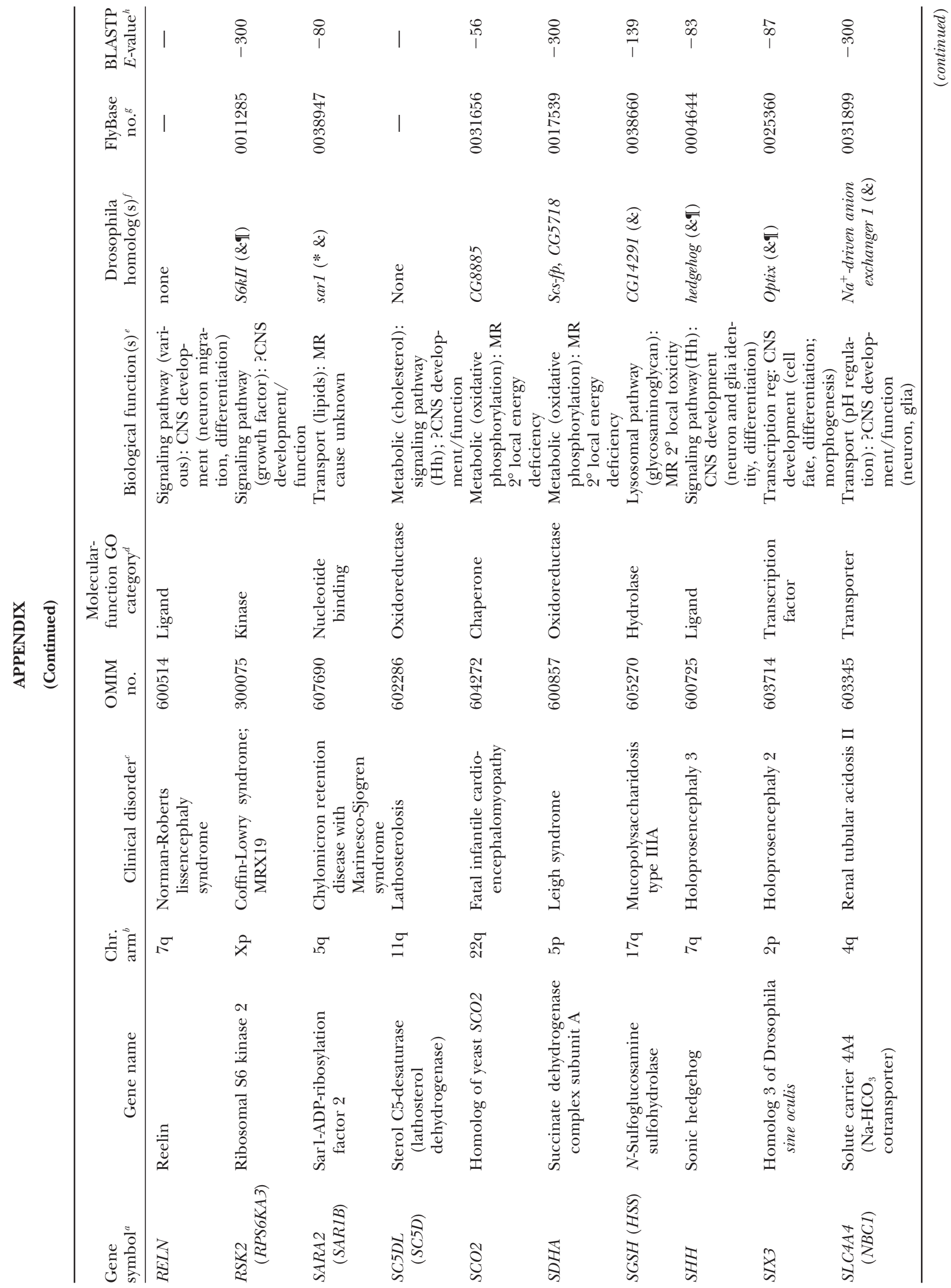




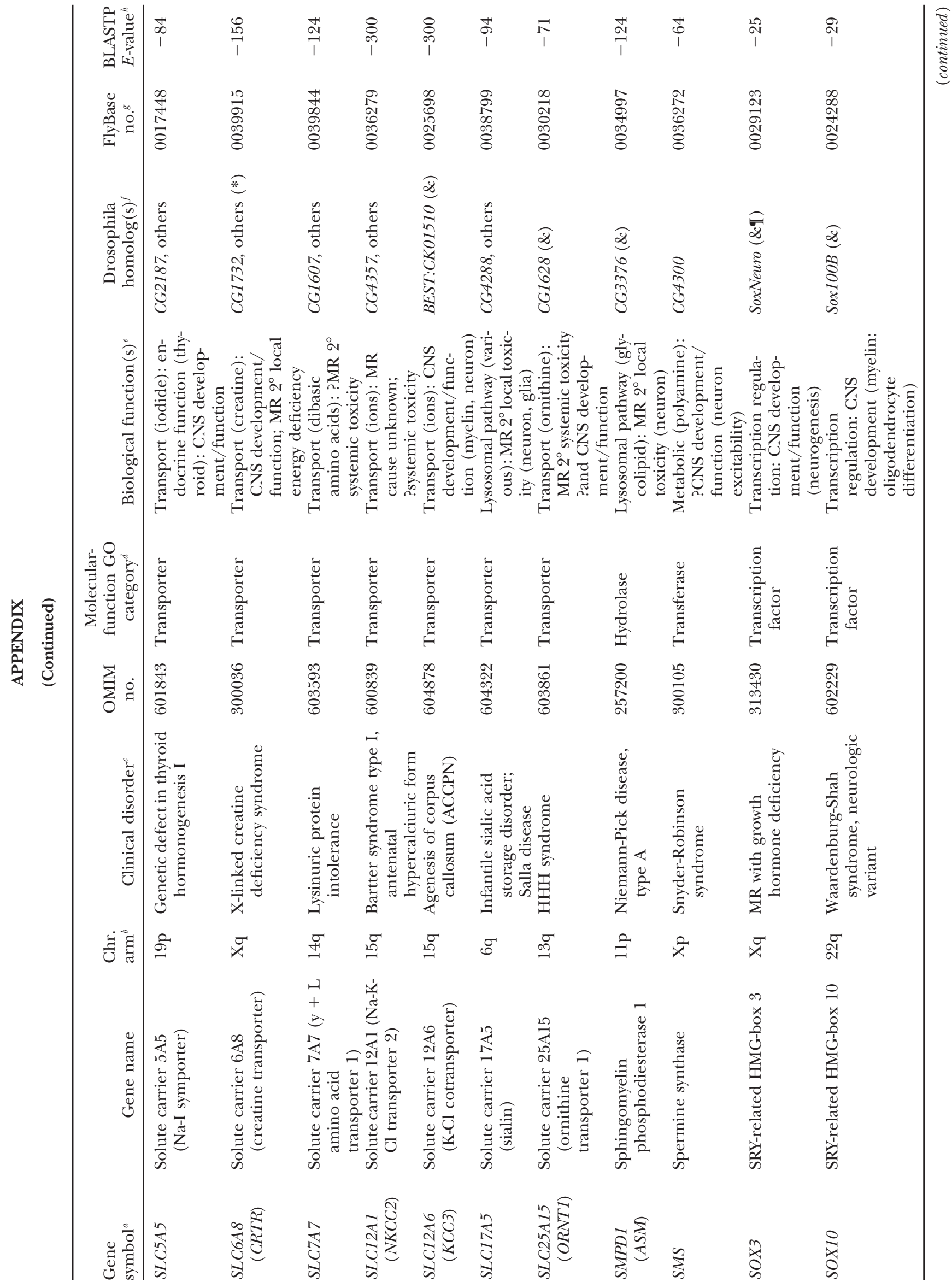




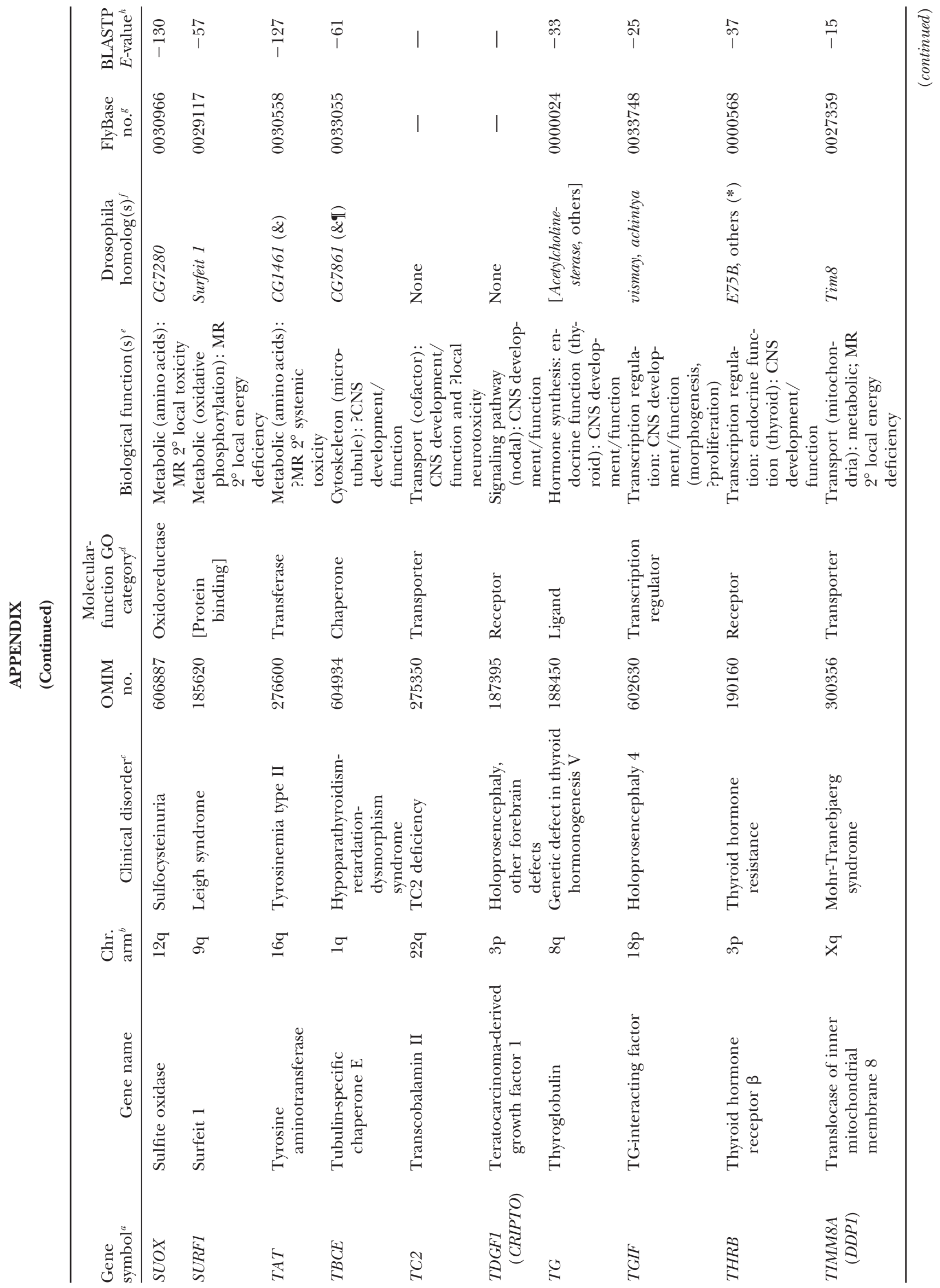




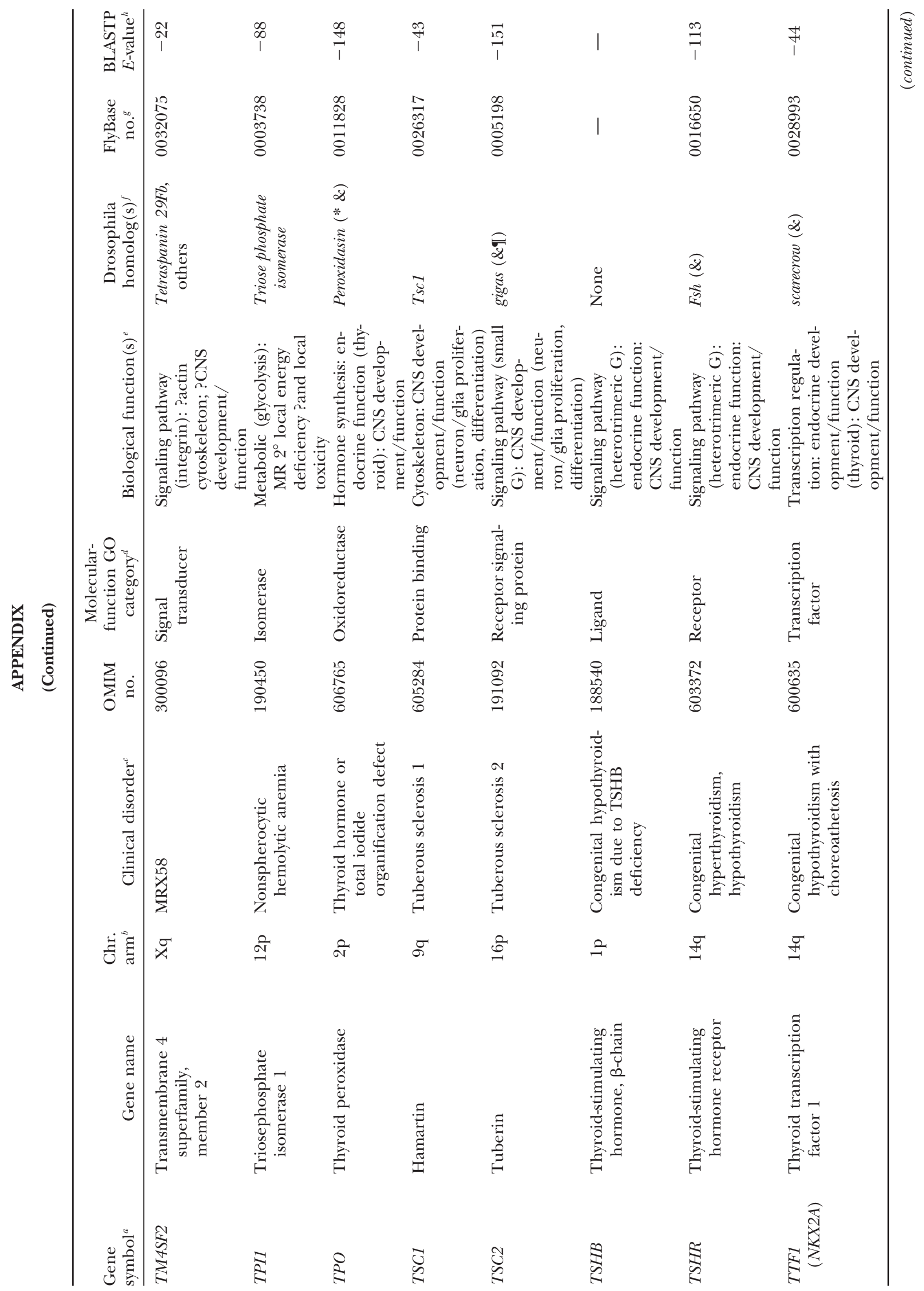


Molecular Genetics of Mental Retardation

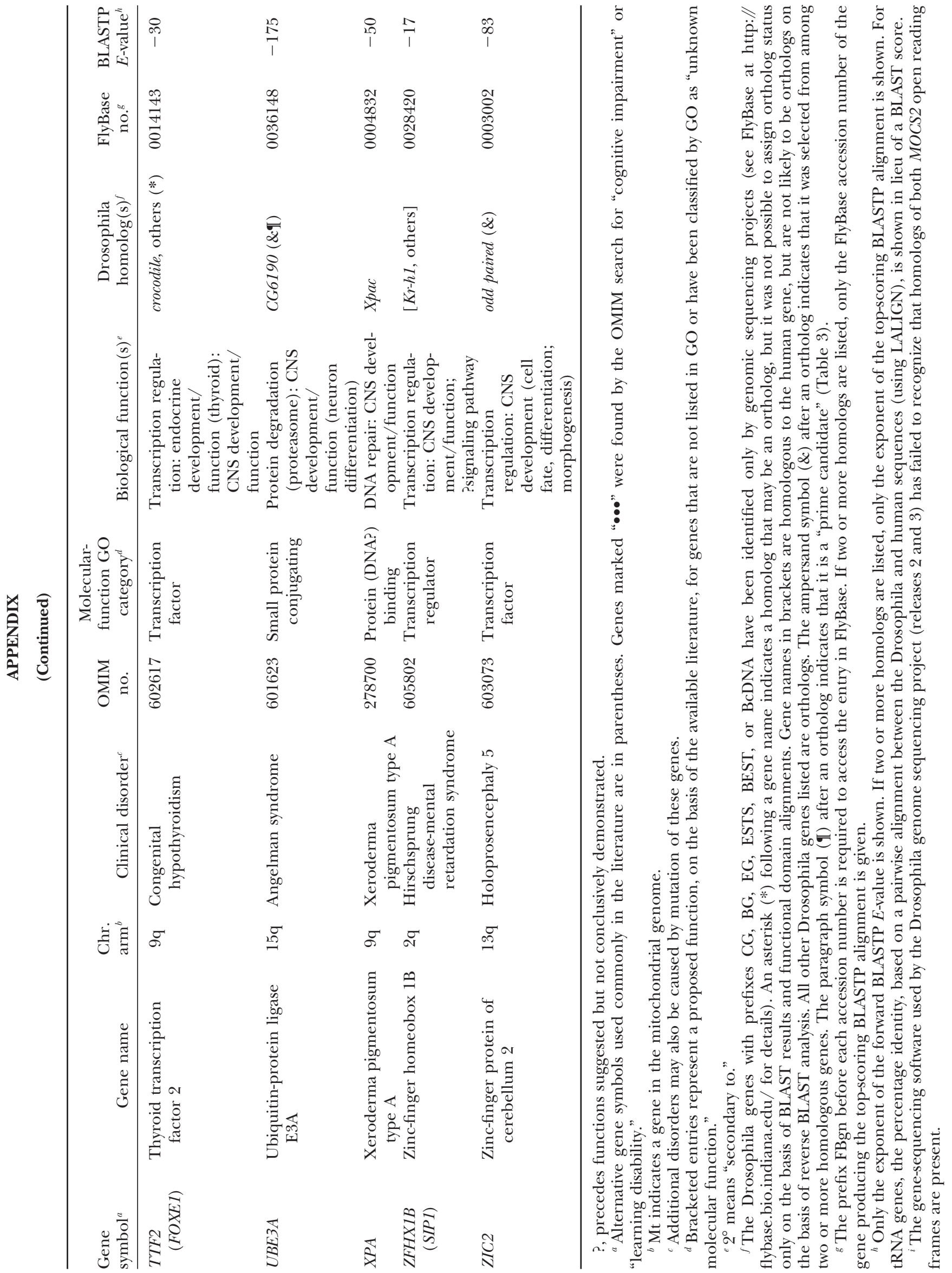


